\title{
Poroelastic Effect on Gas Transport and Storage in Organic Rich Shale Reservoir
}

\author{
Bahiya Jabbar \\ West Virginia University
}

Follow this and additional works at: https://researchrepository.wvu.edu/etd

\section{Recommended Citation}

Jabbar, Bahiya, "Poroelastic Effect on Gas Transport and Storage in Organic Rich Shale Reservoir" (2014). Graduate Theses, Dissertations, and Problem Reports. 119.

https://researchrepository.wvu.edu/etd/119

This Thesis is protected by copyright and/or related rights. It has been brought to you by the The Research Repository @ WVU with permission from the rights-holder(s). You are free to use this Thesis in any way that is permitted by the copyright and related rights legislation that applies to your use. For other uses you must obtain permission from the rights-holder(s) directly, unless additional rights are indicated by a Creative Commons license in the record and/ or on the work itself. This Thesis has been accepted for inclusion in WVU Graduate Theses, Dissertations, and Problem Reports collection by an authorized administrator of The Research Repository @ WVU. For more information, please contact researchrepository@mail.wvu.edu. 
Poroelastic Effect on Gas Transport and Storage in Organic Rich Shale Reservoir

Bahiya Jabbar

Thesis submitted

to the College of Engineering and Mineral Resources

at West Virginia University

in partial fulfillment of the requirements for the degree of

Master of Science in

Petroleum and Natural Gas Engineering

\author{
Approved by \\ Ebrahim Fathi, Ph.D., Committee Chairperson
}

Kashy Aminian, Ph.D.

Ali Takbiri Borujeni, Ph.D.

Department of Petroleum and Natural Gas Engineering

\author{
Morgantown, West Virginia
}

2014

Keywords: poroelastic, multiscale shale matrix, stress depended permeability, storage and transport mechanism, pore compressibility

Copyright 2014 Bahiya Jabbar 


\title{
ABSTRACT \\ POROELASTIC EFFECT ON TRANSPORT AND STORAGE IN ORGANIC RICH SHALE GAS RESEVOIR
}

\author{
By Bahiya Jabbar
}

This study sheds the light on the effect of poroelastic properties of the shale matrix on storage and transportation mechanism in multi-scale organic rich shale gas reservoirs. Over last decades shale gas research widen significantly, however, the behavior and properties of shale formation still need more investigation. Most of our knowledge regarding poroelsctic behavior of shale matrix comes from studies on coalbed methane reservoirs, which is somewhat similar to shale gas reservoirs. The poroelastic effect of coal and shale is a strong function of total organic content (TOC) of these sedimentary rocks. Coalbed methane reservoirs have more than 50\% TOC, however, the TOC of shale gas reservoirs are less than $10 \%$, which leads to expect completely different mechanical behavior in shale than coalbed. Therefore, it is important to understand the poroelastic behavior of shale and it is impact on flow and storage within the matrix. In this research, a new model has been developed to study the poroelastic properties of shale using fundamental governing equations.

In order to study the effect of poroelasticity of the shale precisely, multi-continuum approach has been chosen. The governing equations for the model have been developed from the basic fundamentals of mass and momentum conservation equations and transport in naturally fractured porous media. Different continuum has been coupled using mass exchange term in sprit of Warren and Root coupling approach. The model has been used to represent and investigate four different cases. In the first case, the shale has been seen as a dual-porosity, system where matrix has a single porosity and transport in the matrix is governed by the convective and diffusive flow. The second model is an extension for the first model by adding fracture system. In the third model, detailed descriptions of shale matrix is used; shale matrix is assumed to consist of organic and inorganic continuum. In this case, gas transport in organic matter is assumed to be diffusive while gas transport in inorganic material is governed by convection and diffusion. Finally fracture system is added to multi-scale shale gas matrix and poroelatic effect of shale matrix on transport and storage is investigated. Modified Palmer and Mansoori model (1998) has been used to include the pore compression, matrix shrinkage, and adsorption effect of shale organic matter on overall pore compressibility of the shale matrix. For inorganic part of the matrix, on the other hand, relationship between rock mechanical properties and pore compressibility are obtained following Raaen (1993), Fajaer (1992) and Zimmerman (2000). To include the sorption behavior of shale matrix, Langmuir-Henry dualmodel isotherm is used to describe equilibrium sorption dynamics of shale in more details.

The purpose of this research is to develop governing equations describing gas transport and storage in shale gas reservoirs including the multi-scale nature of the shale matrix, gas sorption behavior, and poroelastic effects due to change in effective stress. Governing equations are derived based on mass and momentum conservation at an isothermal condition using analytical techniques and solved using implicit finite difference approach using MATLAB. MATLAB program has also been used for sensitivity analysis of different poroelastic parameters of shale matrix such as Poisson ratio and Young modulus under specified initial and boundary conditions.

Based on our study, impact of the pore compressibility on gas production is significant. Variation of effective stress shows great impact on poroelastic properties of the shale represented by Poisson ratio and Young modulus and thus, highly influence gas storage and transport in shale reservoirs. In conclusion, new governing equations developed and applied successfully to quantify the poroelastic effects on gas transport and storage in shale gas reservoirs. Moreover, any strategic production plan 
should include the poroelastic properties of the shale formation as a crucial parameter impacting the gas production. 


\section{DEDICATION}

This work is dedicated to my family and my beloved aunt Maysson

Who always being my courage and inspiration no matter what

Without their support this work cannot be done. There are no enough words to express my love to all of you: Mom, Dad, Ahmed, Samaar and Aunt Maysson 


\section{ACKNOWLEDGMENTS}

It is great pleasure to express my gratitude to the people who made this work possible

First of all I want to express my sensor gratitude to my supervisor Dr. Ebrahim Fathi for his dedication, guidance, encouragement, the great efforts he put it throughout the course of my thesis and being such a wonderful adviser.

Second, I would like to think Dr. Kashy Aminian for his valuable information, support, and guidance during my study at WVU.

In addition I would like to extend my thanks to Department chairman Professor Sam Ameri, for his support, help and being more than just a professor for me

Special thanks to Dr. Ali Takbiri Borujeni for his participation in the examining committee

Finally, I would also to thank the entire West Virginia Petroleum and Natural Gas Department for their help, dedication and encouragement. 


\section{TABLE OF CONTENT}

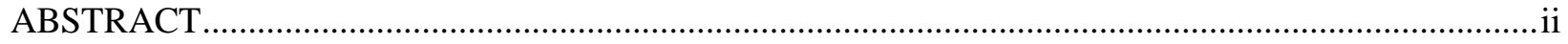

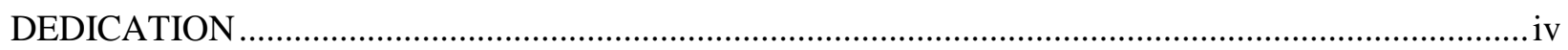

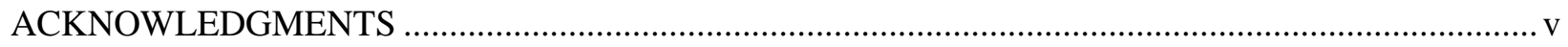

LIST OF FIGURES ……………………………………………………………………………

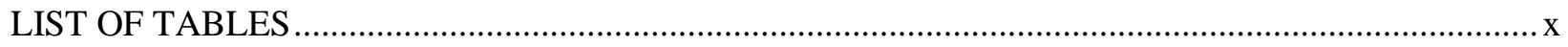

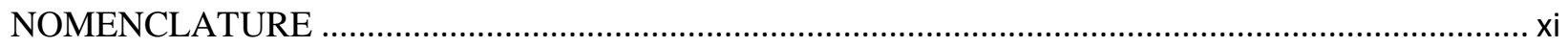

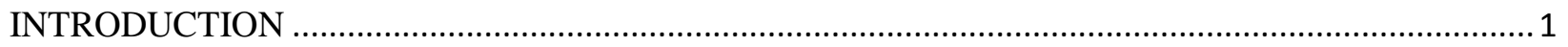

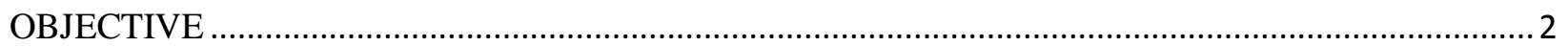

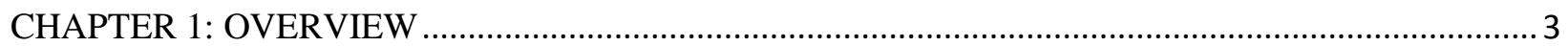

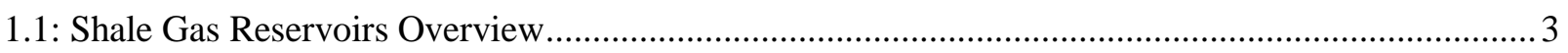

1.2: Overview on Pore Distribution in Shale Matrix ............................................................................

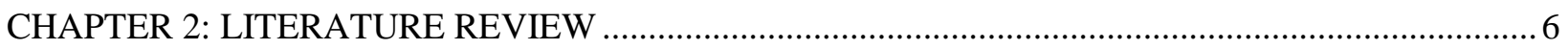

2.1: Gas Storage Mechanism in Multi-scale Shale Matrix ……………………………………........... 6

2.1.1: Adsorption Phenomena in Organic Nanopore of Shale Matrix .................................................

2.1.1.1: Sorption Isotherm Models......................................................................................

2.1.1.1.1: Langmuir Isotherm Model for Organic Rich Reservoir............................................ 8

2.1.1.1.2: Dual Isotherm Model for Rich Organic Reservoir................................................... 10

2.1.2:Multi-component Gas Adsorption in Shale Matrix................................................................. 13

2.2: Gas Transport Mechanisms in Multi-scale Shale Matrix................................................................. 16

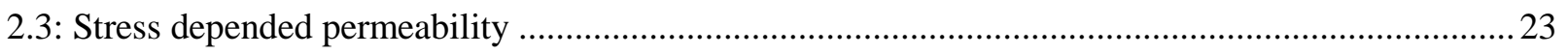

2.4: Poroelastic Models of Organic Rich Reservoir...………………............................................ 26

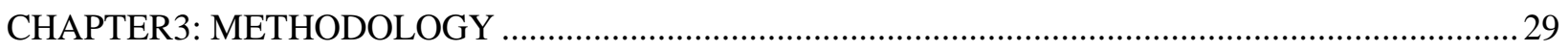

3.1: Governing Equation of Storage and Transport in Organic Rich Shale Porous Media......................2 29

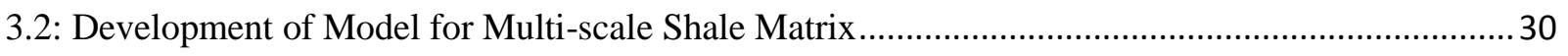

3.3: Initial and Boundary Condition Value Problem ………………………….................................... 32

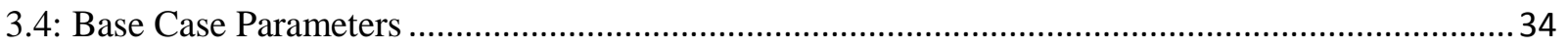

3.5 Development of Storage and Transport Model Including Poroelatic Effect and Dual Isotherm

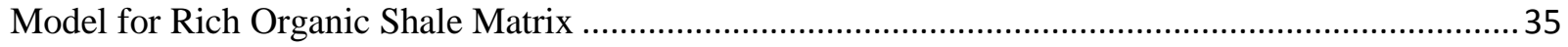

3.5.1:Development of Storage and Transport Model for Shale Matrix "Case I" ..................................35

3.5.2: Development of Storage and Transport Model for Shale Matrix- Fracture "Case II" ................ 39

3.5.3:Development of Storage and Transport Model for Multi-Scale Shale Matrix "Case III"........... 44

3.5.4: Development of Storage and Transport Model for Multi-Scale Matrix- Fracture "Case IV"....52

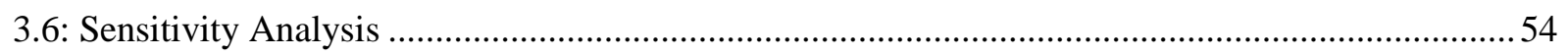




\section{CHAPTER: 4: RUSELTS AND CONCLUSION}

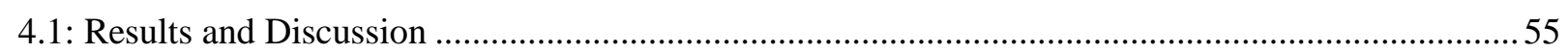

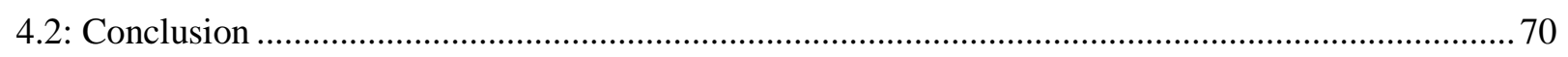

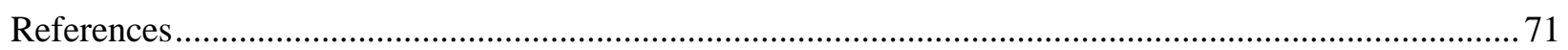




\section{LIST OF FIGURES}

Figure 1Shale gas plays in the lower 48 states (EIA, 2011) ..............................................................

Figure 2FIB/SEM image shows the porosity and kerogen inside the shale matrix. The black depicts pore,

dark gray is kerogen while the light gray is matrix (Ambrose et al, 2010) ............................................ 5

Figure 3methane adsorption data and Langmuir isotherm for Sun Juan basin (Siedle, 2011)................... 10

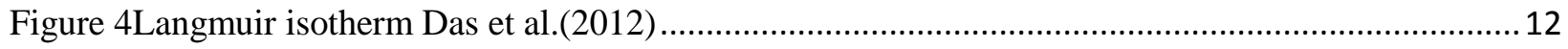

Figure 5 Comparison of Langmuir-Henry dual mode with Langmuir isotherm. The pressure are obtained from ideal gas law (Yi et al., 2009)............................................................................................. 13

Figure 6the principle of the multi-continuum approach for fractured permeable formation (Dietrich et al,

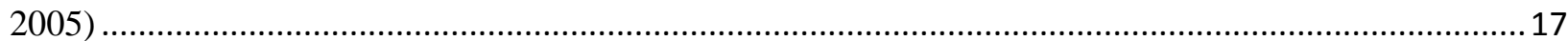

Figure 7 serial, selective and parallel coupling (Dietrich et al, 2005) ................................................ 18

Figure 8 Orgnaic and Inorganic material distribution in the shale and coal matrix (Kang et al, 2010) ......19

Figure 9 Multi-continuum approach for shale has transport in series for rich organic shale (Akkutlu et al.,

2012) 19

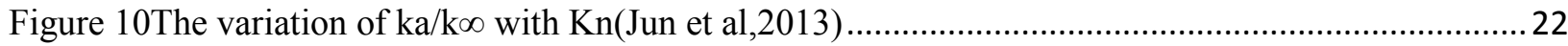

Figure 11 Matchstick coal seam geometry model (Shi et al, 2005) .....................................................24

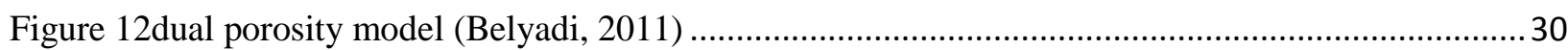

Figure 13Conceptual multi continuum models for gas flow and transport in organic rich shalecase\#2 ....31

Figure 14 Conceptual multi continuum models for gas flow and transport in organic rich shale case\#3 ...31

Figure 15 Conceptual multi continuum models for gas flow and transport in organic rich shale

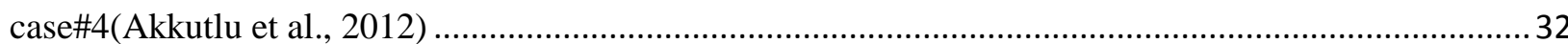

Figure 16 A schematic showing the setup for numerical simulation ..................................................32

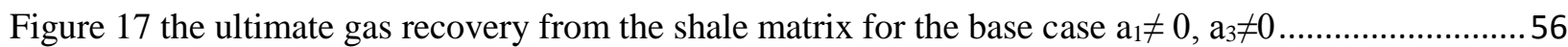

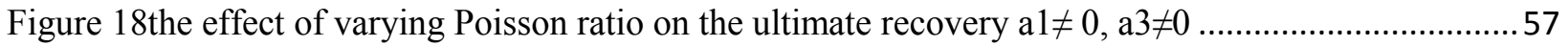

Figure 19(right) shows the effect of varying Poisson ratio on the matrix porosity ;( left) shows the effect

of varying Poisson ratio on the matrix permeability

Figure 20the effect of pore compression on the ultimate recovery of the gas from the shale matrix ;( red) shows the base case recover curve $a 1 \neq 0, a 3 \neq 0$ and the (blue) shows the recovery curve when we neglect the effect of pore compression on the pore compressibility $a_{1}=0, a_{3} \neq 0$.

Figure $21 \mathrm{effect}$ of pore compression on the ultimate recovery of the gas from the shale matrix ; $($ red) shows the base case recover curve $\mathrm{a} 1 \neq 0, \mathrm{a} 3 \neq 0$ and the (blue) shows the recovery curve when we neglect the effect of adsorption on the pore compressibility $a 1 \neq 0, a_{3}=0$......

Figure 22shows the porosity with and without the effect of adsorption on the pore compressibility and the ; ( left) shows the permeability with and without the effect of adsorption on the pore compressibility ......59 Figure 23 comparison between the ultimate gas recovery from the shale matrix for the base case 1 and 2 $\mathrm{a} 1 \neq 0, \mathrm{a} 3 \neq 0$

Figure 24 the effect of increasing fracture volume for case \# 2 on the fractional gas recovery ................61

Figure 25Case \#2: the effect of varying Poisson ratio on the gas ultimate recovery $a 1 \neq 0, a 3 \neq 0$

Figure 26shows the effect of varying Poisson ratio on the matrix porosity ; left) shows the effect of varying Poisson ratio on the matrix permeability 
Figure 27case \#2: the effect of pore compression on the ultimate recovery of the gas from the shale matrix ; (red) shows the base case recover curve $a 1 \neq 0, a 3 \neq 0$ and the (blue) shows the recovery curve when we neglect the effect of adsorption on the pore compressibility

Figure 28 the ultimate gas recovery from the shale matrix for the base case $a 1 \neq 0, a 3 \neq 0$

Figure 29 comparison between the ultimate gas recovery from the shale matrix for the base case 1 and 3

$\mathrm{a} 1 \neq 0, \mathrm{a} 3 \neq 0$.

Figure 30Case \#3 the effect of varying inorganic Poisson ratio on the gas ultimate recovery a1 $\neq 0, a 3 \neq 0$

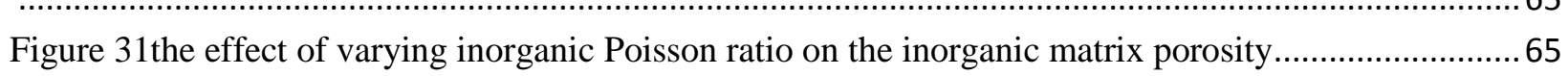

Figure 32the impact of varying inorganic young modulus on the gas ultimate recovery .........................66

Figure 33 comparison between the ultimate gas recovery with and without the pore compressibility effect ; (red) show the recovery with the pore compressibility $a 1 \neq 0, a 3 \neq 0$ and (blue) shows the recovery

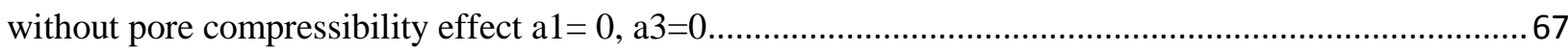

Figure 34the ultimate gas recovery from the shale matrix for the base case $a 1 \neq 0, a 3 \neq 0 \ldots \ldots \ldots \ldots \ldots \ldots \ldots . . . . . . . . .68$

Figure 35Case \#4: the effect of varying Poisson ratio on the gas ultimate recovery a $1 \neq 0, a 3 \neq 0 \ldots \ldots \ldots \ldots .68$

Figure 36shows the effect of varying Poisson ratio on the matrix porosity (red) when Poisson ratio is 0.30

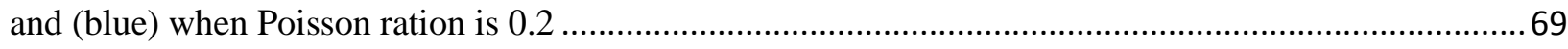

Figure 37the effect of pore compression on the ultimate recovery of the gas from the shale matrix ;( red) shows the base case recover curve $a 1 \neq 0, a 3 \neq 0$ and the (blue) shows the recovery curve when we neglect the effect of adsorption on the pore compressibility..... 


\section{LIST OF TABLES}

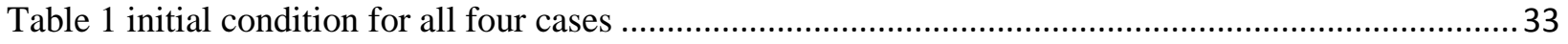

Table 2 boundary condition for all four cases................................................................................. 33

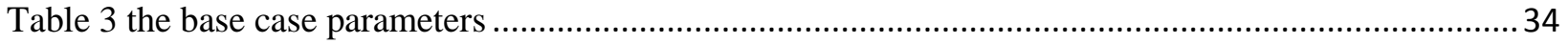

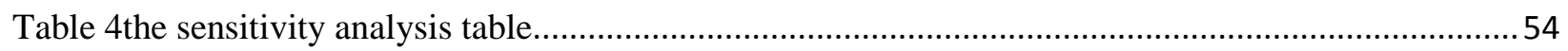




\section{NOMENCLATURE}

$\mathrm{V}_{\mathrm{p}}$ : pore volume

$\mathrm{V}_{\mathrm{b}}$ : bulk or matrix volume

$\mathrm{V}$ : volume of adsorbed gas in

$\mathrm{V}_{\mathrm{L}}$ : Langmuir volume or the maximum sorption capacity

P: pressure in Pascal

$\mathrm{P}_{\mathrm{L}}$ : Langmuir pressure

$\mathrm{C}$ : free gad concentration in $\mathrm{mol} / \mathrm{cm}^{3}$

$\mathrm{K}_{\mathrm{H}}$ : Henry law constant

$\mathrm{n}$ :shape factor of coal body

$\mathrm{Cu}$ : concentration of gas adsorbed by micropors in $\mathrm{mol} / \mathrm{cm}^{3}$

Q: porosity of matrix in fraction

$\mathrm{Q}_{\mathrm{f}}$ : fracture porosity in fraction

$\mathrm{D}_{\mathrm{p}}$ :macropore diffusion coefficient in $\mathrm{cm}^{2} / \mathrm{s}$

$\mathrm{R}_{\mathrm{g}}$ : universal gad constant in

$\mathrm{T}$ : temperature in $\mathrm{k}$

$\mu$ : viscosity of the gas in $\mathrm{kg} / \mathrm{cm} / \mathrm{sec}$

$\mathrm{L}$ : length of matrix in $\mathrm{cm}$

$c_{\mathrm{p}}$ : pore volume compressibility in $1 /$ Pascal

$\mathrm{k}$ : the matrix permeability in $\mathrm{cm}^{2}$

$\mathrm{K}_{\mathrm{L}}$ : fracture dispersion coefficient in $\mathrm{cm}^{2} / \mathrm{s}$

A: cross section area in $\mathrm{cm}^{2}$

$\mathrm{C}_{\text {us: }}$ : maximum sorbed phase concentration in Langmuir isotherm in $\mathrm{mol} / \mathrm{cm}^{3}$

б: horizontal stress in Pascal

$\mathrm{k}_{\mathrm{f}}$ : fracture permeability in $\mathrm{cm}^{2}$

$\mathrm{c}_{\mathrm{f}}$ : cleat volume compressibility in $1 /$ Pascal

$c_{x}$ : shrinkage coefficient in 1/Pascal

f:fraction (0 to 1$)$

M: constrained axial modulus in Pascal

$\gamma$ : grain compressibility $1 /$ Pascal

$\alpha$ : grain thermal expansivity in $1 / \mathrm{K}$

$v$ : poisson's ratio

E: Young's modulus

$\mathrm{K}$ : bulk modulus in Pascal 
$\varepsilon:$ strain

$\varepsilon_{l}$ : dimensionless adjustment parameter

$\mathrm{D}_{\mathrm{s}}$ :micropore (solid) diffusion coefficient $\mathrm{cm}^{2} / \mathrm{s}$

$\mathrm{b}^{\prime}=$ Langmuir constant (bRT)

$\mathrm{k}^{\prime}=$ Coefficient of linear adsorption

$\mathrm{x}$ : space coordinate in $\mathrm{cm}$

$\mathrm{t}$ :time coordinate in seconds 


\section{INTRODUCTION}

Over last three decades, shale gas has becomes one of the important source of the natural gas supply. According to EIA (2011) shale gas contributed in $10 \%$ of the natural gas yearly production in Untied State and there is a potential to rise to $35 \%$ in next years. As a result, more attention is attracted to this potential source of energy. many previous studies like Seidle et al. (1992);Palmer et al.(1998); Shi et al.(2005) and Yi et al. (2008) have reported the relation between stress and the formation permeability in organic rich reservoir such as coal bed methane and shale matrix. Thus, different mathematical approach has been developed to describe this relation between the stress and permeability. Majority of these approaches has introduced based on the experiments on coal bed methane cores and field data.

On the hand, shale gas reservoir has a similar behavior to the coal seam since it shows a great sensitivity to the change in the mechanical properties of the formation and the effective stress. The great sensitivity to the change in stress comes as a result of the intricate nature of shale matrix which consists of organic and inorganic component. Each of these components has a different pore structure and thus different storage and transport mechanisms are involved. As a result there is a great need to study the coupling between pore compressibility and gas storage and transportation to develop poroelastic relations for shale gas reservoir. In this study a poroelastic approach has been developed deriving from the basic governing equations for gas transport in the porous media. Palmer and Manssori (1998) Modified formula is used in this investigation to represent the organic pore compressibility and Dual Langmuir- Henry isotherm is used to describe the sorption dynamic equilibrium. Four different conceptual models have been developed to simulate the storage and transport within the shale matrix. Analytical models then solved numerically using implicit finite difference approach using MATLAB. Sensitivity analysis then

implemented to study the effect of shale mechanical properties on ultimate gas recovery and thus the flow and storage within the shale matrix. 


\section{OBJECTIVE}

The goal of this study is to develop a mathematical approach for poroelastic effect on the gas storage and transport in multi-scale shale matrix including the effect of pore compressibility and dual isotherm model. In order to achieve this goal, a multi-continuum conceptual is developed to model the elastic behavior of the shale matrix. Consequently, Matlab program was used to simulate the impact of the elastic behavior of the shale matrix on the storage and transport mechanism.

Briefly, the objective of this study is summarized as below:

1- Developing a governing equation for the elastic behavior of the shale matrix.

2- Developing base case model for simulating the impact of poroelasticity on the shale matrix storage and transport.

3- Study the effect of poroelastic parameters on the storage and transport.

4- Identify the most effective parameter on the behavior of pore compressibility. 


\section{CHAPTER 1: OVERVIEW}

\section{1: Shale Gas Reservoirs Overview}

Shale has been defined in geological science as clay compacted fine-grained sedimentary rock which usually layered in parallel to the bedding plane. It forms by mechanical weathering and chemical degradation of pre-existing rock then mixed with clay materials which consist of fine grained minerals and phylloosicates (Tiab \& Donadlson 1996). Subsequently, mixture is compacted underground and form shale. Shale is considered to be hydrocarbon source rock because of its organic material content (kerogen).The pore size of the shale formation is extremely small. Thus, shale is defined as comparatively impermeable formation (EIA, 2011).

Shale gas reservoirs play an important role in oil and natural gas industry. According to the current studies shale gas in place is estimated to be 750 trillion cubic feet, however, only $68 \%$ is recoverable (EIA, 2011). Shale gas formation is distributed into three main regions Northeast, Gulf coast and Southwest regions as shown Figure 1. The largest shale gas region are Marcellus Shale (410 Tcf, 55\% of the total recourse), Haynesville shale (74.7 Tcf, $10 \%$ of the total resources) and Barnett shale (43.3 Tcf, $6 \%$ of the total resources respectively (EIA, 2011).

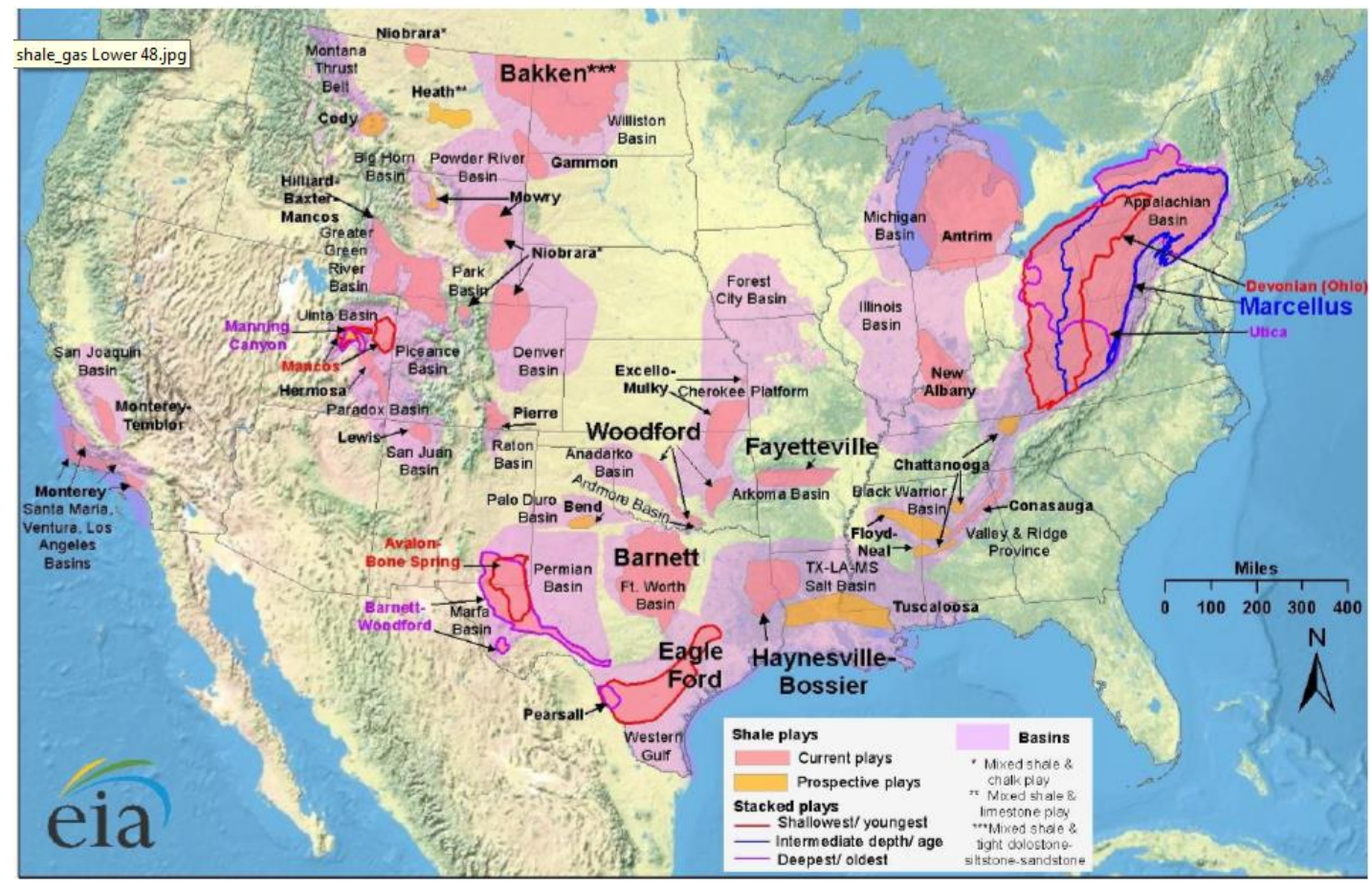

Figure 1Shale gas plays in the lower 48 states (EIA, 2011) 
Shale gas production in North America started in 1821, however, the new era in shale gas production started in 1980s after a successful production from Barnett shale, which is more than million standard cubic feet per day (Horsfield \&Schulz, 2012; Bustin, 2012). Shale gas production is contributed to be $10 \%$ of the United State yearly production and it is expected to reach $35 \%$ or more in next decade (EIA, 2011). Shale gas has been considered to be the key contributor for natural gas supply in the United States and it is important to develop a methodology for best understanding the flow and storage mechanisms and the impacting factors.

\section{2: Overview on Pore Distribution in Shale Matrix}

Shale matrix has a quite complex nature compare to the conventional reservoirs. Typically, shale matrix is consisting of two parts: organic or kerogen material and inorganic matrix. The organic material exists as dispersed porous pockets within inorganic matrix (Akkutlu et al., 2011). Understanding how the pore is distributed and connected within the shale matrix constituent is relatively important since it is the key to characterize the permeability and porosity and thus, storage and transport mechanism of the formation. New developments in the FIB/SEM imaging give us the chance to examine the pore distribution and microstructure and better understand of the flow and storage within the shale matrix.

Most of the earlier studies (Diamond, 1970; Rutherford et al., 1997) on the microstructure of the shale matrix indicated that it is dominated by micro- to meso- pore. However, presence of the extremely small pores within kerogen is also observed and reported (Kuila et al., 2011).

Loucks et al. (2009), and Ambrose et al. (2010) performed series of 2-D, 3-D submicron-scale investigations by using FIB/SEM imaging technology. From these studies they constructed 2-D images of shale matrix components as shown in Figure 2. Figure 2 shows there are two distinct regions in shale matrix (presented by dark and light gray as organic and inorganic materials, respectively). Pore spaces are the black spots, where mostly located in the organic parts (Akkutlu et al, 2011). Both studies indicate that pores are resid in both kerogen and inorganic matrix. However, the majority of the pores are small (less than $100 \mathrm{~nm}$ ) and reside within the keogen material (Ambrose et al, 2010; Crutis \& sondergeld, 2013). The size of pore within the kerogrn materiel is between 200 to $500 \mathrm{~nm}$. However, analytical approach is introduced by Kang et al, (2010) showing that kerogen also has pore size distribution below $4 \mathrm{~nm}$. The pores in the inorganic matrix is significantly larger and they do not shown in this image they could be irregularly shaped voids as shown in Figure 2(Akkutlu et al, 2011). The flow within nano-pore is expected to be a combination of Knudsen diffusion, slip flow and surface diffusion while the flow in the micro-pore is assumed to be Darcy flow. 


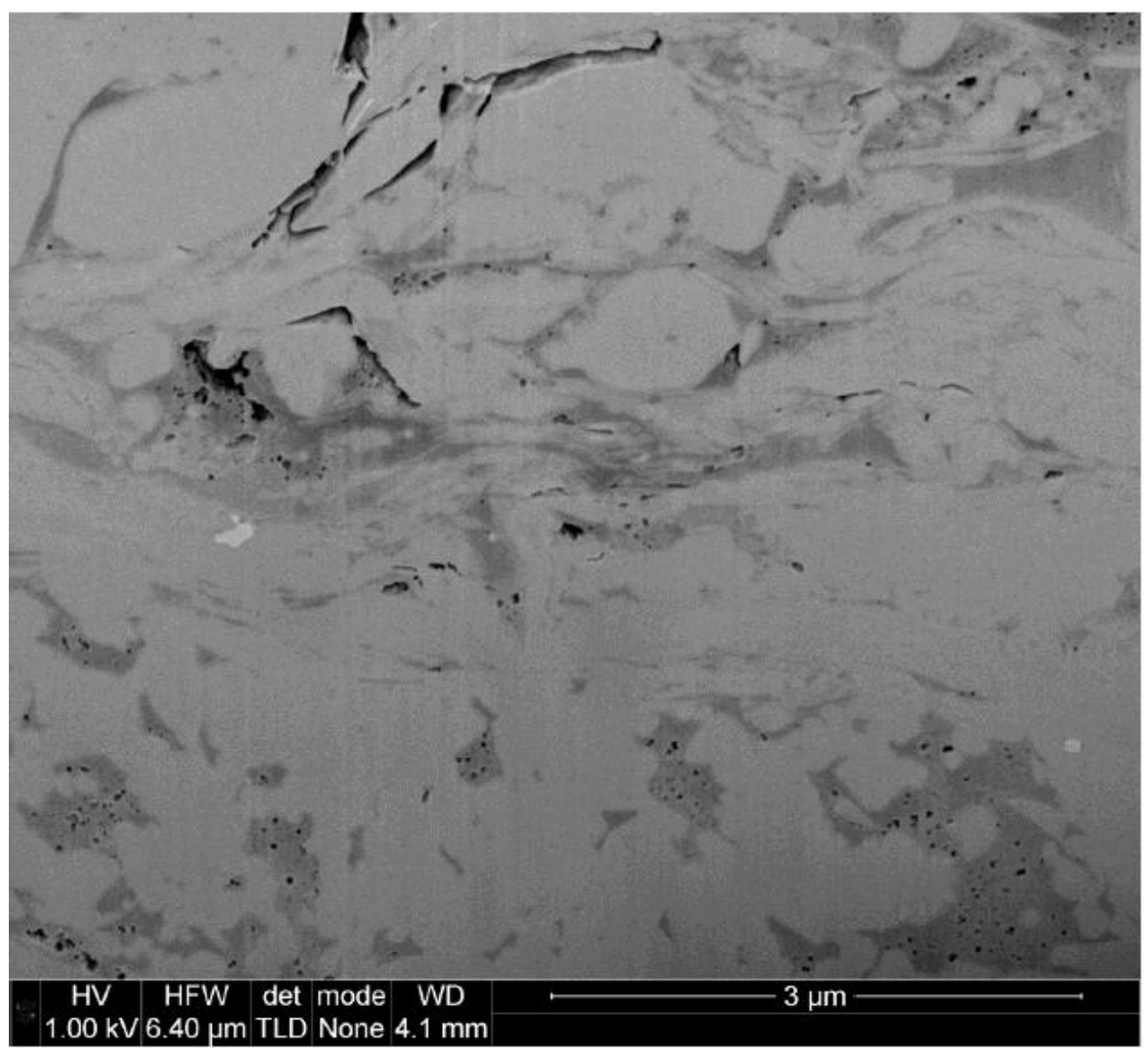

Figure 2FIB/SEM image shows the porosity and kerogen inside the shale matrix. The black depicts pore, dark gray is kerogen while the light gray is matrix (Ambrose et al, 2010) 


\section{CHAPTER 2: LITERATURE REVIEW}

\section{1: Gas Storage Mechanism in Multi-scale Shale Matrix}

One of the features which make the Shale reservoirs different from the conventional reservoirs is the gas storage mechanism. In conventional gas reservoirs gas is stored as free gas in the pore and pore throats of reservoir rock or dissolved in water or hydrocarbon liquid. However, in shale gas reservoirs gas is stored mainly in three different forms: adsorbed gas on inner surface area of organic materials, free gas in the pore and throats of matrix and fractures of the formation, and dissolved gas in the kerogen material. Moreover, some researchers suggest that gas could be adsorbed not only by kerogen but also by clay minerals (Hao et al., 2013). Different gas storage mechanism mentioned above have been introduced first time by Schettler et al.(1989,1991) and confirmed later by Curtis (2002), Javadpoue (2007),(2009), Kang et al.(2010)and, Zhang(2012).

Advanced understanding of gas storage mechanisms and properties of gas stored in each of these three forms in shale gas reservoirs is the key factor for a suitable reservoir development plan and reasonable estimation of the reserves (Zhang et al., 2013). Many investigations have attempted to understand different storage mechanisms involved especially sorption mechanism that seems to have more impact on gas production. Importance of the dissolved gas in the kerogen in the production performance and gas -in -place estimation is considered recently after the studies of Loucks et al. (2012) and Milliken et al. (2012) on the self-diffusion and pore structure. However, this effect on total gas-inplace calculations assumed to be negligible due to very small quantity of gas that can be dissolved in solid (Ambrose et al 2011, Guo, 2013). Furthermore, the understanding of gas storage mechanism is also a crucial factor in the process of enhanced shale gas recovery by $\mathrm{CO} 2$ injection and sequestration in organic-rich reservoirs. 


\subsection{1: Adsorption Phenomena in Organic Nanopore of Shale Matrix}

Adsorption is a process of the molecules accumulation on the material surface which will create a film on the adsorbent surface by Van der Waals forces (Siedle, 2011; Zhang et al.,2013) or more precisely as the process of storing gas in the macro-scale pores of porous medium as condensate or liquid like phase (Yee et al,1993). These phenomena occur in the rich-organic reservoirs like shale and coal bed methane due to the existence of organic nano- and micro -scale pores within the matrix. Nano-pores (less than $2 \mathrm{~nm}, 20 \mathrm{~A}^{\circ}$ ) are the main place where the adsorption process occurs because of the presence of large internal surface area (Yi et al, 2008). In other words, since the walls of the micro-pores are very close, which leads to overlap a potential energy field called Lennard-Jones. This over lap of Lennard-Jones potential energy will enhance the adsorption capacity of the pore system and in turns leads to the starting of gas adsorbed at law pressure (Allen et al, 2009) forming a mono layer on the pore surface with density close to the liquid methane (Siedle, 2011). Also, adsorption is a reversible process which means that adsorption and desorption (the process of releasing the gas molecules from the pore surface) could be represented by the similar isotherms (Yee et al., 1993). Most of the adsorption/desorption studies are conducted on the coal seam (Cui et al., 2004). Recently shale gas reservoirs attracted a lot of interests and more studies are being performed on adsorption/desorption phenomena in shale matrix.

As we mentioned above, the recent studies and development in shale gas industry make it possible to determine the factors that dominate the behavior and mechanism of the adsorption process. The first factor is the properties of the organic material like richness, rank, and thermal maturity (Guo, 2013; Hao et al., 2013; Yi et al, 2009). Zhang et al. (2012) conducted an experiment on different types of samples with different kerogen type and found out that they have different adsorption capacities. They showed that the aromatic high kerogen has more storage capacity than aliphatic keorgen because aromatic high kerogen have higher thermal maturity, which in turn, increasing the organic porosity and surface area and decrease the heterogeneity of the pore surface. The second factor impacting the sorption behavior is found to be the types of inorganic minerals exist within the shale matrix. Ross et al (2007), (2009) and Zhang et al (2012) stated that the minerals have different surface area and pore size which leads to have a different storage capacity, but they also reported that the storage capacity in minerals is decreasing with increasing the formation moisture, which make the effect of mineral adsorption on the storage capacity in shale negligible. The third factor is the pore structure and distribution of the matrix. According to Ross et al. (2009) the gas storage capacity of shale is decreasing by increasing meso- and micro-pore surface area and increasing the porosity (Hao et al, 2013). These result are based on experiment on shale samples from British Columbia to understand the relationship between the pore volume and TOC. Moisture content of the shale formation can also play an important role in sorption 
behavior of the formation. The studies of (Clarkson et al., 1997; and Zhang et al; 2012) reported that increasing in the moisture content reduce the gas storage capacity in organic rich shale significantly since the moisture occupy the sorption site or clog the pore throat (Hao et al, 2013). This effect on gas storage capacity of organic rich shale is much less than that of coal bed methane because of the less organic content of shale compared to coal. Reservoir pressure and temperature also highly impacts shale gas sorption capacity. Sircar (1992) stated that gas storage capacity is decreasing with temperature increasing while for the pressure the gas storage capacity will increase with increasing pressure till it reaches the maximum adsorption capacity of shale(Hao et al, 2013). Each one of these factors we mentioned above impacts gas storage capacity of the shale strata with different magnitude. It also should be take into consideration that there is also a slight difference in the sensitivity of the different shale samples to each one of these factors.

\subsubsection{1: Sorption Isotherm Models}

Sorption isotherm is the term refers to the equilibrium between free gas and its adsorbed phase which represent the content of the adsorbed gas as function of free gas pressure under isothermal condition (Yee et al., 1993). Through sorption isotherm we can determine the quantity of the adsorbed gas, and estimate the actual gas in place. It is also important to note that the accuracy of sorption isotherm depends on the reservoir gas saturation if the reservoir is saturated with the gas then the isotherm model provides a very reliable estimation otherwise the sorption isotherm might overestimates the real gas content.

Different sorption isotherm models are available in the literature but in this review we will focus on most conventional models including Langmuir isotherm and Dual Henry-Langmuir isotherm models.

\subsubsection{1: Langmuir Isotherm Model for Organic Rich Reservoir}

Langmuir adsorption model is introduced in 1916 by Irving Langmuir to describe the accumulation of the atoms on the solid surface as a function of pressure at specified temperature. In his model, Langmuir made the following assumption: each adsorption site has the ability to adsorb only one gas atom, the adsorbed molecule does not affect the other adjacent molecules, gas molecule could not distinguish the sorption sites and also he assumes that adsorption happen on open surface and the gas could reach the adsorption site without any resistance (Daneils \& et al., 1957). However, the last assumption is a wrong because of the fact that the micro-pore throats could form cavities with in the rich organic formation for thousands of molecular diameters long and only few diameters in width (Gregg et al, 1967). Thus, there is a restriction access to the adsorption site which conflict with the assumption has 
been made in Langmuir theory. Having said so Langmuir isotherm provides a good description of adsorption process in micro-porous medium such us coal and shale matrix. Langmuir isotherm can be characterized using Langmuir volume and Langmuir pressure, former is usually known as maximum sorption capacity $\left(\mathrm{V}_{\mathrm{L}}\right)$ and represents the maximum monolayer volumetric capacity per unit weight of solid and later is a pressure at which half of sorption capacity is filled with adsorbed gas. Langmuir isotherm is expressed mathematically as follow:

$$
V=\frac{V_{L} p}{P_{L}+p} \quad \text { eq(1) }
$$

that can also be presented as:

$$
V=V_{L} \frac{b p}{1+b p} \quad \mathrm{eq}(2)
$$

Where $\mathrm{V}$ is the gas content at any given pressure, $\mathrm{V}_{\mathrm{L}}$ is the maximum adsorption capacity, $\mathrm{p}$ is the pressure and $b$ is the Langmuir constant. At (0) pressures the expression above will be reduced to Henry law as shown below:

$$
V=V_{L} b p \quad \text { eq(3) }
$$

The gas content and pressure are related to each other by a linear function and that is why sometimes $b$ is called Henry law constant. Henry law is introduced in 1803 by William Henry to describe the solubility of gas in another fluid, and it stated that under isothermal condition the quantity of the gas which dissolved in a particular type and volume of fluid has a direct proportional relationship to the partial pressure of that fluid. Both VL and PL are treated as empirical constant and to have a physical effect on the data of adsorption process used to generate the Langmuir isotherm should cover the regime from low pressure to high pressure. The Langmuir isotherm for methane is shown in Figure 3. 


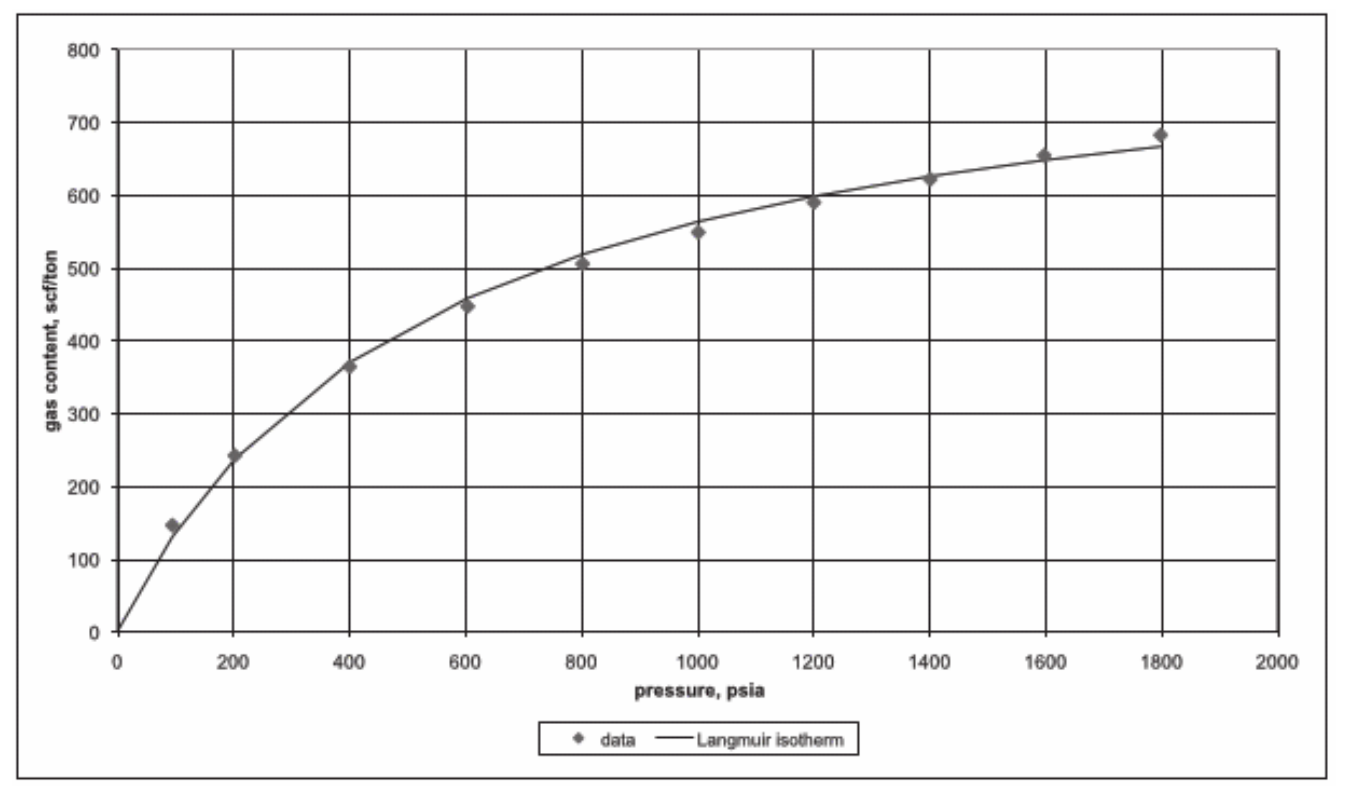

Figure 3methane adsorption data and Langmuir isotherm for Sun Juan basin (Siedle, 2011)

\subsubsection{2: Dual Isotherm Model for Rich Organic Reservoir}

The sorption behavior in glassy polymer matrix is usually described by diffusion-solution model. However, the high adsorption capacity of the glassy polymers cannot be explained by Henry law thus a suggestion has made to correlate this high adsorption capacity to the presence of more than one type of the adsorption in the glassy polymer matrix. This assumption of two adsorption mode is presented by Mattes (1944) during his investigation on water sorption in the cellulose. Mears (1954) used the model for the first time to study the solubility of the small atoms in the glassy polymer. Further modifications are considered for this model and new dual isotherm sorption model is introduced by Barrer et al. (1958) and Michael et al. (1963). The following assumptions have been made developing dual isotherm sorption model as follow: the polymer is comprised of a continued chain matrix and holes frozen within matrix, Henry and Langmuir models govern the sorption behavior simultaneously and they are always in equilibrium, the penetrants molecule which follow the Langmuir isotherm mode are immobilized, diffusion happen just in the dissolved phase and the diffusion coefficient dose not effected by the concentration (Suloff, 2002).

In this model the adsorption mechanism is described in terms of one population of the ordinarily dissolved adsorbed molecules in the polymer matrix which is described by Henry law and the second population is assumed to occupy unrelaxed free volume inside the matrix of the glassy polymer (in the micro voids) and it is following Langmuir isotherm (Green et al, 1994). The unrelaxed free volume occurs as a result of the trapped rotation of the polymer chain in the glassy state which represents the constant 
micro voids or holes which penetrated the polymer (Green et al, 1994). The micro voids will prevent the portion of the penetrated molecules from mobilizing by trapping or binding them at high energy location at their molecular surface in process similar to the adsorption (Green et al, 1994). The dual sorption isotherm mode is represented mathematically by the following form:

$$
C=C_{D}+C_{H}=K_{D}^{\prime} P+\frac{C_{H}^{\prime} b p}{1+b p} \quad \mathrm{eq}(4)
$$

Where $\mathrm{C}$ is the solubility, $\mathrm{K}_{\mathrm{D}}$ is Henry law dissolution constant, $\mathrm{b}$ is the hole affinity constant $\mathrm{C}_{\mathrm{H}}$ ' is the hole saturation constant and $\mathrm{p}$ is the pressure. $C_{D}$ Represents the adsorption of the ordinary diffusive molecular while $C_{H}$ is the adsorption in the microvoids or holes. The above relation will be a linear relation when the $\mathrm{bp}$ is much less than one since micro voids will saturate with sorbate and there is no longer chance for additional penetrate to occur because it will reach to its saturation limit. Dual sorption mode can also be expressed by using following equation (Green et al, 1994):

$$
\begin{gathered}
C=C_{D}+C_{H}=\left(K_{D}^{\prime} P+C_{H}^{\prime} b\right) p \\
C=C_{D}+C_{H}=K_{D}^{\prime} P+C_{H}^{\prime}
\end{gathered}
$$

Where, the dual mode isotherm predicates gas solubility versus pressure representing three different regimes: the low pressure linear regime, nonlinear regime and high pressure linear regime (Green et al, 1994).

In 1994, Green and Selby suggest that Pyridine isotherm curve for coal could be represented by dual mode isotherm model better than Langmuir isotherm and De-Henry dual mode which is usually used to explain the sorption isotherm for the glassy polymer. Both conducted a sorption experiment on a three Argonne Premium coal samples to study the relation between coal micro porosity and the adsorption model. They inferred that a physical adsorption occurs on the coal surface and it obey the Langmuir isotherm while the dissolution which happen in the coal bulk is followed Henry law (Shimizu et al.,1998). Thus the linear part of the isotherm curve represents the dissolution of Pyridine according to the Henry law.

More investigations have been done by Shimizu et al. (1998) performing an adsorption experiment on four coal samples: Pocahontas, Upper Freeport, Illinois No.6 and Beulah- Zap. In that experiment they study the adsorption behavior of different organic vapor like Pyridine, Benzene and Methanol. They inferred that some sorption experimental data fit very well with DR-Henry dual mode other fit better with Langmuir-Henry dual mode or might be both of them depended on the thermal 
maturity or coal rank. However, for all cases the curve fitting lines for Langmuir-henry dual mode have more agreement with the experimental results (Shimizu et al., 1998) than DR-Henry dual mode. Finally, they suggest that the adsorption could be handled by dual Langmuir-henry equation regardless of type of organic. Thus from Green et al. (1994) and Shimizu et al. (1998) the dual Langmuir -Henry isotherm could be written as below:

$$
C_{\mu}=\frac{C_{u s} b^{\prime} C}{1+b^{\prime} C}+k d C^{\prime} \quad \text { eq(6) }
$$

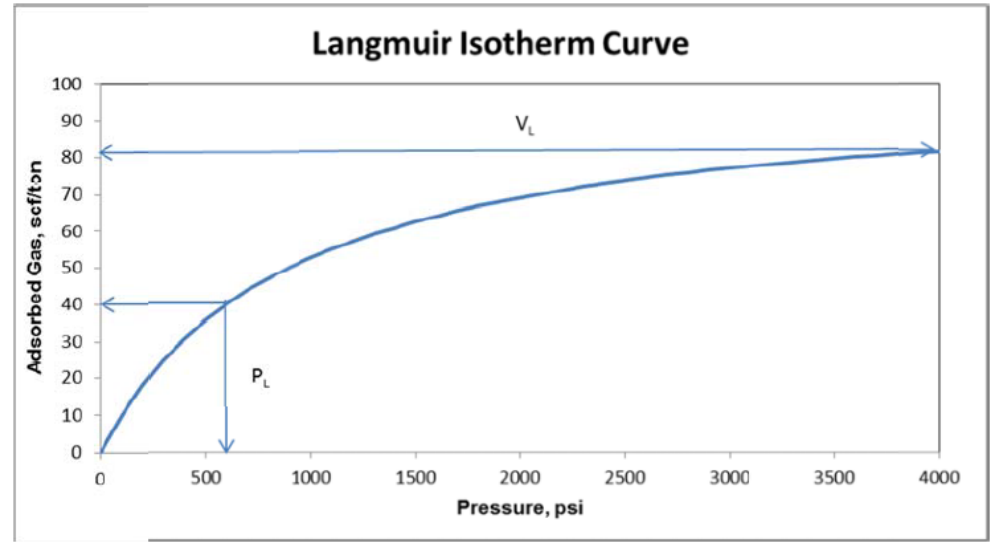

Figure 4Langmuir isotherm Das et al.(2012)

Form all above we could conclude that the dual Langmuir -Henry isotherm is an effective approach to explain the adsorption behavior in coal and other organic rich reservoirs (Yi et al., 2009).Figure 5shows a comparison between dual Langmuir- Henry isotherm and Langmuir isotherm. Form this figure we could notice that according to the dual Langmuir- Henry isotherm the gas adsorption could be increased infinitely with the pressure to complete condensation and blocking the pore space (Yi et al., 2009). 


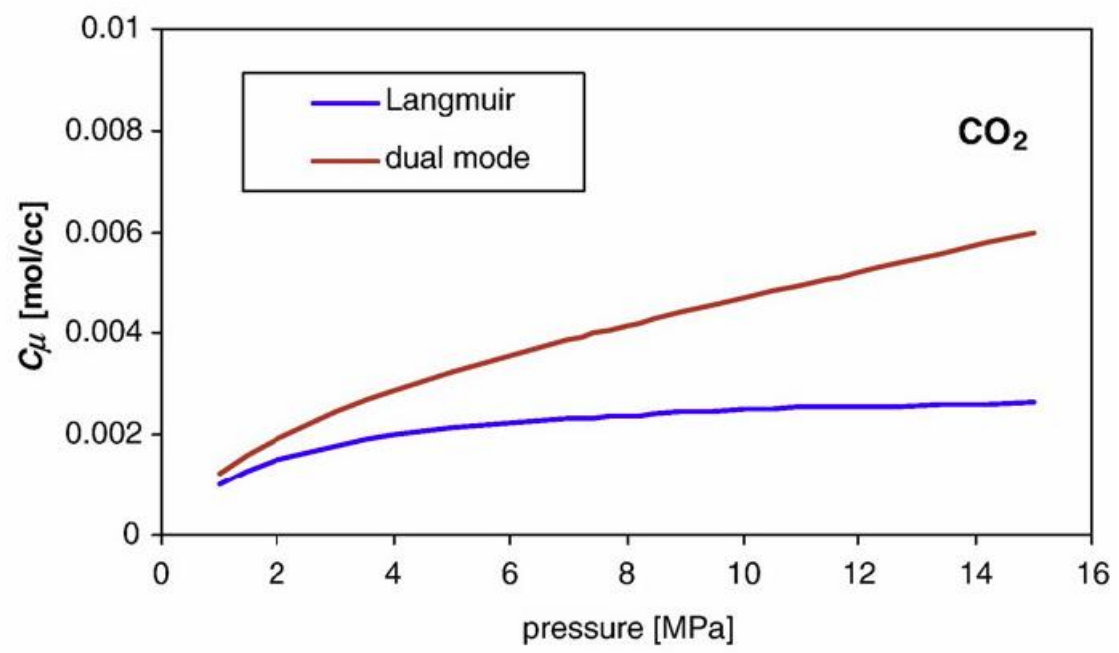

Figure 5 Comparison of Langmuir-Henry dual mode with Langmuir isotherm. The pressure are obtained from ideal gas law (Yi et al., 2009)

\subsection{2: Multi-component Gas Adsorption in Shale Matrix}

Generally, natural gas in organic-rich reservoirs is a multi-component fluid consisting of mixtures of different hydrocarbon and non-hydrocarbon components like methane, nitrogen, carbon dioxide and heavier hydrocarbon component (> C2). However, methane is still the main component (Ambrose et al., 2011; Clarkson et al., 1999). Each of these components have a different sorption affinity and contribution in the total gas phase densities (Ambrose et al, 2011). The phases of shale gas reservoirs are widely varying starting from dry gas phase with one to three components consist $99 \%$ of the gas composition to liquid phase with 40 different components. However, in many shale reservoirs there is a wide transition between liquid and gas areas. This transition area or wet gas area is where the multi-component adsorption model is specifically critical to use for better estimation of the reserve in place and gas phase (Ambrose et al, 2011).Moreover the understanding of the multi-component gas adsorption mechanism becomes more important with the appearance of geological sequestration or underground storage of $\mathrm{CO}_{2}$ technology which used as enhanced gas recovery method in both coalbed methane and shale gas reservoir.

When two or more components exist within the shale matrix they will compete for adsorption sites on the surface of the kerogen material. This process is governed by maximum heat and minimum free energy of adsorption for each component (Clarkson et al., 2013; Ko, 2007) that is called competitive adsorption or multi-component adsorption. The process is similar to the individual adsorption since both of them will lead to reduce the free energy of the system since the molecules will transfer from free gas phase to the to the adsorbent film and lose its translational entropy (Stadie, 2013). However, the actual 
adsorbed amount of a specific gas component from gas mixture is different from the amount adsorbed if that gas is pure (Myers, 1968). Both enthalpy and entropy factor and thus the multi-component adsorption are functions of molecular size of the gas, the structure of the molecules and characteristic of the adsorbent surface such as pore type and size and the thermal maturity of the organic material within the shale matrix (Fathi et al., 2013; Ko, 2007). Studies on these relations are started in 1970 and continued to study the effect of each of these factors on the multi-component adsorption and adsorption selectivity of different gas components in the mixture.

Nicholson et al. (1996) conducted a study on the effect of pore type and size on the adsorption selectivity of $\mathrm{CO}_{2}$ over $\mathrm{CH}_{4}$ in $\mathrm{CO}_{2}-\mathrm{CH}_{4}$ mixture by using of grand canonical Monte Carlo simulation. In this comparison study a different pore size and interaction models are used and the adsorption selectivity of $\mathrm{CO}_{2}$ over $\mathrm{CH}_{4}$ is calculated as a function of pore size. They found out that the Slit shape pore with width of 5 to $8 \mathrm{~A}^{\circ}$ has a maximum $\mathrm{CO}_{2}$ selectivity while for the cylindrical pore model the maximum $\mathrm{CO}_{2}$ selectivity occurred at pore radius around $5 \mathrm{~A}^{\circ}$. This difference in $\mathrm{CO}_{2}$ selectivity between two different pore models can be explained by geometrical effect arising from the restriction for the rotation of $\mathrm{CO} 2$ atom in the cylindrical model (Liu et al, 2012). Also it is found that the smaller the pore size (micro and nano scale pore) within the matrix in organic rich reservoir the stronger the $\mathrm{CO} 2$ selectivity (Kureniawan et al, 2006; Liu et al, 2012). This is attributed to the existing of the micropores providing a high interaction potential between the adsorbate gas and the pore wall (Ko, 2007; Liu et al, 2012).

Liu et al. (2012) studied the effect of polar/nonpolar molecular interaction with induced polarity surface on the adsorption selectivity of $\mathrm{CO}_{2}$ in $\mathrm{CO}_{2}-\mathrm{CH}_{4}$ and $\mathrm{CO}_{2}-\mathrm{N}_{2}$ mixture. The results from adsorption experiment on the two mixtures show that system has a higher selectivity for $\mathrm{CO}_{2}$ than $\mathrm{CH}_{4}$ or $\mathrm{N}_{2}$. This enhancement in $\mathrm{CO}_{2}$ adsorption over $\mathrm{CH}_{4}$ and $\mathrm{N}_{2}$ is related to polarity of the $\mathrm{CO} 2$ molecule. There are two types of adsorption forces: dispersive force and electrostatic force. In polar system the electrostatic force has a strong effect on adsorption process and adsorption selectivity.

The effect of the molecular weight and the molecular size on the adsorption selectivity in organic matter is studied by Cheng et al. (2004). In their study they conduct an adsorption experiment to investigate adsorption selectivity for C1-C6 hydrocarbon in gas mixture. Thus, they inferred there is a strong adsorption selectivity for the heavier gas molecular. Their conclusion supported the previous studies which are also reported that the adsorption selectivity of hydrocarbon gases depends on their molecular weight, size and vapor pressure. Ko (2007) reported that the required time to reach the equilibrium in multicomponent adsorption process is longer for complex gas mixture with higher 
molecular weight. On the other hand, mixture reaches the equilibrium state rapidly if it contains light molecular weight gas components.

Many adsorption models are used to investigate the multicomponent adsorption in organic rich reservoir. The simplest model are the extended Langmuir isotherm which introduced by Yang 1987. Basically the model is introduced to represent the isotherm of single component adsorption process then it extends to represent multicomponent adsorption process. The model is represented mathematically as follow:

$$
n_{a i}=\frac{\left(n_{L}\right)_{i} b_{i} p_{i}}{1+\sum_{j} b_{j} p_{j}} \quad \operatorname{eq}(7)
$$

Where

$\left(n_{L}\right)_{i} \& b i=$ pure gas Langmuir isotherm constants

$p_{i}$ is the partial pressure of the component gases in the free gas phase and it can be calculated by the equation below:

$$
p_{i}=p y_{i} \quad \text { eq(8) }
$$

The extended Langmuir isotherm model is the easiest model to use for rich organic reservoir, but it is not thermodynamically consistent since the maximum adsorption capacity of shale is not the same for all the components. Thus the thermal consistency requirements is not fulfilled and the extend Langmuir model should be viewed as empirical approach when applied to shale gas system (Ambrose et al, 2011; Clarkson et al., 2013;Hartman et al, 2011).

The second model is Ideal Adsorbed Solution theory (IAS) which introduced by Myers et al. (1965). The theory assumes that the adsorbed mixture has a behavior like an ideal adsorbed solution thus the final equation is similar to Rauoults law for bulk solution (Clarkson et al., 2013).In this theory the total amount of adsorbed gas is given by the following equation below:

$$
\frac{1}{n_{t}}=\sum_{i=1}^{n c} \frac{x_{i}}{n_{i}^{o}} \quad \text { eq }(9)
$$

And the amount of each mixture adsorbed is given by:

$$
n_{i}=n_{t} x_{i} \quad \text { eq(10) }
$$


Where

$x_{i}=$ adsorbed phase mole fraction

The third model is Vacancy solution theory, the theory is developed and applied on a single and multi-component adsorption process by Suwanayuen et al (1980) and Crochchran (1985).The theory predicts the multi-component adsorption equilibrium from the single component isotherm without the assumption of ideal adsorbed phase. The isotherm equation for this theory is given by the formula below:

$$
b p=\frac{\theta}{1-\theta} \exp \left(-\frac{2 w \theta}{R T}\right) \quad \operatorname{eq}(11)
$$

Where

$\theta=$ is the fractional saturation

$w=$ is the interaction energy

Sorption models mentioned above are the most popular sorption isotherm models for multicomponent adsorption in organic rich reservoirs. More isotherm models such as Modified Vacancy solution (Clarkson, 2003) model and Simplified Local Density Model SLD also introduced in the literature and can be used to characterize sorption in Shale gas and coalbed methane reservoirs.

\section{2: Gas Transport Mechanisms in Multi-scale Shale Matrix}

Understanding gas transport mechanisms in shale matrix is the key component to surpass the difficulties associated with the shale gas production and development. The gas transport in shale gas reservoirs is a complicated multi-scale process. As stated earlier shale matrix can be divided in to two organic and inorganic materials with multi-scale pore size distributions. Many studies have been done on transport mechanism in shale gas reservoirs showing that Dary law which is usually used to describe the flow in the conventional reservoir is not valid to explain the entire flow mechanism in the shale matrix due to presence of organic nano-pores that leads to high Knudsen number flow and sorption effect (Akkutlu et al., 2013). It is widely accepted that the flow in macro scale pores are conventional flow and Darcy equation is applicable while gas transport in micro-scale pores can include: viscous flow, Knudsen diffusion, molecular diffusion and surface diffusion (Akkutlu et al., 2013, Fathi et al 2013; Jun et al, 2013).Gas transport in micro and macro fractures however can be described by Darcy flow (Jun et al, 2013). 
In general, natural geological systems have complex structures that results in more complexity in physical processes governing transport and storage in them. Both the complexity in structure and physical process occurring inside the geological environment can be represented by conceptual models designed to fulfill the requirement of a specific type of problems on certain scale. These models usually introduce a set of parameters representing the material characteristics and physical description of flow and transport problem under study (Dietrich et al, 2005). Conceptual models are mathematical models describing physical and chemical characteristics of the phenomena. Due to high complexity of the geological problems conceptual models might not have analytical solutions for the problem and therefore numerical techniques might needs to be implemented. In conclusion the choice of the suitable conceptual model depends on the scale of the problem, the geological properties of the area under study and purpose of simulation. Multi-continuum concept is used to model separate and hydraulically coupled component of heterogeneous systems as shown below in the Figure 6 for a three different identified continua. The main difference between the multi-continuum approach and other conceptual models is in multi-continuum approach special distribution of different continua is not explicitly defined.

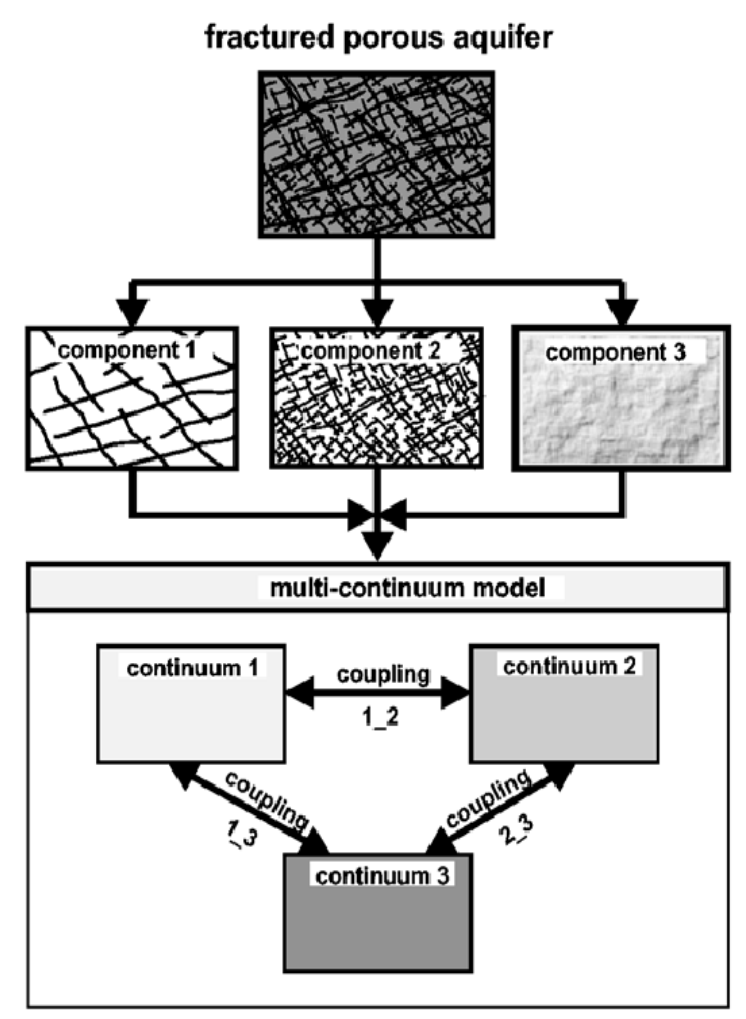

Figure 6the principle of the multi-continuum approach for fractured permeable formation (Dietrich et al, 2005)

Multi-continuum model is identified by the number of component it represents, type of component coupling, hydraulic behavior and mass exchange equations between two medium (Kang et al., 
2010). Multi-continuum model has an advantage over the single continuum model since the last one does not show the effect of interaction between different components on the transportation behavior of the system (Kang et al, 2010). Furthermore, there are three different coupling methods: parallel coupling, serial coupling and selective coupling (Dietrich et al, 2005;Kang et al, 2010). Parallel coupling is used when all the components of the system are coupled with each other directly, while in serial coupling components are connected in the order of hydraulic conductivity (Kang et al, 2010) and the selective coupling is a combination of coupling in parallel and series. Figure 7 shows different types of coupling methods. Also, it should be mentioned that one of the advantages of the multi-continuum model is that the model need only a few input data compare to the other models, but a good data base should be available to assure the quality of the multi-continuum model (Dietrich et al, 2005). The good input data are required so both the hydraulic component and the interaction could be represented effectively in the model (Dietrich et al, 2005).

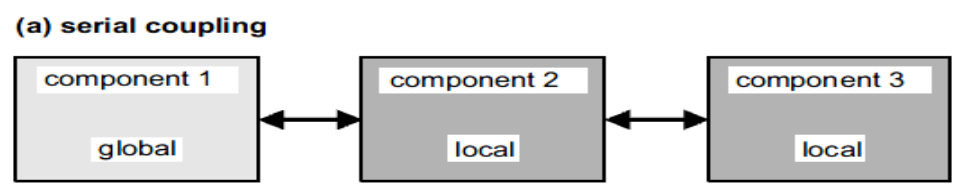

(b) selective coupling

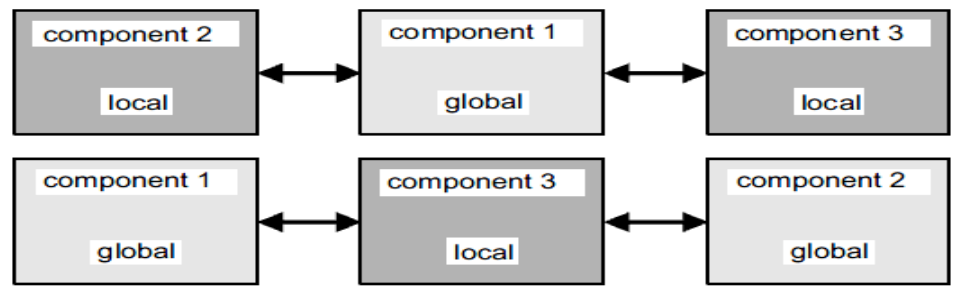

(c) parallel coupling

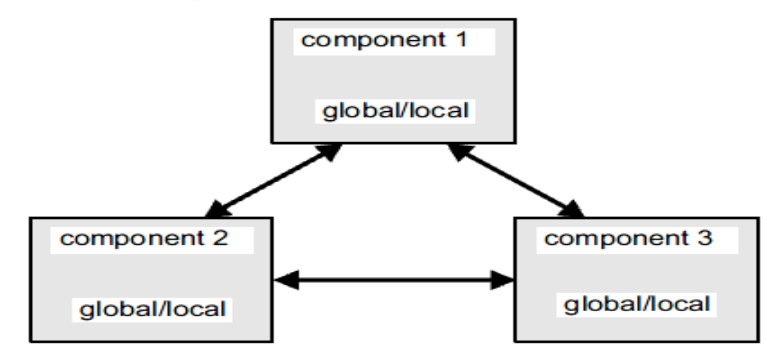

Figure 7 serial, selective and parallel coupling (Dietrich et al, 2005)

Kang et al. (2010) reported that any model for the gas flow through shale matrix should take into consideration presence of dispersed organic porous material within the shale matrix as shown in Figure 8. They also show that during gas production process from shale matrix organic component "Kerogen" is the main supply of gas within the matrix and, there is a large difference in the length scales between the flow of gas in the keorgen and the flow of the gas in the inorganic part of the matrix and fracture (Kang et 
al, 2010). Therefore, Multi-continuum model for shale gas matrix should include separated hydraulic components coupling different continua. Each one of these hydraulic components should distribute continuously in the space and hold the porous medium condition. Thus, the organic rich shale reservoir multi-continuum model should be consisting of at least three components, organic, inorganic and fracture as shown in Figure 9 (Kang et al, 2010).

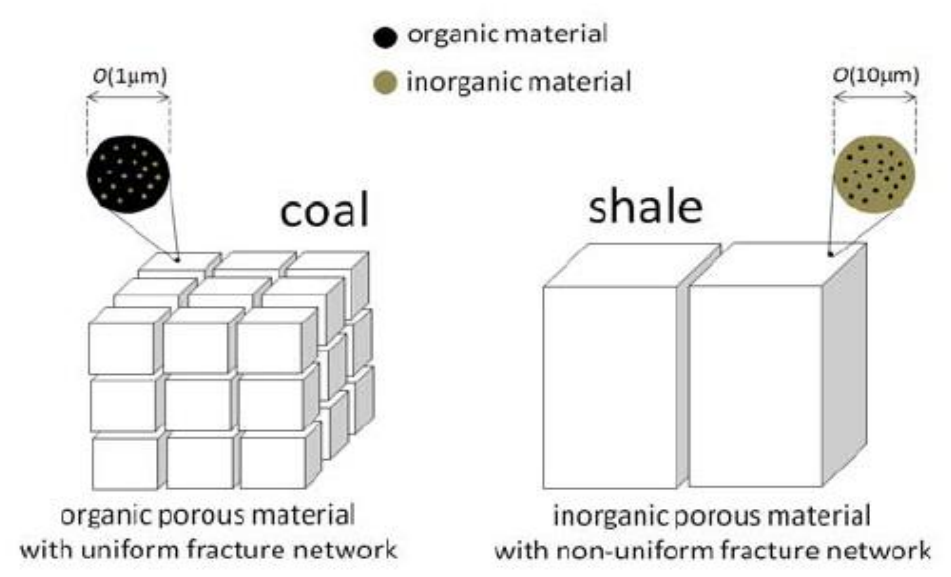

Figure 8 Orgnaic and Inorganic material distribution in the shale and coal matrix (Kang et al, 2010)

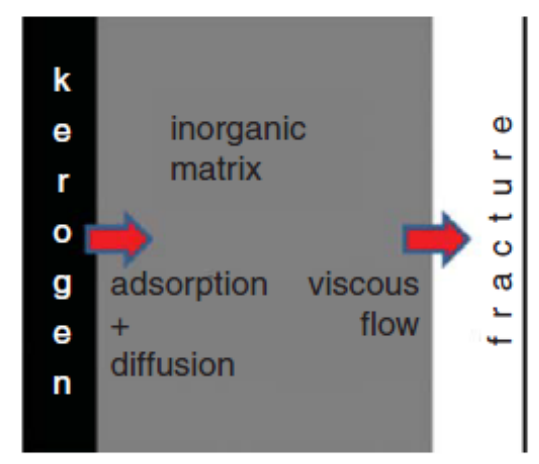

Figure 9 Multi-continuum approach for shale has transport in series for rich organic shale (Akkutlu et al., 2012)

As mentioned above, a conceptual model should be developed for the system in order to solve the problem. As any other approaches for a flow and transport in porous system the governing equations should follow the principles of mass and momentum conservation. Thus, conservation equations need to be developed for each continua and coupled through mass exchange terms discussed earlier. Similar approach as presented by Dietrich et al, (2005) is used for this purpose, where general conservation equations for coupling to continua $\propto$ and $\beta$ can be presented as follow:

The flow equation for the system will be 


$$
\emptyset_{\propto}\left(S_{S, \propto} \frac{\partial h_{\propto}^{\overline{ }}}{\partial t}-\frac{\partial}{\partial x_{i}} k_{i j, \propto} \frac{\partial h_{\propto}^{\overline{\bar{x}}}}{\partial x_{j}}+Q_{Q, S, \alpha}\right)+\varphi_{\alpha} \varphi_{\beta} W_{Q 1, \alpha \beta}=0
$$

While the transport equation is represented by advection-dispersion equation

$$
\emptyset_{\propto}\left(\bar{n}_{e, \propto} \frac{\partial \overline{\bar{c}}_{\propto}}{\partial t}+\overline{\overline{q_{l, \alpha}}} \frac{\partial \overline{\bar{c}}_{\propto}}{\partial x_{i}}-\frac{\partial}{\partial x_{i}} \overline{\bar{D}}_{i j, \propto} \frac{\partial \overline{\bar{c}}_{\propto}}{\partial x_{j}}+Q_{Q, S, \propto}\left(C_{R}-\overline{\bar{c}}_{\propto}\right)\right)+\varphi_{\alpha} \varphi_{\beta} W_{c, \propto \beta}=0
$$

Where

$\bar{n}_{e, \propto}:$ is the equivalent porosity

$q_{i, \propto}:$ is the Darcy velocity

$\overline{\bar{D}}_{i j}$ : tensor of hydraulic dispersion

$$
\overline{\bar{D}}_{i j}=\bar{\propto}_{t} \delta_{i j}\left|q_{i j}\right|+\left(\bar{\propto}_{l}-\bar{\propto}_{t}\right) * \frac{q_{i} q_{j}}{\overline{\bar{q}}}+\bar{n} \overline{D_{m, l j}} \quad \text { eq(15) }
$$

$Q_{Q, S, \propto}\left(C_{R}-\overline{\bar{c}}_{\propto}\right):$ is the source term

$W_{c, \alpha \beta}$ : is the mass exchange between $\alpha$ and $\beta$ because of the concentration gradient and local and regional advection.

Other models are also introduced in the literature to investigate the transport mechanism within the shale matrix but they attracted less attention. Javadpour (2009) introduced a transport model for gas transport in the shale. He suggests that apparent permeability equation which assumes both Knudsen diffusion and viscous flow in single nanotube can be extended to model gas transport in shale. The model is represented mathematically as follow:

$$
N_{t}=-\frac{\rho K_{a}}{\mu}(\nabla p) \quad \mathrm{eq}(16)
$$

Where

$N_{t}=$ mass flux in porous media in $\mathrm{kg} /\left(\mathrm{m}^{2} . \mathrm{s}\right)$

$\mu=$ gas viscosity in Pa.s

$\rho=$ is the gas density $\mathrm{kg} / \mathrm{m}^{3}$ 
$K_{a}=$ is the apparent permeability of the medium in $\mathrm{m}^{2}$

$$
K_{a}=\left[\frac{2 \mu M}{3 R T \rho}\left(\frac{8 R T}{\pi M}\right)^{0.5} * \frac{8}{r}+\left[1+\left(\frac{8 \pi R T}{M}\right)^{0.5} \frac{\mu}{p r}\left(\frac{2}{\alpha}-1\right)\right]\right] K_{\infty} \quad \text { eq(17) }
$$

Where

$\mathrm{M}=$ is the molar mass in $\mathrm{kg} / \mathrm{mol}$

$\mathrm{R}=$ is the universal gas constant in

$\mathrm{r}=$ is the radius of nanotube

$\mathrm{m}$ and $\propto=$ is the tangential momentum accommodation coefficient

$K_{\infty}=$ is the intrinsic permeability of the medium in $\mathrm{m}^{2}$

$$
K_{\infty}=\frac{\emptyset r^{2}}{8 \tau_{h}}
$$

Where $\varnothing$ is the medium porosity and $\tau_{h}$ is the tortuosity of the medium.

Civan (2010) proposed a model for gas transport in shale taking into the consideration the contribution of both Knudsen diffusion and viscous flow in the transportation process. He described the gas transport in the shale matrix as presented earlier by Beskok and Karniadakis (1999) and used Knudsen number to express the apparent permeability in shale:

$$
K_{a}=K_{\infty} f\left(K_{n}\right)=K_{\infty}\left(1+\propto\left(K_{n}\right) K_{n}\right)\left[1+\frac{4 K n}{1-b K n}\right] \quad \text { eq(18) }
$$

Where $\mathrm{b}$ is the slip coefficient and $\propto\left(K_{n}\right)$ is the rarefaction coefficient which is given by the formula below:

$$
\propto\left(K_{n}\right)=\frac{128}{15 \pi^{2}} \tan ^{-1}\left[4 K_{n}^{0.4}\right]
$$

The relation between $\mathrm{ka} / \mathrm{k} \infty$ and Knudsen number is shown in Figure 10. Figure 10 shows nonlinear relation between Knudsen diffusion and $\mathrm{ka} / \mathrm{k} \infty$. According to this model four flow regimes can be defined in the porous media. The first regime is when $\mathrm{ka} / \mathrm{k} \infty$ is equal to 1 and $\mathrm{Kn}<0.001$ in this case Darcy flow is dominate and effect of the Knudsen diffusion could be neglected. Navier-Stocks equation with non-slip boundary condition and Darcy equation are applicable in this regime. The second regime is 
when $\mathrm{ka} / \mathrm{k} \infty$ less than 1.48 and $\mathrm{Kn}$ is in the range of 0.001 to 0.1 in this case Dacry equation is not valid and Navier-stokes equations with slip boundary condition needs to be applied in continuum flow modeling. Third regime is when $\mathrm{ka} / \mathrm{k} \infty$ increases when $\mathrm{Kn}$ is the range of 0.1 to 10 in this regime Knudsen diffusion mainly governs the flow and Navier-Stokes equations even with slip boundary condition is not valid at this point continuum description of flow collapses and Burnet equation or Blotzmann equation governing flow and transport, this is what we call . If Knudsen number exceeds 10 it is the free molecular regime and gas flow is governed by Knudsen diffusion.

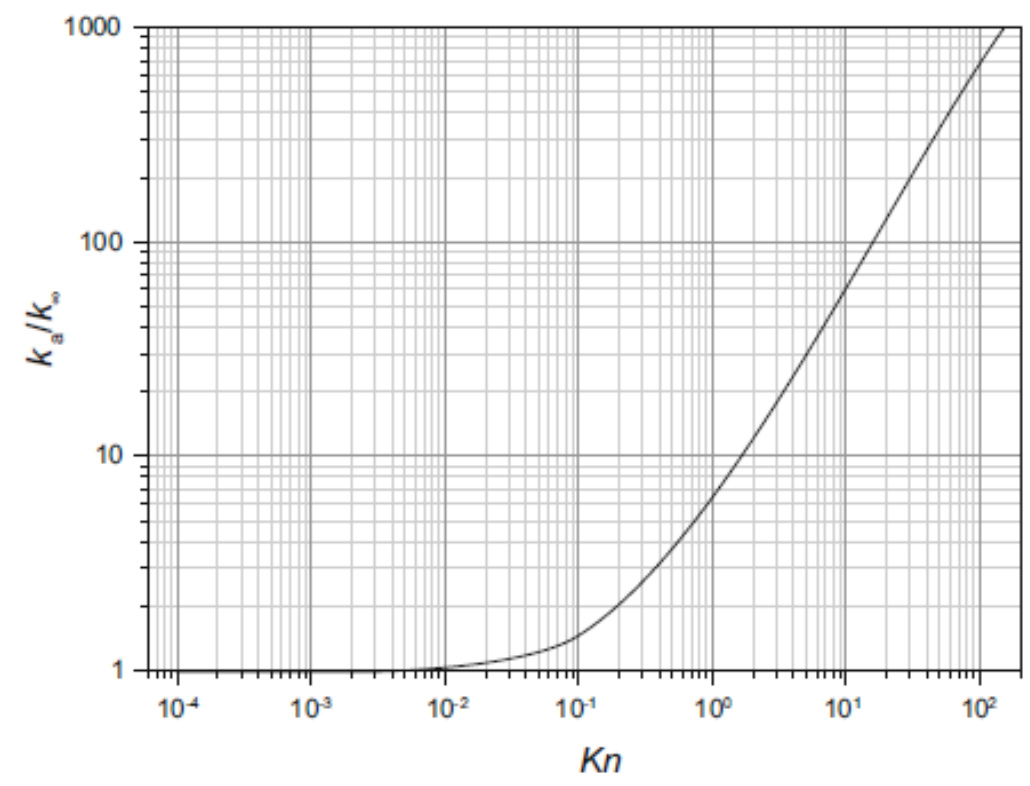

Figure 10The variation of ka/ko with $\mathrm{Kn}(\mathrm{Jun}$ et al,2013)

The last transport model is Dusty Gas Model (DGM), this model has the advantage of combined Darcy flow, Knudsen diffusion and ordinary diffusion together (Jun et al, 2013). Thus, DGM is used to develop a gas transport model for a single gas component in porous media:

$$
K_{a}=K_{\infty}\left(1+\frac{b_{K}}{P}\right) \quad, b_{K}=\frac{D_{k} \mu}{K_{\infty}} \quad \text { eq(19) }
$$

Where $b_{K}$ is the Klinkenberg coefficient in $\mathrm{Pa}$; $\mathrm{D}_{\mathrm{k}}$ is the Knudsen diffusion coefficient in $\mathrm{m}^{2} / \mathrm{s}$.

$$
D_{K}=\frac{\emptyset}{\tau_{h}} \frac{2 r}{2} \sqrt{\frac{8 R T}{\pi M}}
$$

For this study we will use the Multi-continuum concept to model the problem. 


\section{3: Stress depended permeability}

In the reservoir literature, it has known that coal bed methane and shale matrix show permeability stress dependency through pore compressibility similar to conventional reservoir (Sedile et al., 1992). But, unlike pore compressibility in conventional reservoir the compressibility in coal bed methane and shale matrix is mainly due two factor, adsorption/desorption process that happen within the shale or coal matrix and overburden stress (Guorcu et al., 2007). These two mechanisms are in competition to impact reservoir matrix permeability. When gas is injected in shale or coalbed methane reservoir that leads to increase in pore pressure decreasing the effective net stress that could lead to increase in permeability however injected gas also adsorbs to the shale organic and coal matrix leading to matrix swelling that results in reduction in pore radius and therefore reducing the permeability. During gas production the process is reversed; gas production leads to pore pressure drop and increasing effective stress that close outs mainly the slit like pores and fractures reducing the permeability meanwhile pore pressure drop leads to gas desorption and matrix shrinkage that tends to increase permeability. The relation between stress, porosity and permeability in coal seam is introduced first by Mckee 1986. McKee's equation has been used for both laboratory and field scale studies even though it carries major limitations regarding closure stress, matrix compressibility and the depth on which the equation is applicable (Mckee et al., 1988). Different attempts have been made to surpass these limitations by Gray (1987) and Seidle et al. (1992).

In 1987, a new approach describing coal bed matrix shrinkage/swelling under stress has introduced by Gray. Gray stress depended permeability model assumes that shrinkage/swelling of coal matrix is directly proportional to the change in sorption pressure. The approach is represented mathematically as shown below:

$$
\sigma-\sigma_{\circ}=-\frac{v}{1-v}\left(\mathrm{p}-p_{\mathrm{o}}\right)+\frac{E}{1-v} \frac{\Delta \varepsilon_{l}}{\Delta p_{s}} \Delta p_{s} \quad \text { eq }(20)
$$

According to Grays approach when the reservoir pressure decreases the permeability also decreases. However, later investigation shows that matrix shrinkage/swelling is more related to volume of sorption/desorption and it is proportional to it than to sorption pressure (Shi et al, 2005).

In 1992, Seidle et al. investigate the permeability-stress behavior in coal bed seam when the stress increases during drawdown on the cores from Sun Juan basin and Warrior basin both experimentally and theoretically. Thus, they compare the increasing in the permeability due to matrix shrinkage to the decreasing in permeability caused by stress. To achieve that they assume the coal seam geometry represented by matchstick model (shown in Figure 11) and matrix shrinkage coefficient has used to find the increase in permeability. As a result they introduce a reliable and effective approach to explain the 
pore behavior instead of old expensive and time consuming conventional pore compressibility measurement. Seidle and Jeansonne model expresses the permeability as a function of stress rather than the conventional model, which does not reflect the properties of a naturally fractured reservoir like coal bed methane and shale gas.

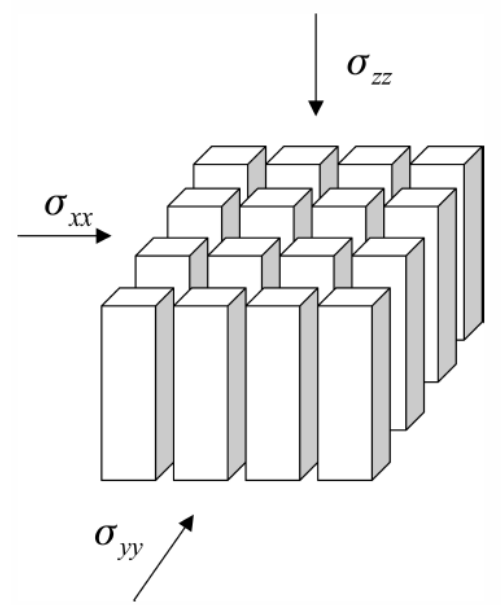

Figure 11 Matchstick coal seam geometry model (Shi et al, 2005)

Siedle and Jeansonne approach for the stress depended permeability is shown in the equation below:

$$
\frac{k_{f 2}}{k_{f 1}}=\exp \left[-3 c_{f}\left(\sigma_{h 2}-\sigma_{h 1}\right)\right] \quad \text { eq }(21)
$$

While the permeability increasing due to matrix shrinkage introduced by the equation below:

$$
\frac{k_{f 2}}{k f 1}=\frac{\left(1+\frac{2 c_{x} \Delta p}{\emptyset_{f 1}}\right)^{3}}{1-c_{x} \Delta p} \quad \text { eq(22) }
$$

It should be mentioned that Seidle and Jeansone conclude that the increasing in the coal seam permeability because of matrix shrinkage will eliminate the effect of permeability decreasing caused by stress increasing effect.

In 1998 Palmer and Mansoori introduced a new mathematical approach to express the effect of change in stress or pore pressure on permeability and compressibility of the matrix in coal seam derived from fundamental equations. This approach surpass Siedle and Jeansonne equation which is inferred from conducting PV compressibility measurement on the core from Sun Juan basin and black warrior basin in the laboratory because it derived from the fundamental equations and also being applicable under axial stress condition (Palmer et al., 1998).Furthermore, the approach shows the effect of both stress and matrix shrinkage in one formula instead of as assuming independent summation of the effect. Their model also 
has the advantage of being applicable in dynamic conditions like enhanced gas production ECBM (Shi et al, 2005).

Theoretically, under the effect of uniaxial strain the pore volume strain will change leads to change in matrix porosity as show below:

$-d \emptyset=\left[\frac{1}{M}-(1-\emptyset) f \gamma\right](d S-d p)+\left[\frac{K}{M}-(1-\emptyset)\right] \gamma d p-\left[\frac{K}{M}-(1-\emptyset)\right] \alpha d T \quad$ eq(23)

Assuming the presence of a high compressible fluid inside the pore, in such case fluid thermal expansivity and fluid compressibility terms are taken off from equation. Furthermore, for low porosity systems $\emptyset \ll 1$ and by assuming there is no change in overburden stress we have:

$-d \varnothing=\frac{1}{M} d p+\left[\frac{K}{M}+f-1\right] \gamma d p-\left[\frac{K}{M}-1\right] \alpha d T \quad$ eq $(24)$

Where

$\frac{K}{M}=\frac{1}{3}\left[\frac{1+v}{1-v}\right]$

$\frac{M}{E}=\frac{1-v}{(1-v)(1-2 v)}$

$\alpha d T=\frac{d}{d p}\left(\frac{\varepsilon_{l} \beta_{p}}{1+\beta_{p}}\right) d p$

So the modified Palmer and Mansoori equation will be:

$d \emptyset=c_{m} d p+\varepsilon_{l}\left[\frac{K}{M}-1\right] \frac{d}{d p}\left(\frac{\varepsilon_{l} \beta_{p}}{1+\beta_{p}}\right) d p \quad$ eq $(25)$

Where

$c_{m}=\frac{1}{M}\left[\frac{K}{M}+f-1\right] \gamma$

Then the equation (25) is integrated to get explicit for porosity:

$\frac{\emptyset}{\emptyset_{\circ}}=1+\frac{c_{m}}{\emptyset_{\circ}}\left(p-p_{\circ}\right)+\frac{\varepsilon_{l}}{\emptyset_{\circ}}\left(\frac{K}{M}-1\right) *\left(\frac{\beta_{p}}{1+\beta_{p}}-\frac{\beta_{p_{\circ}}}{1+\beta_{p_{\circ}}}\right) \quad$ eq(26)

Porosity then can be related to the permeability using Mckee's cubic relationship:

$$
\frac{k}{k_{\circ}}=\left(\frac{\emptyset}{\emptyset_{\circ}}\right)^{3} \quad \text { eq }(27)
$$

Thus, from the equation above the permeability is expressed as a function of Poisson ratio, Young modulus, initial porosity, adsorption and pressure change (Palmer et al., 1998). However, we should 
mention that theory has worked pretty well when the change in porosity is less than the factor of 2 therefore permeability change should be less than factor of 10(Palmer et al, 1998).

For the purpose of our study we will use the modified formula of Palmer and Manssori 1998 approach. The formula is modified to show the effect of gas adsorption and dissolution in coal seam as well as the pore compression due to overburden stress according to Cui et al. (2005). This approach assumes the shape of the volumetric strain-sorbed gas concentration curve is Langmuir-henry isotherm of the form given in equation (5)" (Yi et al., 2009). The modified Palmer and Manssori equation is shown below:

$d \emptyset=\left[a_{1}+\frac{1}{C} a_{2}+a_{3} \frac{b^{\prime}}{\left(1+b^{\prime} C\right)^{2}}\right] d c \quad \mathrm{eq}(28)$

Where

$a_{1}=\left[\frac{R T}{M}-\left(\frac{K}{M}-1+f\right) \gamma R T\right] \quad$ Represent the macro-pore compression

$a_{2}=\left[\left(\frac{K}{M}-1\right) K^{\prime} d\right] \quad$ Represent the shrinkage/swelling due to gas dissolution

$a_{3}=\left[\left(\frac{K}{M}-1\right) \varepsilon_{l}\right] \quad$ Represent the adsorption

For the purpose of this study, since the amount of the organic material within shale matrix is small compare to the coal seam the effect of shrinkage/swelling due gas dissolution will be neglected.

\section{4: Poroelastic Models of Organic Rich Reservoir}

Gas transport and storage in organic rich reservoirs are sensitive to the change in the mechanical properties of the formation. As we mentioned in previous section, gas is stored as free compressed gas in free space, dissolved gas in solid and adsorbed gas on the surface. Presence of the organic and inorganic materials makes this organic rich reservoir more sensitive to the change in effective stress than the conventional reservoir. In order to investigate the coupling between pore compressibility and gas storage and transportation a poroelastic relations are developed. In this review we will focus on two poroelastic models has developed earlier.

Haung et al. (2011) proposed a poroelastic model to describe the interaction between gas diffusion and shale matrix deformation. The model is developed based on an approach introduced by Zhang et al. (2008) to study the interaction between desorption and poroelasticity in coal seams (Haung et al., 2011). The model takes into account the compressible nature of gas thus it has an advantage over other models assuming ideal gas law like et al. (2004) model and Zhang's et al (2008) model. Porosity is 
assumed to be a function of reservoir pressure, elastic properties and gas desorption isotherm parameters (Haung et al, 2011). Also permeability is treated as a function of dynamic porosity and the cubic relation is used to calculate the change in permeability. The poroelastic model is developed by coupling three nonlinear equations. The first equation is a constitutive equation to describe the shale matrix deformation due to desorption, the second equation describes gas flow in shale matrix including free and adsorbed gas phase build up based on the mass conservation theory and the third equation is a general porosity model to describe the change in the pore space with ignoring the grain compressibility. By coupling the rock constitutive equation with gas flow equation by using of general porosity model an approach to describe the matrix deformation as a function of gas diffusivity following equation obtained (Haung et al, 2011).

$$
\propto \frac{2 p}{\mu Z} \frac{\partial \varepsilon_{v}}{\partial t}+\left(\frac{1}{M}+\frac{\left(B_{g} \rho_{r} V_{L}-\alpha \varepsilon_{L}\right) P_{L}}{\left(p+P_{L}^{2}\right)}\right) \frac{\partial m(p)}{\partial t}=\frac{k_{a}}{\mu} \nabla^{2} m(p)+\gamma \frac{2 R T}{\mu M_{g}} \quad \text { eq(29) }
$$

Where, $\propto$ is Biots constant. $p$ is the gas pressure in pore space. $\mathrm{Z}$ is the gas compressibility factor. $\mu$ is the viscosity. $\varepsilon_{v}$ is the volumetrix deformation of the porous medium. $M$ is the Biot modulus. $\mathrm{Bg}$ is the gas formation volume factor. $\rho_{r}$ is the density of gas shale. PL and VL are Langmuir pressure and volume respectively. $\varepsilon_{L}$ is the Langmuir volume strain. $k_{a}$ is the apparent permeability. $M_{g}$ is the gas molecular weight. Finally, $\mathrm{m}$ is the gas content with unit volume of medium which consist of both adsorbed and free gas.

Yi et al. (2008) introduced a poroelastic model to describe the single component gas adsorption and transportation in coal seams. In this approach coal seam is assumed to be a dual porosity system and treated as a poroelastic medium shrinkage/swelling due to the effect of desorption, dissolution and overburden stress. In this model gas flow is assumed to follow Ficks law associated with molecular and surface diffusion. The porosity of the coal seam is assumed to vary none uniformly in space and time. The adsorption equilibrium dynamic is described by the dual Langmuir-Henry isotherm model. Pore compressibility is represented by modified Palmer and Mansoori formula inserted in the governing equations. The governing equations for this poroelastic approach consist of second order conservation equation to describe the gas mass diffusion within the coal seam. The transport governing equation is coupled with an auxiliary equations represent the dynamic equilibrium isotherm and pore volume strain due to the effect of adsorption and overburden pressure (Yi et al, 2008).Condensed form of their model is presented as follow:

$$
\begin{aligned}
{\left[\emptyset+(1-\emptyset) \frac{\partial C_{u}}{\partial C}+\right.} & \left.\left(C-C_{u}\right) \frac{\partial \emptyset}{\partial C}\right] \frac{\partial C}{\partial t} \\
& =\left[\varnothing D_{p}+(1-\emptyset) D_{s} \frac{\partial C_{u}}{\partial C}\right] \frac{1}{x^{n}} \frac{\partial}{\partial x}\left(x^{n} \frac{\partial C}{\partial x}\right)+\left[\left(D_{p}-D_{s} \frac{\partial C_{u}}{\partial C}\right) \frac{\partial \emptyset}{\partial C}+(1-\emptyset) D_{s} \frac{\partial^{2} C_{u}}{\partial C^{2}}\right]\left(\frac{\partial C}{\partial x}\right)^{2} \text { eq(30) }
\end{aligned}
$$


In equation (30), $\varnothing$ is the coal seam porosity. $\mathrm{C}$ and $\mathrm{Cu}$ are the free gas and the mocro-pore solid phase concentration respectively. $D_{p}$ is the pore diffusion coefficient. $\mathrm{D}_{\mathrm{s}}$ is the micro-pore solid diffusion coefficient. $\mathrm{x}$ and $\mathrm{t}$ are dimensional radial coordinate and real time coordinate respectively.

Both models indicate the impact of pore compressibility and stress on gas transport and storage process in organic rich matrix. Also they referred to the relation between the gas affinity and the adsorption and transport process and its impact on the pore volumes. In this study a poroelastic model is developed to investigate the effect of pore compressibility in the shale matrix from the fundamentals equations of mass conservation and transport mechanisms coupling with the effect of adsorption and pore compression. 


\section{CHAPTER3: METHODOLOGY}

\section{1: Governing Equation of Storage and Transport in Organic Rich Shale Porous Media}

Mathematical description of gas storage and transport in shale gas reservoirs are discussed in this chapter. The transport process in the shale matrix consists of a combination of different transport mechanisms: viscous flow, pore and solid diffusion and adsorption/desorption. The storage mechanisms include in our model are free gas storage in matrix and fracture and also adsorbed gas storage on organic surface area. Adsorption in inorganic matrix and fracture and gas dissolution is ignored due to negligible amount compared to aforementioned storage mechanisms. Next, governing equations describing mass balance in each continua will be discussed.

During the developing of this poroelastic model, the compressible nature of the gas is considered and the real gas law is used to represent the thermodynamic behavior of the gas. Porosity is treated as a function of reservoir pressure, adsorption parameters and stress. Permeability is assumed to change with porosity following Mckee's cubic relationship. Finally mass conversation equations for shale matrix are coupled with two auxiliary equations describing pore compressibility and dynamic sorption behavior. Moreover, inorganic pore compressibility is developed from basic bulk and pore compressibility definitions.

The governing equations describing mass balance in the matrix (31) and fracture (32) used to develop the base model are shown below:

$$
\begin{aligned}
& \frac{\partial \emptyset \mathrm{C}}{\partial \mathrm{t}}+\frac{\partial\left(1-\emptyset-\emptyset_{\mathrm{f}}\right) \mathrm{C}_{\mathrm{u}}}{\partial \mathrm{t}}=\frac{\partial}{\partial \mathrm{x}}\left(\varnothing \mathrm{C} \frac{\mathrm{R}_{\mathrm{g}} \mathrm{Tk} \mathrm{p}}{\mathrm{u}} \frac{\partial \mathrm{C}}{\partial \mathrm{x}}\right)+\frac{\partial}{\partial \mathrm{x}}\left(\varnothing \mathrm{D}_{\mathrm{p}} \frac{\partial \mathrm{C}}{\partial \mathrm{x}}\right)+\frac{\partial}{\partial \mathrm{x}}\left[\left(1-\emptyset-\emptyset_{\mathrm{f}}\right) \mathrm{D}_{\mathrm{s}} \frac{\partial \mathrm{C}_{\mathrm{u}}}{\partial \mathrm{x}}\right] \mathrm{eq}(31) \\
& \frac{\partial}{\partial t}\left(\emptyset_{f} C_{f}\right)=\emptyset_{f} k_{L} \frac{\partial}{\partial x}\left[\frac{\partial C_{f}}{\partial x}\right]+\emptyset_{f} \frac{R_{g} * T * k_{f}}{\mu} * \frac{\partial}{\partial x}\left[C_{f} * \frac{\partial C_{f}}{\partial x}\right]-\emptyset_{f} a\left(b C_{f}-C\right) \quad \mathrm{eq}(32)
\end{aligned}
$$

Where dual Langmuir-Henry isotherm model is used to relate the adsorbed and free gas concentrations:

$$
\mathrm{C}_{\mu}=\frac{\mathrm{C}_{\mathrm{us}} \mathrm{b}^{\prime} \mathrm{C}}{1+\mathrm{b}_{\mathrm{C}}}+\mathrm{kd} \mathrm{d} \quad \text { eq(33) }
$$

In more detailed case matrix will be divided to organic and inorganic parts governed by equations (34) and (35) respectively.

$$
\frac{\partial \emptyset_{k} C_{k}}{\partial t}+\frac{\partial\left(1-\emptyset_{k}\right) C_{u}}{\partial t}=\frac{\partial}{\partial x}\left(\emptyset_{k} D_{k} \frac{\partial C_{K}}{\partial x}\right)+\frac{\partial}{\partial x}\left(\left(1-\emptyset_{k}\right) D_{s} \frac{\partial C_{u}}{\partial x}\right) \quad \text { eq(34) }
$$




$$
\frac{\partial \emptyset_{I} C}{\partial t}=\frac{\partial}{\partial x}\left[\emptyset_{I} Z R T C \frac{k}{\mu} \frac{\partial C}{\partial x}\right]-W_{k m} \quad \mathrm{eq}(35)
$$

\section{2: Development of Model for Multi-scale Shale Matrix}

As stated in the literature review the main idea of multi-continuum modeling is to be able to model the coupled components of heterogeneous reservoir (Dietrich et al, 2005). Thus a multi-continuum model is developed to investigate the impact of poroelasticity on gas transport and storage in organic rich shale reservoirs. Four different continuum models have been developed in this study to investigate the impact of pore compressibility on gas storage and transport. We started with a case in which we have only shale matrix as a dual porosity single permeability system as shown in Figure 12.

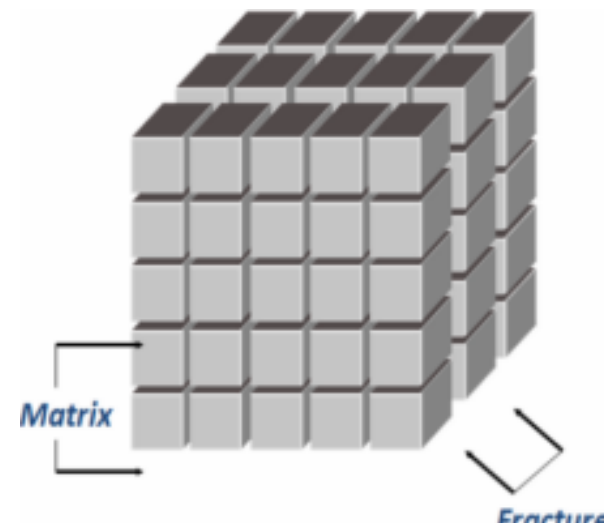

Figure 12dual porosity model (Belyadi, 2011)

In the second case fracture system has added to the first model as shown in Figure 13. The system is treated as triple porosity dual permeability system. In this model a matrix and fracture is coupled in series. This type of coupling is depended on the hydraulic conductivity between different medium of multi-continuum model. This coupling model assumes gas flow from matrix to the fracture and from fracture to the wellbore as shown in Figure 13.

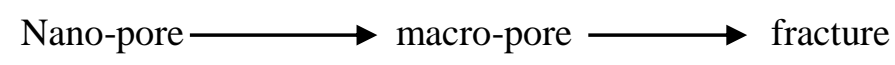




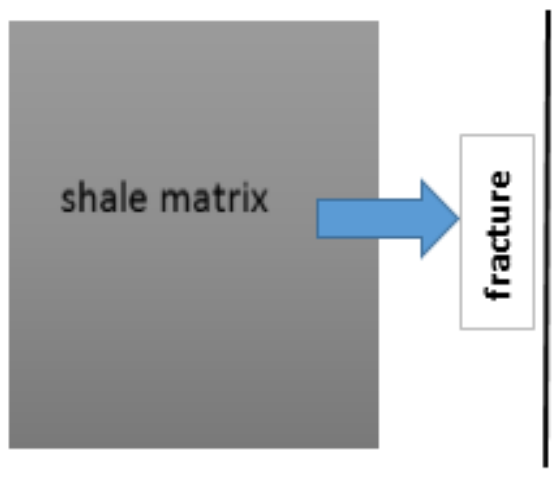

Figure 13Conceptual multi continuum models for gas flow and transport in organic rich shalecase\#2

Third model studied here assumes multi continuum model where shale gas matrix is consist of organic and inorganic materials as shown in Figure 14. The system is assumed to be triple porosity single permeability system. Series coupling is also used in this case to represent the mass exchange between organic and inorganic materials in the matrix. During production due to pressure gradient applied first free gas in macro-pores of inorganic materials will be produced and later desorption leads to gas being released from micro-pore surface areas and flow in macro-pores of inorganics and reaches to fractures. Thus the transport follows sequence given below during process of gas production.

$$
\text { Kerogen } \longrightarrow \text { inorganic matrix }
$$

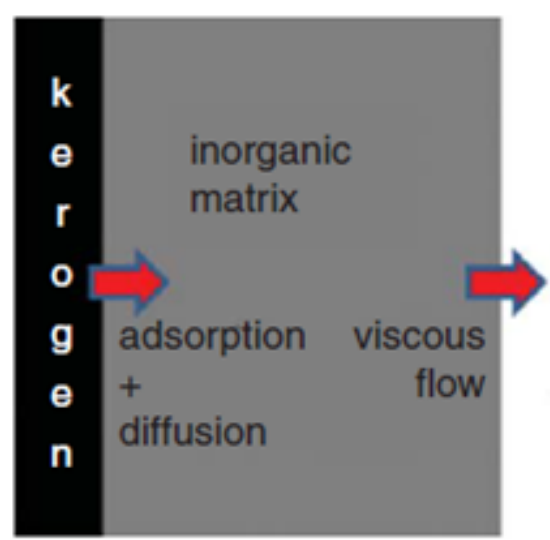

Figure 14 Conceptual multi continuum models for gas flow and transport in organic rich shale case\#3

In the last case Shale matrix is seen as a multi-continuum model consist of two different porous components organic or kerogen material and inorganic materials in the matrix surrounded with fracture network, Figure 15. This system is assumed to be a quad porosity dual permeability system, i.e. 
adsorption sites, organic and inorganic porosity in matrix and fracture porosity and also inorganic and fracture permeability (Akkuttlue et al., 2012).

Kerogen $\longrightarrow$ inorganic matrix $\longrightarrow$ fracture network

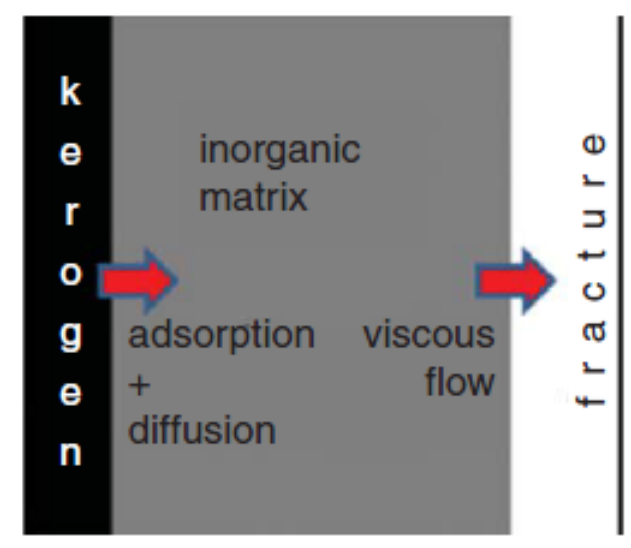

Figure 15 Conceptual multi continuum models for gas flow and transport in organic rich shale case\#4(Akkutlu et al., 2012)

\section{3: Initial and Boundary Condition Value Problem}

Governing equations described earlier have been used to study the poroelastic effect of shale organic and inorganic materials on gas storage and transport using proper boundary conditions. Initially single component single phase Methane is assumed to be in equilibrium between matrix and fracture. Boundary conditions for four different cases discussed previously are presented in Table 1 and schematics of numerical domain are presented in following Figure 16:

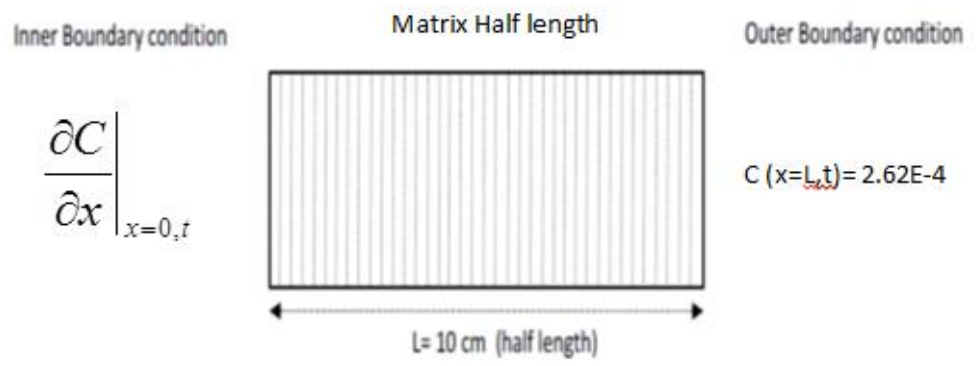

Figure 16 A schematic showing the setup for numerical simulation 


\begin{tabular}{|c|c|c|}
\hline Case & \multicolumn{2}{|c|}{ Initial conditions } \\
\hline Case1 & $\mathrm{t}=0$ & $\mathrm{C}(0, \mathrm{x})=0.00052$ \\
\hline Case2 & $\mathrm{t}=0$ & $\mathrm{C}(0, \mathrm{x})=0.000262, \mathrm{C}(0, \mathrm{x})_{\mathrm{f}}=0.000262$ \\
\hline Case3 & $\mathrm{t}=0$ & $\mathrm{C}(0, \mathrm{x})=0.000262, \mathrm{C}(0, \mathrm{x})_{\mathrm{k}}=0.000262$ \\
\hline Case 4 & $\mathrm{t}=0$ & $\mathrm{C}(0, \mathrm{x})=0.000175, \mathrm{C}(\mathrm{x}, 0)_{\mathrm{k}}=0.000175, \mathrm{C}(0, \mathrm{x})_{\mathrm{f}}=0.000175$ \\
\hline
\end{tabular}

Table 1 initial condition for all four cases

Simulation domain is a half-length matrix due to homogeneous and isotropic properties assigned in this model. Therefore, in left boundary at the center of the matrix we have no flow boundary and at right hand side we have fixed Drichlet boundary condition. Summary of boundary conditions used in the four different cases are shown in Table 2.

\begin{tabular}{|c|c|c|}
\hline Case & & Boundary conditions \\
\hline \multirow[t]{2}{*}{ Case1 } & $\mathrm{x}=0$ & $\partial u / \partial x=0$ \\
\hline & $\mathrm{x}=100$ & $u=0.000005$ \\
\hline \multirow[t]{2}{*}{ Case2 } & $\mathrm{x}=0$ & $\partial u_{1} / \partial x=0, \partial u_{2} / \partial x=0$ \\
\hline & $\mathrm{x}=100$ & $u_{1}=0.000001, u_{2}=0.000001$ \\
\hline \multirow[t]{2}{*}{ Case3 } & $\mathrm{x}=0$ & $\partial u_{1} / \partial x=0, \partial u_{2} / \partial x=0$ \\
\hline & $\mathrm{x}=100$ & $u_{1}=0.000001, u_{2}=0.000001$ \\
\hline \multirow[t]{2}{*}{ Case 4} & $\mathrm{x}=0$ & $\partial u_{1} / \partial x=0, \partial u_{2} / \partial x=0, \partial u_{3} / \partial x=0$ \\
\hline & $\mathrm{x}=100$ & $u_{1}=0.000001, u_{2}=0.000001, u_{3}=0.000005$ \\
\hline
\end{tabular}

Table 2 boundary condition for all four cases 


\section{4: Base Case Parameters}

Parameters used to develop the base case model to investigate the poroelastic effect on the storage and transport in organic rich shale gas matrix are shown in Table 3.

\begin{tabular}{|c|c|c|}
\hline Parameters & value & unit \\
\hline Kerogen Poisson ratio & 0.39 & dimensionless \\
\hline kerogen young modulus & 5 & Gps \\
\hline inorganic Poisson ratio & 0.166 & dimensionless \\
\hline inorganic young modulus & 1.4 & Gpa \\
\hline initial matrix porosity & 0.05 & frac \\
\hline fracture porosity & 0.005 & \\
\hline initial bulk permeability & $1.00 \mathrm{E}-15$ & $(100 \mathrm{nd}) \mathrm{cm}^{\wedge} 2$ \\
\hline fracture permeability & $5.00 \mathrm{E}-13$ & $\mathrm{~cm}^{\wedge} 2$ \\
\hline $\mathrm{Z}$ compressibility factor & 0.98 & dimensionless \\
\hline b' Langmuir isotherm constant & 800 & $\mathrm{cc} / \mathrm{mole}$ \\
\hline Cus maximum sorbed phase concentration & $3.80 \mathrm{E}-03$ & mole/cm 3 of solid \\
\hline $\mathrm{Rg}$ universal gas constant & $8.31 \mathrm{E}+04$ & $\mathrm{~kg} \mathrm{~cm}^{\wedge} 2 / \mathrm{k} / \mathrm{mol} / \mathrm{sec}^{\wedge} 2$ \\
\hline Kd Herny constant & 0.28 & for methne \\
\hline $\mathrm{R} 1$ & 10 & $\mathrm{~cm}$ \\
\hline $\mathrm{b}$ & 1 & dimensionless \\
\hline KL fracture dispersion coefficient & $1.00 \mathrm{E}-05$ & $\mathrm{~cm}^{\wedge} 2 / \mathrm{sec}$ \\
\hline viscosity & $2.00 \mathrm{E}-07$ & $\mathrm{Kg} / \mathrm{cm} / \mathrm{sec}$ \\
\hline a1 & 0.268 & $\mathrm{~cm} 3 / \mathrm{mol}$ \\
\hline $\mathrm{a} 2$ & 0 & $\mathrm{~cm} 3 / \mathrm{mol}$ \\
\hline a3 & -0.00296 & dimensionless \\
\hline surface diffusion coefficient & 5 e- 8 & $\mathrm{~cm} 2 / \mathrm{s}$ \\
\hline pore diffusion coefficient for kerogen & $5 e-6$ & $\mathrm{~cm} 2 / \mathrm{s}$ \\
\hline pore diffusion coefficient for inorganic part & $5 e-7$ & $\mathrm{~cm} 2 / \mathrm{s}$ \\
\hline temperature & 322 & $\mathrm{~K}$ \\
\hline matrix shape factor & 0.3 & \\
\hline fracture shape factor & 0.5 & \\
\hline Biot constant & 0.5 & \\
\hline kerogen pore volume per total matrix pore volume & 0.53 & \\
\hline
\end{tabular}

Table 3 the base case parameters 


\subsection{Development of Storage and Transport Model Including Poroelatic Effect and Dual Isotherm Model for Rich Organic Shale Matrix}

\subsection{1:Development of Storage and Transport Model for Shale Matrix "Case I"}

In this case shale matrix is seen as dual porosity system. Starting with one dimensional gas transport in organic rich shale mass balance equation shale can be written as follow:

$\frac{\partial \emptyset \mathrm{C}}{\partial \mathrm{t}}+\frac{\partial(1-\emptyset) \mathrm{C}_{\mathrm{u}}}{\partial \mathrm{t}}=\frac{\partial}{\partial \mathrm{x}}\left(\varnothing \mathrm{C} \frac{\mathrm{R}_{\mathrm{g}} \mathrm{Tk}_{\mathrm{p}}}{\mathrm{u}} \frac{\partial \mathrm{C}}{\partial \mathrm{x}}\right)+\frac{\partial}{\partial \mathrm{x}}\left(\varnothing \mathrm{D}_{\mathrm{p}} \frac{\partial \mathrm{C}}{\partial \mathrm{x}}\right)+\frac{\partial}{\partial \mathrm{x}}\left[(1-\emptyset) \mathrm{D}_{\mathrm{s}} \frac{\partial \mathrm{C}_{\mathrm{u}}}{\partial \mathrm{x}}\right] \quad$ eq(36)

First and second term in left hand side of equation (31) are storage terms based of free and adsorbed gas concentration in pore and solid respectively. Note the porosity is not assumed constant but changes with time. Right hand side of equation includes three transport terms namely convective flow of free gas (defined as Darcy flow), diffusive transport of free gas (Fickian diffusion) and solid or surface diffusion of adsorbed gas. Left hand side of the equation can be expanded using chai rule a follow:

$\frac{\partial \emptyset \mathrm{C}}{\partial \mathrm{t}}+\frac{\partial(1-\emptyset) \mathrm{C}_{\mathrm{u}}}{\partial \mathrm{t}}=$ the left hand side

$\frac{\partial \emptyset \mathrm{C}}{\partial \mathrm{t}}=\varnothing \frac{\partial \mathrm{C}}{\partial \mathrm{t}}+\mathrm{C} \frac{\partial \emptyset}{\partial \mathrm{t}}$

$\frac{\partial(1-\emptyset) \mathrm{C}_{\mathrm{u}}}{\partial \mathrm{t}}=(1-\emptyset) \frac{\partial \mathrm{C}_{\mathrm{u}}}{\partial \mathrm{t}}+\left[-\frac{\partial \emptyset}{\partial \mathrm{t}}\right] \mathrm{C}_{\mathrm{u}}$

Then by using the chain rule

$\frac{\partial \emptyset}{\partial \mathrm{x}}=\frac{\partial \emptyset}{\partial \mathrm{C}} * \frac{\partial \mathrm{C}}{\partial \mathrm{x}}$

$\frac{\partial \mathrm{C}_{\mathrm{u}}}{\partial \mathrm{x}}=\frac{\partial \mathrm{C}_{\mathrm{u}}}{\partial \mathrm{C}} * \frac{\partial \mathrm{C}}{\partial \mathrm{x}}$

$\frac{\partial \mathrm{C}_{\mathrm{u}}}{\partial \mathrm{t}}=\frac{\partial \mathrm{C}_{\mathrm{u}}}{\partial \mathrm{C}} * \frac{\partial \mathrm{C}}{\partial \mathrm{t}}$

$\frac{\partial \mathrm{C}_{\mathrm{u}}}{\partial \mathrm{x}}=\frac{\partial \mathrm{C}_{\mathrm{u}}}{\partial \mathrm{C}} * \frac{\partial \mathrm{C}}{\partial \mathrm{x}}$

$\frac{\partial \emptyset}{\partial t}=\frac{\partial \emptyset}{\partial \mathrm{C}} * \frac{\partial C}{\partial t}$

That leads to change the first term in right hand side to:

$=\varnothing \frac{\partial \mathrm{C}}{\partial \mathrm{t}}+\mathrm{C} \frac{\partial \emptyset}{\partial \mathrm{C}} * \frac{\partial \mathrm{C}}{\partial \mathrm{t}}$ 
And the second term to:

$=(1-\emptyset) \frac{\partial \mathrm{C}_{\mathrm{u}}}{\partial \mathrm{C}} * \frac{\partial \mathrm{C}}{\partial \mathrm{t}}-\frac{\partial \emptyset}{\partial \mathrm{C}} * \frac{\partial \mathrm{C}}{\partial \mathrm{t}} \mathrm{C}_{\mathrm{u}}$

Combining these two terms lft hand side can be written in following form:

$=\left\{\varnothing+\mathrm{C} \frac{\partial \emptyset}{\partial \mathrm{C}}+(1-\varnothing) \frac{\partial \mathrm{C}_{\mathrm{u}}}{\partial \mathrm{C}}-\mathrm{C}_{\mathrm{u}}\left(\frac{\partial \emptyset}{\partial \mathrm{C}}\right)\right\} \frac{\partial \mathrm{C}}{\partial \mathrm{t}}$

One can expand on right hand side terms in equation (31) as follow:

$$
\begin{aligned}
=\frac{\partial}{\partial x}\left(\varnothing \mathrm{C} \frac{\mathrm{R}_{\mathrm{g}} T \mathrm{k}_{\mathrm{p}}}{\mathrm{u}} \frac{\partial \mathrm{C}}{\partial \mathrm{x}}\right)+\frac{\partial}{\partial \mathrm{x}}\left(\varnothing \mathrm{D}_{\mathrm{p}} \frac{\partial \mathrm{C}}{\partial \mathrm{x}}\right)+\frac{\partial}{\partial \mathrm{x}}\left[(1-\emptyset) \mathrm{D}_{\mathrm{s}} \frac{\partial \mathrm{C}_{\mathrm{u}}}{\partial \mathrm{x}}\right] \\
\text { let } \quad \mathrm{S}=\frac{\mathrm{R}_{\mathrm{g}} \mathrm{Tk}_{\mathrm{p}}}{\mathrm{u}} \quad \text { and } \mathrm{B}=(1-\emptyset) \text { then }
\end{aligned}
$$

Convection term in right hand side can be expanded as

$$
\begin{array}{r}
\frac{\partial}{\partial \mathrm{x}}\left(\varnothing \mathrm{C} \frac{\mathrm{R}_{\mathrm{g}} T \mathrm{~T}_{\mathrm{p}}}{\mathrm{u}} \frac{\partial \mathrm{C}}{\partial \mathrm{x}}\right)=\frac{\partial}{\partial \mathrm{x}}\left(\mathrm{C} \frac{\partial \mathrm{C}}{\partial \mathrm{x}}\right) * \frac{\emptyset \mathrm{R}_{\mathrm{g}} \mathrm{Tk}_{\mathrm{p}}}{\mathrm{u}}+\frac{\partial \emptyset \mathrm{C} \mathrm{R}_{\mathrm{g}} \mathrm{Tk}_{\mathrm{p}}}{\mathrm{u}} \frac{\partial \mathrm{C}}{\partial \mathrm{x}} \\
=\varnothing \mathrm{S} \frac{\partial}{\partial \mathrm{x}}\left(\mathrm{C} \frac{\partial \mathrm{C}}{\partial \mathrm{x}}\right)+\mathrm{CS} \frac{\partial \emptyset}{\partial \mathrm{x}} \frac{\partial \mathrm{C}}{\partial \mathrm{x}}
\end{array}
$$

Where new term "S "has been used for simplicity:

$=\varnothing S *\left(\frac{\partial \mathrm{C}}{\partial \mathrm{x}}\right)^{2}+\varnothing S C * \frac{\partial}{\partial x} * \frac{\partial \mathrm{C}}{\partial \mathrm{x}}+C S * \frac{\partial \emptyset}{\partial x} * \frac{\partial \mathrm{C}}{\partial \mathrm{x}}$

By applying the chain rule above terms can be expanded to:

$=\varnothing S *\left(\frac{\partial \mathrm{C}}{\partial \mathrm{x}}\right)^{2}+\varnothing S C * \frac{\partial}{\partial x} * \frac{\partial \mathrm{C}}{\partial \mathrm{x}}+C S * \frac{\partial \emptyset}{\partial C} *\left(\frac{\partial \mathrm{C}}{\partial \mathrm{x}}\right)^{2}$

Diffusive term in equation (36) also can be expanded as follow:

$\frac{\partial}{\partial \mathrm{x}}\left(\varnothing \mathrm{D}_{\mathrm{p}} \frac{\partial \mathrm{C}}{\partial \mathrm{x}}\right)=\mathrm{D}_{\mathrm{p}} \emptyset * \frac{\partial^{2} \mathrm{C}}{\partial \mathrm{x}^{2}}+\mathrm{Dp} \frac{\partial \emptyset}{\partial \mathrm{x}} * \frac{\partial \mathrm{C}}{\partial \mathrm{x}} \quad$ Dp $:$ constant

Then by applying the chain rule

$\frac{\partial}{\partial \mathrm{x}}\left(\varnothing \mathrm{D}_{\mathrm{p}} \frac{\partial \mathrm{C}}{\partial \mathrm{x}}\right)=\mathrm{D}_{\mathrm{p}} \varnothing * \frac{\partial}{\partial \mathrm{x}}\left(\frac{\partial \mathrm{C}}{\partial \mathrm{x}}\right)+\mathrm{Dp} * \frac{\partial \emptyset}{\partial \mathrm{C}} *\left(\frac{\partial C}{\partial x}\right)^{2}$

And finally we expanded the surface or solid flux as:

$\frac{\partial}{\partial \mathrm{x}}\left[(1-\emptyset) \mathrm{D}_{\mathrm{s}} \frac{\partial \mathrm{C}_{\mathrm{u}}}{\partial \mathrm{x}}\right]=(1-\emptyset) \frac{\partial}{\partial \mathrm{x}}\left(\mathrm{D}_{\mathrm{s}} \frac{\partial \mathrm{C}_{\mathrm{u}}}{\partial \mathrm{x}}\right)-\frac{\partial \emptyset}{\partial \mathrm{x}} \mathrm{D}_{\mathrm{s}} \frac{\partial \mathrm{C}_{\mathrm{u}}}{\partial \mathrm{x}}$ 
$=(1-\emptyset) \frac{\partial}{\partial \mathrm{x}}\left(\mathrm{D}_{\mathrm{s}} \frac{\partial \mathrm{C}_{\mathrm{u}}}{\partial \mathrm{x}}\right)-\mathrm{D}_{\mathrm{s}} \frac{\partial \mathrm{C}_{\mathrm{u}}}{\partial \mathrm{x}} * \frac{\partial \emptyset}{\partial \mathrm{x}}$

Then by using the chain rule

$=B \frac{\partial}{\partial \mathrm{x}}\left(\mathrm{D}_{\mathrm{s}} \frac{\partial \mathrm{C}_{\mathrm{u}}}{\partial \mathrm{C}} * \frac{\partial \mathrm{C}}{\partial \mathrm{x}}\right)-\mathrm{D}_{\mathrm{s}} \frac{\partial \mathrm{C}_{\mathrm{u}}}{\partial \mathrm{C}} * \frac{\partial \mathrm{C}}{\partial \mathrm{x}} * \frac{\partial \emptyset}{\partial \mathrm{C}} * \frac{\partial \mathrm{C}}{\partial \mathrm{x}}$

$=B \frac{\partial}{\partial \mathrm{x}}\left(\mathrm{D}_{\mathrm{s}} \frac{\partial \mathrm{C}_{\mathrm{u}}}{\partial \mathrm{C}} * \frac{\partial \mathrm{C}}{\partial \mathrm{x}}\right)-\mathrm{D}_{\mathrm{s}} \frac{\partial \mathrm{C}_{\mathrm{u}}}{\partial \mathrm{C}} * \frac{\partial \emptyset}{\partial \mathrm{C}} *\left(\frac{\partial \mathrm{C}}{\partial \mathrm{x}}\right)^{2}$

$=B \frac{\partial}{\partial \mathrm{x}}\left(\mathrm{D}_{\mathrm{s} *} J * \frac{\partial \mathrm{C}}{\partial \mathrm{x}}\right)-\mathrm{D}_{\mathrm{s}} * \mathrm{~J} * \frac{\partial \emptyset}{\partial \mathrm{C}} *\left(\frac{\partial \mathrm{C}}{\partial \mathrm{x}}\right)^{2}$

$=B * \mathrm{D}_{\mathrm{s}} * \frac{\partial J}{\partial x} *\left(\frac{\partial \mathrm{C}}{\partial \mathrm{x}}\right)+B * \mathrm{D}_{\mathrm{s} *} J * \frac{\partial}{\partial \mathrm{x}}\left(\frac{\partial \mathrm{C}}{\partial \mathrm{x}}\right)-\mathrm{D}_{\mathrm{s}} * \mathrm{~J} * \frac{\partial \emptyset}{\partial \mathrm{C}} *\left(\frac{\partial \mathrm{C}}{\partial \mathrm{x}}\right)^{2}$

New terms "B" and "J" is used to condense the equation. Combining all the transport terms in right hand side we will have:

$$
\begin{gathered}
=\varnothing S *\left(\frac{\partial C}{\partial x}\right)^{2}+ \\
\qquad S C * \frac{\partial}{\partial x} *\left(\frac{\partial C}{\partial x}\right)+C S * \frac{\partial \emptyset}{\partial \mathrm{C}} *\left(\frac{\partial C}{\partial x}\right)^{2}+\mathrm{D}_{\mathrm{p}} \emptyset * \frac{\partial}{\partial \mathrm{x}}\left(\frac{\partial \mathrm{C}}{\partial \mathrm{x}}\right)+\mathrm{Dp} * \frac{\partial \emptyset}{\partial \mathrm{C}} *\left(\frac{\partial C}{\partial x}\right)^{2}+B * \mathrm{D}_{\mathrm{s}} \\
+\frac{\partial J}{\partial x} *\left(\frac{\partial \mathrm{C}}{\partial \mathrm{x}}\right)+B * \mathrm{D}_{\mathrm{s} *} J * \frac{\partial}{\partial \mathrm{x}}\left(\frac{\partial \mathrm{C}}{\partial \mathrm{x}}\right)-\mathrm{D}_{\mathrm{s}} * \mathrm{~J} * \frac{\partial \emptyset}{\partial \mathrm{C}} *\left(\frac{\partial \mathrm{C}}{\partial \mathrm{x}}\right)^{2}
\end{gathered}
$$

Rearranging the right hand side we have:

$=\left[\varnothing \mathrm{S} *\left(\frac{\partial \mathrm{C}}{\partial \mathrm{x}}\right)^{2}+B * \mathrm{D}_{\mathrm{S}} * \frac{\partial J}{\partial x} *\left(\frac{\partial \mathrm{C}}{\partial \mathrm{x}}\right)\right]+\left[\varnothing \mathrm{SC}+B \mathrm{D}_{\mathrm{s}} J+\mathrm{D}_{\mathrm{p}} \varnothing\right] \frac{\partial}{\partial \mathrm{x}}\left(\frac{\partial \mathrm{C}}{\partial \mathrm{x}}\right)+\left[C S+\mathrm{D}_{\mathrm{p}}-\mathrm{D}_{\mathrm{s}} * J\right] * \mathrm{~W} *$ $\left(\frac{\partial \mathrm{C}}{\partial \mathrm{x}}\right)^{2}$

Now we can re-write the expanded governing equation for mass balance in matrix (eq.36) as follow:

$$
\begin{gathered}
\{\varnothing+\mathrm{CW}+\mathrm{BJ}-\mathrm{FW}\} \frac{\partial \mathrm{C}}{\partial \mathrm{t}}=\left[\varnothing \mathrm{S} *\left(\frac{\partial \mathrm{C}}{\partial \mathrm{x}}\right)^{2}+B * \mathrm{D}_{\mathrm{s}} * \frac{\partial J}{\partial x} *\left(\frac{\partial \mathrm{C}}{\partial \mathrm{x}}\right)\right]+\left[\varnothing \mathrm{SC}+B \mathrm{D}_{\mathrm{s}} J+\mathrm{D}_{\mathrm{p}} \varnothing\right] \frac{\partial}{\partial \mathrm{x}}\left(\frac{\partial \mathrm{C}}{\partial \mathrm{x}}\right)+ \\
{\left[C S+\mathrm{D}_{\mathrm{p}}-\mathrm{D}_{\mathrm{s}} * J\right] * \mathrm{~W} *\left(\frac{\partial \mathrm{C}}{\partial \mathrm{x}}\right)^{2}} \\
\{\varnothing+\mathrm{CW}+\mathrm{BJ}-\mathrm{FW}\} \frac{\partial \mathrm{C}}{\partial \mathrm{t}} \\
=B * \mathrm{D}_{\mathrm{s}} * \frac{\partial J}{\partial x} *\left(\frac{\partial \mathrm{C}}{\partial \mathrm{x}}\right)+\left[\varnothing \mathrm{SC}+B \mathrm{D}_{\mathrm{s}} J+\mathrm{D}_{\mathrm{p}} \varnothing\right] \frac{\partial}{\partial \mathrm{x}}\left(\frac{\partial \mathrm{C}}{\partial \mathrm{x}}\right) \\
+\left[\left(C S+\mathrm{D}_{\mathrm{p}}-\mathrm{D}_{\mathrm{s}} * J\right) * \mathrm{~W}+\emptyset \mathrm{S}\right] *\left(\frac{\partial \mathrm{C}}{\partial \mathrm{x}}\right)^{2}
\end{gathered}
$$

Where:

$$
\frac{\partial \emptyset}{\partial \mathrm{C}}=W, \frac{\partial \mathrm{C}_{\mathrm{u}}}{\partial \mathrm{C}}=J, B=(1-\emptyset), C_{u}=F
$$


Let assume $\left[\varnothing \mathrm{SC}+B \mathrm{D}_{\mathrm{s}} J+\mathrm{D}_{\mathrm{p}} \varnothing\right]=A$

Divided both sides of the equation (35) by A we have:

$$
\left[\frac{\emptyset+\mathrm{CW}+\mathrm{BJ}-\mathrm{FW}}{\emptyset \mathrm{SC}+B \mathrm{D}_{\mathrm{s}} J+\mathrm{D}_{\mathrm{p}} \varnothing}\right] \frac{\partial \mathrm{C}}{\partial \mathrm{t}}=\frac{\partial}{\partial \mathrm{x}}\left(\frac{\partial \mathrm{C}}{\partial \mathrm{x}}\right)+\left[\frac{\left(C S+\mathrm{D}_{\mathrm{p}}-\mathrm{D}_{\mathrm{s}} * J\right) * \mathrm{~W}+\emptyset \mathrm{S}+\mathrm{BD}_{\mathrm{s}} V}{\emptyset \mathrm{SC}+B \mathrm{D}_{\mathrm{s}} J+\mathrm{D}_{\mathrm{p}} \varnothing}\right]\left(\frac{\partial \mathrm{C}}{\partial \mathrm{x}}\right)^{2}
$$

Here, $\mathrm{x}-\mathrm{t}$ are the space and time coordinate. $\mathrm{C}$ and $\mathrm{Cu}$ are the free gas concentration and the micro-pore solid phase concentration respectively. $\varnothing$ is the total matrix porosity changing with time due to the poroelastic effects of shale matrix as shown in the equation $(40) .(1-\emptyset)$ represents the solid volume over bulk volume of the shale matrix. $\mathrm{D}_{\mathrm{s}}$ adsorbed gas surface diffusion coefficient and $\mathrm{D}_{\mathrm{p}}$ is the pore diffusion of free gas in the matrix.

Dual Langmuir-Henry isotherm is used to describe the nonlinear relation between free and adsorbed gas concentrations as follow:

$$
C_{\mu}=\frac{C_{u s} b^{\prime} C}{1+b^{\prime} C}+k d ́ c
$$

This equation can also be used to obtain the rate of change in adsorbed phase concentration with free gas concentration as equation (38).

$$
\begin{aligned}
J=\frac{\partial \mathrm{C}_{\mathrm{u}}}{\partial \mathrm{C}} & =\frac{\left(1+\mathrm{b}^{\prime} \mathrm{C}\right) * \mathrm{C}_{\mathrm{us}} \mathrm{b}^{\prime}-\mathrm{C}_{\mathrm{us}} \mathrm{b}^{\prime} \mathrm{C} * \mathrm{~b}^{\prime}}{\left(1+\mathrm{b}^{\prime} \mathrm{C}\right)^{2}}+\mathrm{kd} \\
& =\frac{\mathrm{C}_{\mathrm{us}} \mathrm{b}^{\prime}+\mathrm{C}_{\mathrm{us}} \mathrm{b}^{2} \mathrm{C}-\mathrm{C}_{\mathrm{us}} \mathrm{b}^{2} \mathrm{C}}{\left(1+\mathrm{b}^{\prime} \mathrm{C}\right)^{2}}+\mathrm{kd} \\
& =\frac{\mathrm{C}_{\mathrm{us}} \mathrm{b}^{\prime}}{\left(1+\mathrm{b}^{\prime} \mathrm{C}\right)^{2}}+\mathrm{kd} \quad \mathrm{eq}(38)
\end{aligned}
$$

Rate of change in "J" with distance then can be obtained freely as follow:

$$
\frac{\partial J}{\partial x}=\frac{-2 \mathrm{~b}^{\prime 2} C_{u s}}{\left(1+\mathrm{b}^{\prime} C\right)^{3}} \frac{\partial \mathrm{C}}{\partial \mathrm{x}}=V \frac{\partial \mathrm{C}}{\partial \mathrm{x}}
$$

Dynamics of change in shale matrix pore volume, $\frac{\partial \emptyset}{\partial \mathrm{C}}$,is represented using modified Palmer and Mansoori equation (28):

$$
\mathrm{d} \varnothing=\left[\mathrm{a}_{1}+\frac{1}{c} \mathrm{a}_{2}+\mathrm{a}_{3} \frac{\mathrm{b}^{\prime}}{\left(1+\mathrm{b}^{\prime} \mathrm{C}\right)}\right] \mathrm{dc}
$$




$$
\frac{\partial \emptyset}{\partial \mathrm{C}}=\left[\mathrm{a}_{1}+\frac{1}{\mathrm{c}} \mathrm{a}_{2}+\mathrm{a}_{3} \frac{\mathrm{b}^{\prime}}{\left(1+\mathrm{b}^{\prime} \mathrm{C}\right)}\right]
$$

Non-linear relation between porosity and free gas concentration and shale matrix mechanical properties, i.e., Young Modulus and Poisson Ratio, can be obtained by integrating Palmer and Mansorri equation as follow:

$\frac{\partial \emptyset}{\partial \mathrm{C}}=\left[\mathrm{a}_{1}+\mathrm{a}_{2} * \frac{1}{C}+\mathrm{a}_{3} \frac{\mathrm{b}^{\prime}}{\left(1+\mathrm{b}^{\prime} C_{k}\right)}\right]$

$\int_{\varnothing_{0}}^{\varnothing} \mathrm{d} \varnothing=\int_{0}^{\mathrm{C}}\left[\mathrm{a}_{1}+\mathrm{a}_{2} \frac{1}{\mathrm{C}}+\mathrm{a}_{3} \frac{\mathrm{b}^{\prime}}{\left(1+\mathrm{b}^{\prime} \mathrm{C}\right)^{2}}\right] \mathrm{dC}$

$\varnothing-\emptyset_{\circ}=\mathrm{a}_{1} \mathrm{C}+\mathrm{a}_{2} \ln \mathrm{C}-\mathrm{a} 3 * \frac{1}{\left(1+\mathrm{b}^{\prime} \mathrm{C}\right)}$

$\emptyset=\emptyset_{\circ}+\mathrm{a}_{1} \mathrm{C}+\mathrm{a}_{2} \ln \mathrm{C}-\mathrm{a} 3 * \frac{1}{\left(1+\mathrm{b}^{\prime} \mathrm{C}\right)} \quad \mathrm{eq}(40)$

To relate porosity change with pressure to permeability the cubic relationship between permeability and porosity in organic rich reservoirs are used as:

Where

$k_{\circ}$ : initial permeability

$\emptyset_{\circ}$ initial porosity

\subsection{2: Development of Storage and Transport Model for Shale Matrix- Fracture "Case II"}

\section{1-Deriving the governing equation for the matrix}

In this case gas storage and transport model is developed including dual porosity shale matrix and fracture. Starting with one dimensional gas transport model in organic rich shale the governing equation for storage and transport for this case is derived as shown below:

The mass balance equation for methane inside shale matrix is given by the following equation:

$$
\begin{gathered}
\frac{\partial \emptyset \mathrm{C}}{\partial \mathrm{t}}+\frac{\partial\left(1-\emptyset-\emptyset_{\mathrm{f}}\right) \mathrm{C}_{\mathrm{u}}}{\partial \mathrm{t}}=\frac{\partial}{\partial \mathrm{x}}\left(\varnothing \mathrm{C} \frac{\mathrm{R}_{\mathrm{g}} \mathrm{Tk} \mathrm{p}}{\mathrm{u}} \frac{\partial \mathrm{C}}{\partial \mathrm{x}}\right)+\frac{\partial}{\partial \mathrm{x}}\left(\varnothing \mathrm{D}_{\mathrm{p}} \frac{\partial \mathrm{C}}{\partial \mathrm{x}}\right)+\frac{\partial}{\partial \mathrm{x}}\left[\left(1-\emptyset-\emptyset_{\mathrm{f}}\right) \mathrm{D}_{\mathrm{s}} \frac{\partial \mathrm{C}_{\mathrm{u}}}{\partial \mathrm{x}}\right] \quad \text { eq(41) } \\
\mathrm{C}_{\mu}=\frac{\mathrm{C}_{\mathrm{us}} \mathrm{b}^{\prime} \mathrm{C}}{1+\mathrm{b}^{\mathrm{C}} \mathrm{C}}+\mathrm{kd} \mathrm{C}
\end{gathered}
$$


Note that above governing equation for matrix now includes the effect of fracture porosity too that needs to be considered. Now shale matrix is coupled with fracture continua where gas mass balance in fracture is defined as:

$$
\frac{\partial}{\partial t}\left(\emptyset_{f} C_{f}\right)=\emptyset_{f} k_{L} \frac{\partial}{\partial x}\left[\frac{\partial C_{f}}{\partial x}\right]+\emptyset_{f} \frac{R_{g} * T * k_{f}}{\mu} * \frac{\partial}{\partial x}\left[C_{f} * \frac{\partial C_{f}}{\partial x}\right]-\emptyset_{f} a\left(b C_{f}-C\right) \quad \text { eq(42) }
$$

First term in left hand side of above equation represents the transient term of fracture and in right hand side we have macro-dispersion term, convection or Dacry flow and mass exchange term between matrix and fracture. Coming back to matrix equation similar technique as discussed earlier for case one is used to develop the governing equations.

$\frac{\partial \emptyset \mathrm{C}}{\partial \mathrm{t}}+\frac{\partial\left(1-\emptyset-\emptyset_{\mathrm{f}}\right) \mathrm{C}_{\mathrm{u}}}{\partial \mathrm{t}}=\frac{\partial}{\partial \mathrm{x}}\left(\varnothing \mathrm{C} \frac{\mathrm{R}_{\mathrm{g}} \mathrm{Tk}_{\mathrm{p}}}{\mathrm{u}} \frac{\partial \mathrm{C}}{\partial \mathrm{x}}\right)+\frac{\partial}{\partial \mathrm{x}}\left(\varnothing \mathrm{D}_{\mathrm{p}} \frac{\partial \mathrm{C}}{\partial \mathrm{x}}\right)+\frac{\partial}{\partial \mathrm{x}}\left[\left(1-\emptyset-\emptyset_{\mathrm{f}}\right) \mathrm{D}_{\mathrm{s}} \frac{\partial \mathrm{C}_{\mathrm{u}}}{\partial \mathrm{x}}\right]$

$\frac{\partial \emptyset \mathrm{C}}{\partial \mathrm{t}}+\frac{\partial(1-\emptyset) \mathrm{C}_{\mathrm{u}}}{\partial \mathrm{t}}=$ the left hand side

Left hand side can be expanded as:

$$
\begin{aligned}
& \frac{\partial \emptyset \mathrm{C}}{\partial \mathrm{t}}=\emptyset \frac{\partial \mathrm{C}}{\partial \mathrm{t}}+\mathrm{C} \frac{\partial \emptyset}{\partial \mathrm{t}} \\
& \frac{\partial\left(1-\emptyset-\emptyset_{\mathrm{f}}\right) \mathrm{C}_{\mathrm{u}}}{\partial \mathrm{t}}=\left(1-\emptyset-\emptyset_{\mathrm{f}}\right) \frac{\partial \mathrm{C}_{\mathrm{u}}}{\partial \mathrm{t}}+\left[-\frac{\partial \emptyset}{\partial \mathrm{t}}\right] \mathrm{C}_{\mathrm{u}}
\end{aligned}
$$

Then by using the chain rule

$$
\begin{aligned}
& \frac{\partial \emptyset}{\partial \mathrm{x}}=\frac{\partial \emptyset}{\partial \mathrm{C}} * \frac{\partial \mathrm{C}}{\partial \mathrm{x}} \\
& \frac{\partial \mathrm{C}_{\mathrm{u}}}{\partial \mathrm{x}}=\frac{\partial \mathrm{C}_{\mathrm{u}}}{\partial \mathrm{C}} * \frac{\partial \mathrm{C}}{\partial \mathrm{x}} \\
& \frac{\partial \mathrm{C}_{\mathrm{u}}}{\partial \mathrm{t}}=\frac{\partial \mathrm{C}_{\mathrm{u}}}{\partial \mathrm{C}} * \frac{\partial \mathrm{C}}{\partial \mathrm{t}} \\
& \frac{\partial \mathrm{C}_{\mathrm{u}}}{\partial \mathrm{x}}=\frac{\partial \mathrm{C}_{\mathrm{u}}}{\partial \mathrm{C}} * \frac{\partial \mathrm{C}}{\partial \mathrm{x}} \\
& \frac{\partial \emptyset}{\partial t}=\frac{\partial \emptyset}{\partial \mathrm{C}} * \frac{\partial C}{\partial t}
\end{aligned}
$$

The first term will be

$$
=\varnothing \frac{\partial \mathrm{C}}{\partial \mathrm{t}}+\mathrm{C} \frac{\partial \emptyset}{\partial \mathrm{C}} * \frac{\partial \mathrm{C}}{\partial \mathrm{t}}
$$


And the second term will be

$=\left(1-\emptyset-\emptyset_{\mathrm{f}}\right) \frac{\partial \mathrm{C}_{\mathrm{u}}}{\partial \mathrm{C}} * \frac{\partial \mathrm{C}}{\partial \mathrm{t}}-\frac{\partial \emptyset}{\partial \mathrm{C}} * \frac{\partial \mathrm{C}}{\partial \mathrm{t}} \mathrm{C}_{\mathrm{u}}$

Combining both terms in left hand side of the equation we have:

The right hand side then will simplify to:

$=\frac{\partial}{\partial \mathrm{x}}\left(\varnothing \mathrm{C} \frac{\mathrm{R}_{\mathrm{g}} \mathrm{Tk}_{\mathrm{p}}}{\mathrm{u}} \frac{\partial \mathrm{C}}{\partial \mathrm{x}}\right)+\frac{\partial}{\partial \mathrm{x}}\left(\varnothing \mathrm{D}_{\mathrm{p}} \frac{\partial \mathrm{C}}{\partial \mathrm{x}}\right)+\frac{\partial}{\partial \mathrm{x}}\left[\left(1-\emptyset-\emptyset_{\mathrm{f}}\right) \mathrm{D}_{\mathrm{s}} \frac{\partial \mathrm{C}_{\mathrm{u}}}{\partial \mathrm{x}}\right]$

let $\mathrm{S}=\frac{\mathrm{R}_{\mathrm{g}} \mathrm{Tk}_{\mathrm{p}}}{\mathrm{u}}$

$=\left\{\varnothing+\mathrm{C} \frac{\partial \emptyset}{\partial \mathrm{C}}+\left(1-\emptyset-\emptyset_{\mathrm{f}}\right) \frac{\partial \mathrm{C}_{\mathrm{u}}}{\partial \mathrm{C}}-\mathrm{C}_{\mathrm{u}}\left(\frac{\partial \emptyset}{\partial \mathrm{C}}\right)\right\} \frac{\partial \mathrm{C}}{\partial \mathrm{t}}$

The first term can be expanded as:

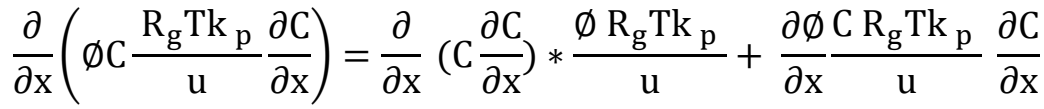

Where:

$=\varnothing S *\left(\frac{\partial C}{\partial x}\right)^{2}+\varnothing S C * \frac{\partial}{\partial x} *\left(\frac{\partial C}{\partial x}\right)+C S * \frac{\partial \emptyset}{\partial \mathrm{x}} * \frac{\partial \mathrm{C}}{\partial \mathrm{x}}$

By applying the chain rule

$=\varnothing S *\left(\frac{\partial \mathrm{C}}{\partial \mathrm{x}}\right)^{2}+\emptyset S C * \frac{\partial}{\partial x} * \frac{\partial \mathrm{C}}{\partial \mathrm{x}}+C S * \frac{\partial \emptyset}{\partial C} *\left(\frac{\partial \mathrm{C}}{\partial \mathrm{x}}\right)^{2}$

The second term will be

$\frac{\partial}{\partial \mathrm{x}}\left(\varnothing \mathrm{D}_{\mathrm{p}} \frac{\partial \mathrm{C}}{\partial \mathrm{x}}\right)=\mathrm{D}_{\mathrm{p}} \emptyset * \frac{\partial^{2} \mathrm{C}}{\partial \mathrm{x}^{2}}+\mathrm{Dp} \frac{\partial \emptyset}{\partial \mathrm{x}} * \frac{\partial \mathrm{C}}{\partial \mathrm{x}} \quad$ Dp : constant

Then by applying the chain rule we have:

$\frac{\partial}{\partial \mathrm{x}}\left(\varnothing \mathrm{D}_{\mathrm{p}} \frac{\partial \mathrm{C}}{\partial \mathrm{x}}\right)=\mathrm{D}_{\mathrm{p}} \varnothing * \frac{\partial}{\partial \mathrm{x}}\left(\frac{\partial \mathrm{C}}{\partial \mathrm{x}}\right)+\mathrm{Dp} * \frac{\partial \emptyset}{\partial \mathrm{C}} *\left(\frac{\partial C}{\partial x}\right)^{2}$

The third term can also be expanded in similar way as:

$$
\begin{aligned}
& \frac{\partial}{\partial \mathrm{x}}\left[\left(1-\emptyset-\emptyset_{\mathrm{f}}\right) \mathrm{D}_{\mathrm{s}} \frac{\partial \mathrm{C}_{\mathrm{u}}}{\partial \mathrm{x}}\right]=\left(1-\emptyset-\emptyset_{\mathrm{f}}\right) \frac{\partial}{\partial \mathrm{x}}\left(\mathrm{D}_{\mathrm{s}} \frac{\partial \mathrm{C}_{\mathrm{u}}}{\partial \mathrm{x}}\right)-\frac{\partial \emptyset}{\partial \mathrm{x}} \mathrm{D}_{\mathrm{s}} \frac{\partial \mathrm{C}_{\mathrm{u}}}{\partial \mathrm{x}} \\
& =\left(1-\emptyset-\emptyset_{\mathrm{f}}\right) \frac{\partial}{\partial \mathrm{x}}\left(\mathrm{D}_{\mathrm{s}} \frac{\partial \mathrm{C}_{\mathrm{u}}}{\partial \mathrm{x}}\right)-\mathrm{D}_{\mathrm{s}} \frac{\partial \mathrm{C}_{\mathrm{u}}}{\partial \mathrm{x}} * \frac{\partial \emptyset}{\partial \mathrm{x}}
\end{aligned}
$$


Then by using the chain rule and assuming $B=\left(1-\emptyset-\emptyset_{\mathrm{f}}\right)$

$=B \frac{\partial}{\partial \mathrm{x}}\left(\mathrm{D}_{\mathrm{s}} \frac{\partial \mathrm{C}_{\mathrm{u}}}{\partial \mathrm{C}} * \frac{\partial \mathrm{C}}{\partial \mathrm{x}}\right)-\mathrm{D}_{\mathrm{s}} \frac{\partial \mathrm{C}_{\mathrm{u}}}{\partial \mathrm{C}} * \frac{\partial \mathrm{C}}{\partial \mathrm{x}} * \frac{\partial \emptyset}{\partial \mathrm{C}} * \frac{\partial \mathrm{C}}{\partial \mathrm{x}}$

$=B \frac{\partial}{\partial \mathrm{x}}\left(\mathrm{D}_{\mathrm{s}} \frac{\partial \mathrm{C}_{\mathrm{u}}}{\partial \mathrm{C}} * \frac{\partial \mathrm{C}}{\partial \mathrm{x}}\right)-\mathrm{D}_{\mathrm{s}} \frac{\partial \mathrm{C}_{\mathrm{u}}}{\partial \mathrm{C}} * \frac{\partial \emptyset}{\partial \mathrm{C}} *\left(\frac{\partial \mathrm{C}}{\partial \mathrm{x}}\right)^{2}$

$=B \frac{\partial}{\partial \mathrm{x}}\left(\mathrm{D}_{\mathrm{S} *} J * \frac{\partial \mathrm{C}}{\partial \mathrm{x}}\right)-\mathrm{D}_{\mathrm{S}} * \mathrm{~J} * \frac{\partial \emptyset}{\partial \mathrm{C}} *\left(\frac{\partial \mathrm{C}}{\partial \mathrm{x}}\right)^{2}$

$=B * \mathrm{D}_{\mathrm{s}} * \frac{\partial \mathrm{J}}{\partial x} *\left(\frac{\partial \mathrm{C}}{\partial \mathrm{x}}\right)+B * \mathrm{D}_{\mathrm{s} *} J * \frac{\partial}{\partial \mathrm{x}}\left(\frac{\partial \mathrm{C}}{\partial \mathrm{x}}\right)-\mathrm{D}_{\mathrm{s}} * \mathrm{~J} * \frac{\partial \emptyset}{\partial \mathrm{C}} *\left(\frac{\partial \mathrm{C}}{\partial \mathrm{x}}\right)^{2}$

Combining all terms together, the right hand side will be

$$
\begin{gathered}
=\varnothing S *\left(\frac{\partial C}{\partial x}\right)^{2}+ \\
\qquad S C * \frac{\partial}{\partial x} *\left(\frac{\partial C}{\partial x}\right)+C S * \frac{\partial \emptyset}{\partial \mathrm{C}} *\left(\frac{\partial C}{\partial x}\right)^{2}+\mathrm{D}_{\mathrm{p}} \emptyset * \frac{\partial}{\partial \mathrm{x}}\left(\frac{\partial \mathrm{C}}{\partial \mathrm{x}}\right)+\mathrm{Dp} * \frac{\partial \emptyset}{\partial \mathrm{C}} *\left(\frac{\partial C}{\partial x}\right)^{2}+B * \mathrm{D}_{\mathrm{s}} \\
+\frac{\partial J}{\partial x} *\left(\frac{\partial \mathrm{C}}{\partial \mathrm{x}}\right)+B * \mathrm{D}_{\mathrm{s} *} J * \frac{\partial}{\partial \mathrm{x}}\left(\frac{\partial \mathrm{C}}{\partial \mathrm{x}}\right)-\mathrm{D}_{\mathrm{s}} * \mathrm{~J} * \frac{\partial \emptyset}{\partial \mathrm{C}} *\left(\frac{\partial \mathrm{C}}{\partial \mathrm{x}}\right)^{2}
\end{gathered}
$$

Define new parameters as follow:

$$
\begin{aligned}
& \frac{\partial \emptyset}{\partial \mathrm{C}}=W, \frac{\partial \mathrm{C}_{\mathrm{u}}}{\partial \mathrm{C}}=J, C_{u}=F \\
& =\left[\varnothing \mathrm{S} *\left(\frac{\partial \mathrm{C}}{\partial \mathrm{x}}\right)^{2}+B * \mathrm{D}_{\mathrm{s}} * \frac{\partial J}{\partial x} *\left(\frac{\partial \mathrm{C}}{\partial \mathrm{x}}\right)\right]+\left[\varnothing \mathrm{SC}+B \mathrm{D}_{\mathrm{s}} J+\mathrm{D}_{\mathrm{p}} \varnothing\right] \frac{\partial}{\partial \mathrm{x}}\left(\frac{\partial \mathrm{C}}{\partial \mathrm{x}}\right)+\left[C S+\mathrm{D}_{\mathrm{p}}-\mathrm{D}_{\mathrm{s}} *\right. \\
& J] * \mathrm{~W} *\left(\frac{\partial \mathrm{C}}{\partial \mathrm{x}}\right)^{2}
\end{aligned}
$$

$$
\begin{aligned}
\{\varnothing+\mathrm{CW}+\mathrm{BJ}- & \mathrm{FW}\} \frac{\partial \mathrm{C}}{\partial \mathrm{t}} \\
& =B * \mathrm{D}_{\mathrm{s}} * \frac{\partial J}{\partial x} *\left(\frac{\partial \mathrm{C}}{\partial \mathrm{x}}\right)+\left[\varnothing \mathrm{SC}+B \mathrm{D}_{\mathrm{s}} J+\mathrm{D}_{\mathrm{p}} \varnothing\right] \frac{\partial}{\partial \mathrm{x}}\left(\frac{\partial \mathrm{C}}{\partial \mathrm{x}}\right) \\
& +\left[\left(C S+\mathrm{D}_{\mathrm{p}}-\mathrm{D}_{\mathrm{s}} * J\right) * \mathrm{~W}+\varnothing \mathrm{S}\right] *\left(\frac{\partial \mathrm{C}}{\partial \mathrm{x}}\right)^{2}
\end{aligned}
$$

Let assume $\left[\varnothing \mathrm{SC}+B \mathrm{D}_{\mathrm{s}} J+\mathrm{D}_{\mathrm{p}} \varnothing\right]=A$

Divided both sides by A

$\left[\frac{\emptyset+\mathrm{CW}+\mathrm{BJ}-\mathrm{FW}}{\varnothing \mathrm{SC}+B \mathrm{D}_{\mathrm{s}} J+\mathrm{D}_{\mathrm{p}} \emptyset}\right] \frac{\partial \mathrm{C}}{\partial \mathrm{t}}=\frac{\partial}{\partial \mathrm{x}}\left(\frac{\partial \mathrm{C}}{\partial \mathrm{x}}\right)+\left[\frac{\left(C S+\mathrm{D}_{\mathrm{p}}-\mathrm{D}_{\mathrm{s}} * J\right) * \mathrm{~W}+\emptyset \mathrm{S}+\mathrm{BD}_{\mathrm{s}} V}{\emptyset \mathrm{SC}+B \mathrm{D}_{\mathrm{s}} J+\mathrm{D}_{\mathrm{p}} \emptyset}\right]\left(\frac{\partial \mathrm{C}}{\partial \mathrm{x}}\right)^{2}$

Non-linear relation between porosity and free gas concentration and shale matrix mechanical properties, i.e., Young Modulus and Poisson Ratio, is defined as presented in equation (40). 


\section{2-Deriving the governing equation for the fracture}

One dimensional mass balance equation for single phase single component methane in the fracture is given by the equation (45). Assuming constant fracture porosity $\emptyset_{f}$ equation (41) can be expanded as follow:

$\frac{\partial}{\partial t}\left(\emptyset_{f} C_{f}\right)=\emptyset_{f} k_{L} \frac{\partial}{\partial x}\left[\frac{\partial C_{f}}{\partial x}\right]+\emptyset_{f} \frac{R_{g} * T * k_{f}}{\mu} * \frac{\partial}{\partial x}\left[C_{f} * \frac{\partial C_{f}}{\partial x}\right]-\emptyset_{f} a\left(b C_{f}-C\right)$

The left hand side will simplify to

$\frac{\partial}{\partial t}\left(\emptyset_{f} C_{f}\right)=\emptyset_{f} \frac{\partial C_{f}}{\partial t}$

And right hand side can be expanded for macro-dispersion as:

$\emptyset_{f} k_{L} \frac{\partial}{\partial x}\left[\frac{\partial C_{f}}{\partial x}\right]=\emptyset_{f} k_{L} \frac{\partial^{2} C_{f}}{\partial x^{2}}$

And also convection term can be written as:

$\emptyset_{f} \frac{R_{g} * T * k_{f}}{\mu} * \frac{\partial}{\partial x}\left[C_{f} * \frac{\partial C_{f}}{\partial x}\right]=\emptyset_{f} \frac{R_{g} * T * k_{f}}{\mu} *\left[C_{f} * \frac{\partial^{2} C_{f}}{\partial x^{2}}+\frac{\partial C_{f}}{\partial x} * \frac{\partial C_{f}}{\partial x}\right]$

$=\emptyset_{f} \frac{R_{g} * T * k_{f}}{\mu} *\left[C_{f} * \frac{\partial^{2} C_{f}}{\partial x^{2}}+\left(\frac{\partial C_{f}}{\partial x}\right)^{2}\right]$

$=\emptyset_{f} \frac{R_{g} * T * k_{f}}{\mu} * C_{f} * \frac{\partial^{2} C_{f}}{\partial x^{2}}+\emptyset_{f} \frac{R_{g} * T * k_{f}}{\mu}\left(\frac{\partial C_{f}}{\partial x}\right)^{2}$

$\frac{R_{g} * T * k_{f}}{\mu}=S$

$=\emptyset_{f} S C_{f} * \frac{\partial^{2} C_{f}}{\partial x^{2}}+\emptyset_{f} S\left(\frac{\partial C_{f}}{\partial x}\right)^{2}$

Combing macro-dispersion, convection and source terms we have:

$\emptyset_{f} \frac{\partial C_{f}}{\partial t}=\emptyset_{f} k_{L} \frac{\partial^{2} C_{f}}{\partial x^{2}}+\emptyset_{f} S C_{f} * \frac{\partial^{2} C_{f}}{\partial x^{2}}+\emptyset_{f} S\left(\frac{\partial C_{f}}{\partial x}\right)^{2}-\emptyset_{f} a\left(b C_{f}-C\right)$

$\emptyset_{f} \frac{\partial C_{f}}{\partial t}=\emptyset_{f} k_{L} \frac{\partial}{\partial x}\left(\frac{\partial C_{f}}{\partial x}\right)+\emptyset_{f} S C_{f} * \frac{\partial}{\partial x}\left(\frac{\partial C_{f}}{\partial x}\right)+\emptyset_{f} S\left(\frac{\partial C_{f}}{\partial x}\right)^{2}-\emptyset_{f} a\left(b C_{f}-C\right)$ 
$\emptyset_{f} \frac{\partial C_{f}}{\partial t}=\left(\emptyset_{f} k_{L}+\emptyset_{f} S C_{f}\right) \frac{\partial^{2} C_{f}}{\partial x^{2}}+\emptyset_{f} S\left(\frac{\partial C_{f}}{\partial x}\right)^{2}-\emptyset_{f} a\left(b C_{f}-C\right) \quad$ eq(46)

In equation (46) $\emptyset_{f}$ is the fracture porosity which is assumes to be constant. b is the partition coefficient equal to 1 due to single component single phase nature of the problem. $C$ and $C_{f}$ are the free gas concentration in the matrix and fracture respectively. $K_{L}$ is the fracture dispersion coefficient. mass exchange term is defined in the spirit of sorption kinetics model for shale gas reservoirs as $a\left(b C_{f}-C\right)$ that couples matrix and fracture continua represented as sink or source term in governing equation (Fathi et al, 2008)."a" is the desorption rate coefficient which is calculated by the formula below and it is depended on the concentration of adsorbed and free gas and its given in equation (47) below:

$a=\frac{15 D}{R^{2}}$

$a=\frac{15}{R^{2}}\left[\varnothing D_{p}+\varnothing C \frac{R_{g} T k_{p}}{\mu}+\left(1-\emptyset-\emptyset_{f}\right) D_{s} *\left(\frac{\mathrm{C}_{\mathrm{us}} \mathrm{b}^{\prime}}{\left(1+\mathrm{b}^{\prime} \mathrm{C}\right)^{2}}+\mathrm{kd}\right)\right] \quad$ eq(47)

Let assume $\left(\emptyset_{f} k_{L}+\emptyset_{f} S C_{f}\right)=A$ and divide both side of the gas mass balance in fracture by "A" to find final form of governing equation in fracture:

$$
\frac{\emptyset_{f}}{\left(\emptyset_{f} k_{L}+\emptyset_{f} S C_{f}\right)} \frac{\partial C_{f}}{\partial t}=\frac{\partial}{\partial x} \frac{\partial C_{f}}{\partial x}+\frac{\emptyset_{f} S\left(\frac{\partial C_{f}}{\partial x}\right)^{2}-\emptyset_{f} a\left(b C_{f}-C\right)}{\left(\emptyset_{f} k_{L}+\emptyset_{f} S C_{f}\right)}
$$

\subsection{3: Development of Storage and Transport Model for Multi-Scale Shale Matrix "Case III"}

In this case shale matrix is seen as a Multi-scale matrix consists of organic and inorganics. The system is assumed to be a triple porosity single permeability system. Derivation of governing equations for both organic and inorganic is shown below:

\section{1-Gas transport in organic (kerogen material)}

Equation (43) represents the free gas mass balance in organic material. Starting with this equation a governing equation for gas storage and transport in organic material is derived. We assume that both porosity and gas concentrations are changing in time $(\mathrm{t})$ and space $(\mathrm{x})$.

$\frac{\partial \emptyset_{k} C_{k}}{\partial t}+\frac{\partial\left(1-\emptyset_{k}\right) C_{u}}{\partial t}=\frac{\partial}{\partial x}\left(\emptyset_{k} D_{k} \frac{\partial C_{K}}{\partial x}\right)+\frac{\partial}{\partial x}\left(\left(1-\emptyset_{k}\right) D_{s} \frac{\partial C_{u}}{\partial x}\right)$ 
Note that here $\emptyset_{k}$ stands for kerogen porosity. In left hand side of the equation we have transient terms for free and adsorbed gas concentrations and in right hand side transport assumed to be only diffusive, (free pore and adsorbed surface diffusion) due to ultra-tight nature of organic matrix with pore sizes in the order of nano-meters. Applying the chain rule to first and second transient terms we have:

Where derivatives can be represented as:

$$
\begin{aligned}
& \frac{\partial \emptyset_{k}}{\partial t}=\frac{\partial \emptyset_{k}}{\partial C_{k}} * \frac{\partial C_{k}}{\partial t} \\
& \frac{\partial C_{u}}{\partial t}=\frac{\partial C_{u}}{\partial C_{k}} * \frac{\partial C_{k}}{\partial t} \\
& \frac{\partial C_{u}}{\partial x}=\frac{\partial C_{u}}{\partial C_{k}} * \frac{\partial C_{k}}{\partial x} \\
& \frac{\partial \emptyset_{k}}{\partial x}=\frac{\partial \emptyset_{k}}{\partial C_{k}} * \frac{\partial C_{k}}{\partial x} \\
& \frac{\partial \emptyset_{k} C_{k}}{\partial t}=\emptyset_{k} * \frac{\partial C_{k}}{\partial t}+C_{k} * \frac{\partial \emptyset_{k}}{\partial t} \\
& \frac{\partial \emptyset_{k} C_{k}}{\partial t}=\emptyset_{k} * \frac{\partial C_{k}}{\partial t}+C_{k} * \frac{\partial \emptyset_{k}}{\partial C_{k}} * \frac{\partial C_{k}}{\partial t} \\
& \frac{\partial\left(1-\emptyset_{k}\right) C_{u}}{\partial t}=\left(1-\emptyset_{k}\right) * \frac{\partial C_{u}}{\partial t}-C_{u} * \frac{\partial \emptyset_{k}}{\partial t} \\
& \frac{\partial\left(1-\emptyset_{k}\right) C_{u}}{\partial t}=\left(1-\emptyset_{k}\right) * \frac{\partial C_{u}}{\partial C_{k}} * \frac{\partial C_{k}}{\partial t}-C_{u} * \frac{\partial \emptyset_{k}}{\partial C_{k}} * \frac{\partial C_{k}}{\partial t}
\end{aligned}
$$

Considering the right hand side of the equation (48)

$=\frac{\partial}{\partial x}\left(\emptyset_{k} D_{k} \frac{\partial C_{k}}{\partial x}\right)+\frac{\partial}{\partial x}\left(\left(1-\emptyset_{k}\right) D_{s} \frac{\partial C_{u}}{\partial x}\right)$

Diffusive transport term for free gas transport then can be written as:

$$
\begin{aligned}
& \frac{\partial}{\partial x}\left(\emptyset_{k} D_{k} \frac{\partial C_{k}}{\partial x}\right)=D_{k} * \emptyset_{k} * \frac{\partial^{2} C_{k}}{\partial x^{2}}+D_{k} * \frac{\partial \emptyset_{k}}{\partial x} * \frac{\partial C_{k}}{\partial x} \\
& \frac{\partial}{\partial x}\left(\emptyset_{k} D_{k} \frac{\partial C_{k}}{\partial x}\right)=D_{k} * \emptyset_{k} * \frac{\partial^{2} C_{k}}{\partial x^{2}}+D_{k} * \frac{\partial \emptyset_{k}}{\partial C_{k}} * \frac{\partial C_{k}}{\partial x} * \frac{\partial C_{k}}{\partial x}
\end{aligned}
$$


$\frac{\partial}{\partial x}\left(\emptyset_{k} D_{k} \frac{\partial C_{k}}{\partial x}\right)=D_{k} * \emptyset_{k} * \frac{\partial^{2} C_{k}}{\partial x^{2}}+D_{k} * \frac{\partial \emptyset_{k}}{\partial C_{k}} *\left(\frac{\partial C_{k}}{\partial x}\right)^{2}$

And for adsorbed phase transport can be written as:

$$
\begin{aligned}
& \frac{\partial}{\partial x}\left(\left(1-\emptyset_{k}\right) D_{s} \frac{\partial C_{u}}{\partial x}\right)=\left(1-\emptyset_{k}\right) D_{s} * \frac{\partial}{\partial x}\left(\frac{\partial C_{u}}{\partial x}\right)-D_{s} * \frac{\partial C_{u}}{\partial x} * \frac{\partial \emptyset_{k}}{\partial x} \\
& \frac{\partial}{\partial x}\left(\left(1-\emptyset_{k}\right) D_{s} \frac{\partial C_{u}}{\partial x}\right)=\left(1-\emptyset_{k}\right) D_{s} * \frac{\partial}{\partial x}\left(\frac{\partial C_{u}}{\partial C_{k}} * \frac{\partial C_{k}}{\partial x}\right)-D_{s} * \frac{\partial C_{u}}{\partial C_{k}} * \frac{\partial C_{k}}{\partial x} * \frac{\partial \emptyset_{k}}{\partial C_{k}} * \frac{\partial C_{k}}{\partial x} \\
& \frac{\partial}{\partial x}\left(\left(1-\emptyset_{k}\right) D_{s} \frac{\partial C_{u}}{\partial x}\right)=\left(1-\emptyset_{k}\right) D_{s} * \frac{\partial}{\partial x}\left(\frac{\partial C_{u}}{\partial C_{k}} * \frac{\partial C_{k}}{\partial x}\right)-D_{s} * \frac{\partial C_{u}}{\partial C_{k}} * \frac{\partial \emptyset_{k}}{\partial C_{k}} *\left(\frac{\partial C_{k}}{\partial x}\right)^{2}
\end{aligned}
$$

Replacing different expanded terms in governing equation (48) one can find:

$$
\begin{aligned}
{\left[\emptyset_{k}+C_{k} * \frac{\partial \emptyset_{k}}{\partial C_{k}}\right.} & \left.+\left(1-\emptyset_{k}\right) * \frac{\partial C_{u}}{\partial C_{k}}-C_{u} * \frac{\partial \emptyset_{k}}{\partial C_{k}}\right] \frac{\partial C_{k}}{\partial t} \\
& =D_{k} * \emptyset_{k} * \frac{\partial^{2} C_{k}}{\partial x^{2}}+D_{k} * \frac{\partial \emptyset_{k}}{\partial C_{k}} *\left(\frac{\partial C_{k}}{\partial x}\right)^{2}+\left(1-\emptyset_{k}\right) D_{s} * \frac{\partial}{\partial x}\left(\frac{\partial C_{u}}{\partial C_{k}} * \frac{\partial C_{k}}{\partial x}\right)-D_{s} * \frac{\partial C_{u}}{\partial C_{k}} \\
& * \frac{\partial \emptyset_{k}}{\partial C_{k}} *\left(\frac{\partial C_{k}}{\partial x}\right)^{2}
\end{aligned}
$$

And it can be arranged as follow:

$$
\begin{aligned}
{\left[\emptyset_{k}+C_{k} * \frac{\partial \emptyset_{k}}{\partial C_{k}}\right.} & \left.+\left(1-\emptyset_{k}\right) * \frac{\partial C_{u}}{\partial C_{k}}-C_{u} * \frac{\partial \emptyset_{k}}{\partial C_{k}}\right] \frac{\partial C_{k}}{\partial t} \\
& =D_{k} * \emptyset_{k} * \frac{\partial}{\partial x}\left(\frac{\partial C_{k}}{\partial x}\right)+\left(1-\emptyset_{k}\right) D_{s} * \frac{\partial^{2} C_{u}}{\partial x \partial C_{k}} * \frac{\partial C_{k}}{\partial x}+\left(1-\emptyset_{k}\right) D_{s} * \frac{\partial C_{u}}{\partial C_{k}} * \frac{\partial}{\partial x}\left(\frac{\partial C_{k}}{\partial x}\right) \\
& +D_{k} * \frac{\partial \emptyset_{k}}{\partial C_{k}} *\left(\frac{\partial C_{k}}{\partial x}\right)^{2}-D_{s} * \frac{\partial C_{u}}{\partial C_{k}} * \frac{\partial \emptyset_{k}}{\partial C_{k}} *\left(\frac{\partial C_{k}}{\partial x}\right)^{2} \quad e q(49)
\end{aligned}
$$

Using the definition for term " $A$ " the final form of governing equation can be written in condensed form as:

$$
\begin{aligned}
& D_{k} * \emptyset_{k}+\left(1-\emptyset_{k}\right) D_{s} * \frac{\partial C_{u}}{\partial C_{k}}=A \\
& \frac{\left[\emptyset_{k}+C_{k} * \frac{\partial \emptyset_{k}}{\partial C_{k}}+\left(1-\emptyset_{k}\right) * \frac{\partial C_{u}}{\partial C_{k}}-C_{u} * \frac{\partial \emptyset_{k}}{\partial C_{k}}\right]}{\left[D_{k} * \emptyset_{k}+\left(1-\emptyset_{k}\right) D_{s} * \frac{\partial C_{u}}{\partial C_{k}}\right]} \frac{\partial C_{k}}{\partial t} \\
& =\frac{\partial}{\partial x}\left(\frac{\partial C_{k}}{\partial x}\right)+\frac{\left[D_{k} * \frac{\partial \emptyset_{k}}{\partial C_{k}} *-D_{s} * \frac{\partial C_{u}}{\partial C_{k}} * \frac{\partial \emptyset_{k}}{\partial C_{k}}+\left(1-\emptyset_{k}\right) D_{s} * \frac{\partial^{2} C_{u}}{\partial x \partial C_{k}}\right]}{\left[D_{k} * \emptyset_{k}+\left(1-\emptyset_{k}\right) D_{s} * \frac{\partial C_{u}}{\partial C_{k}}\right]}\left(\frac{\partial C_{k}}{\partial x}\right)^{2}
\end{aligned}
$$


In equation (49) $\mathrm{x}$ and $\mathrm{t}$ are space and time coordinate. $\emptyset_{k}$ is the kerogen porosity derived including the volumetric total organic content of shale as introduced earlier by Akkutlu et al.(2013). In this equation $\emptyset_{k}$ is a dynamic quantity that changes in time and space due to kerogen porelaticity effect as a function of pressure. $C_{k}$ and $C_{u}$ are the free and adsorbed gas concentrations in organic material respectively. $\left(1-\emptyset_{k}\right)$ is the kerogen solid to bulk volume ratio.

Note here rate of change in kerogen porosity with pressure is defined using Palmer and Mansoori (1998) modified model used for coalbed methane reservoirs as follow:

$\frac{\partial \emptyset_{k}}{\partial C_{k}}=\left[\mathrm{a}_{1}+\mathrm{a}_{2} * \frac{1}{C_{k}}+\mathrm{a}_{3} \frac{\mathrm{b}^{\prime}}{\left(1+\mathrm{b}^{\prime} C_{k}\right)}\right]$

The change in porosity with respect to the free gas concentration is given by the equation below:

$\emptyset_{k}=\emptyset_{k 0}+\mathrm{a}_{1} \mathrm{C}_{\mathrm{k}}+\mathrm{a}_{2} \ln \mathrm{C}_{\mathrm{k}}-\mathrm{a} 3 * \frac{1}{\left(1+\mathrm{b}^{\prime} \mathrm{C}_{\mathrm{k}}\right)}$

$\frac{\partial C_{u}}{\partial C_{k}}$ is the rate of change in adsorbed gas concentration with free gas concentration and its second derivative with respect to location can be obtained from Langmuir-Henry dual isotherm model as shown below:

$\frac{\partial C_{u}}{\partial C_{k}}=\frac{\mathrm{C}_{\mathrm{us}} \mathrm{b}^{\prime}}{\left(1+\mathrm{b}^{\prime} \mathrm{C}_{\mathrm{k}}\right)^{2}}+\mathrm{kd}$

$\frac{\partial}{\partial x}\left(\frac{\partial C_{u}}{\partial C_{k}}\right)=\frac{\partial}{\partial x}\left(\frac{\mathrm{C}_{\mathrm{us}} \mathrm{b}^{\prime}}{\left(1+\mathrm{b}^{\prime} \mathrm{C}_{\mathrm{k}}\right)^{2}}+\mathrm{kd}\right)=\frac{-2 \mathrm{~b}^{2} C_{u s}}{\left(1+\mathrm{b}^{\prime} \mathrm{C}_{\mathrm{k}}\right)^{2}}\left(\frac{\partial C_{k}}{\partial x}\right)$

Substituting the definition of "J" we have:

$\frac{\partial J}{\partial x}=\frac{-2 \mathrm{~b}^{2} C_{u s}}{\left(1+\mathrm{b}^{\prime} C_{\mathrm{k}}\right)^{2}}=V\left(\frac{\partial C_{k}}{\partial x}\right)$

\section{2-Gas Mass balance in matrix inorganics}

Equation (51) represents the free gas mass balance in the inorganic matrix. Starting with this equation the governing equation for gas storage and transport in inorganic matrix is derived as shown below. We assume that both porosity and concentration are changing in time (t) and space (x). Matrix inorganics are found to have macro-pore sizes where transport is mainly governed by Darcy equation. Mass exchange term representing the ease of gas transport from organic materials to inorganics are presented in spirit of Warren and Roots (1963) mass exchange model as follow: 


$$
\frac{\partial \emptyset_{I} C}{\partial t}=\frac{\partial}{\partial x}\left[\emptyset_{I} Z R T C \frac{k}{\mu} \frac{\partial C}{\partial x}\right]-W_{k m}
$$

Equation (51) can be expanded using chain rule as follow:

$$
\begin{aligned}
& \frac{\partial \emptyset_{I} C}{\partial t}=\emptyset_{I} * \frac{\partial C}{\partial t}+C * \frac{\partial \emptyset_{I}}{\partial t} \\
& \frac{\partial \emptyset_{I} C}{\partial t}=\emptyset_{I} * \frac{\partial C}{\partial t}+C * \frac{\partial \emptyset_{I}}{\partial C} * \frac{\partial C}{\partial t}
\end{aligned}
$$

Convective term in right hand side of equation (51) can also be expanded as follow:

$$
\begin{aligned}
& \frac{\partial}{\partial x}\left[\emptyset_{I} Z R T C \frac{k}{\mu} \frac{\partial C}{\partial x}\right]=Z R T \frac{k}{\mu}\left[\emptyset_{I} * \frac{\partial}{\partial x}\left(C \frac{\partial C}{\partial x}\right)+\frac{\partial \emptyset_{I}}{\partial x} * C \frac{\partial C}{\partial x}\right] \\
& =Z R T \frac{k}{\mu}\left[\emptyset_{I} * \frac{\partial}{\partial x}\left(C \frac{\partial C}{\partial x}\right)+\frac{\partial \emptyset_{I}}{\partial C} * \frac{\partial C}{\partial x} * C \frac{\partial C}{\partial x}\right] \\
& =Z R T \frac{k}{\mu}\left[\emptyset_{I} * \frac{\partial}{\partial x}\left(C \frac{\partial C}{\partial x}\right)+\frac{\partial \emptyset_{I}}{\partial C} * C *\left(\frac{\partial C}{\partial x}\right)^{2}\right]
\end{aligned}
$$

Substituting the new terms in main equation (51) leads to:

$$
\left[\emptyset_{I}+C * \frac{\partial \emptyset_{I}}{\partial C}\right] \frac{\partial C}{\partial t}=Z R T \frac{k}{\mu}\left[\emptyset_{I} * \frac{\partial}{\partial x}\left(C \frac{\partial C}{\partial x}\right)+\frac{\partial \emptyset_{I}}{\partial C} * C *\left(\frac{\partial C}{\partial x}\right)^{2}\right]-W_{k m}
$$

Which can be written in final form of:

$$
\left[\emptyset_{I}+C * \frac{\partial \emptyset_{I}}{\partial C}\right] \frac{\partial C}{\partial t}=Z R T \frac{k}{\mu} \emptyset_{I} * \frac{\partial}{\partial x}\left(C \frac{\partial C}{\partial x}\right)+Z R T \frac{k}{\mu} * \frac{\partial \emptyset_{I}}{\partial C} * C *\left(\frac{\partial C}{\partial x}\right)^{2}-W_{k m} \quad \text { eq(52) }
$$

Normalizing both sides by common term $Z R T \frac{k}{\mu} \emptyset_{I}$ it simplifies to:

$$
\begin{aligned}
& \frac{\left[\emptyset_{I}+C * \frac{\partial \emptyset_{I}}{\partial C}\right]}{Z R T \frac{k}{\mu} \emptyset_{I}} \frac{\partial C}{\partial t}= \\
& \qquad \frac{\partial}{\partial x}\left(C \frac{\partial C}{\partial x}\right)+\frac{Z R T \frac{k}{\mu} * \frac{\partial \emptyset_{I}}{\partial C} * C *\left(\frac{\partial C}{\partial x}\right)^{2}-W_{k m}}{Z R T \frac{k}{\mu} \emptyset_{I}}
\end{aligned}
$$

Where $W_{k m}$ is the coupling term representing the mass transfer between organic and inorganic continua. $W_{k m}$ is a function of $\tau_{m}$ shape factor, $\Psi$ diffusive transport and difference in the concentration between organic and inorganic continua at interface as shown in the equation (53). 


$$
\begin{aligned}
& W_{k m}=\tau_{m} \Psi\left(C-C_{k}\right) \quad e q(53) \\
& W_{k m}=\emptyset_{I} \tau_{m}\left(D-\frac{C_{u}}{C-C_{k}} D_{s}\right)\left(C-C_{k}\right) \quad \text { eq }(54)
\end{aligned}
$$

In equations (48) and (50), $\mathrm{x}$ and $\mathrm{t}$ are space and time coordinates. $\emptyset_{I}$ is inorganic matrix porosity. $C$ and $C_{u}$ are as define earlier free and adsorbed gas concentrations in inorganic matrix pores. $k$ is the inorganic matrix permeability. $\mu$ is the gas viscosity. $\tau_{m}$ is the matrix shape factor. Also in the equation above the compressibility equation is used to represent the thermodynamic behavior of the gas $p=z C R T$.

$\frac{\partial \emptyset_{I}}{\partial C}$ represents pore compressibility of inorganic matrix . A formula for inorganic pore compressibility is derived from the fundamental bulk and pore compressibility equation as shown below:

Bulk volume can be written as sum of pore and matrix volumes (55)

$V_{b}=V_{P}+V_{M} \quad$ eq(55)

Where porosity is defined as:

$\emptyset=\frac{V_{P}}{V_{b}} \quad$ eq(56)

Following conventional definition of rock compressibility we have:

$-\frac{1}{V_{b}} \frac{\partial V_{b}}{\partial P}=\emptyset \frac{1}{V_{P}} \frac{\partial V_{P}}{\partial P}-(1-\emptyset) \frac{1}{V_{m}} \frac{\partial V_{m}}{\partial P} \quad$ eq $(57)$

From the definition of Raaen (1993), Faejer (1992) and Zimmerman (2000) for the reservoir compaction coefficients under uniaxial stress condition bulk, pore and rock compressibility in Inorganic materials can be written as:

$C_{b}=-\frac{1}{V_{b}} \frac{\partial V_{b}}{\partial P} \quad$ eq (58) $\quad$ is the bulk compressibility

$C_{P}=\frac{1}{V_{P}} \frac{\partial V_{P}}{\partial P} \quad$ eq (59) is the pore compressibility

$C_{m}=-\frac{1}{V_{m}} \frac{\partial V_{m}}{\partial P} \quad \mathrm{eq}(60) \quad$ is the rock compressibility

Substituting the definition of bulk, pore and rock compressibility in equation (57)

$C_{b}=\varnothing C_{P}+(1-\emptyset) C_{m} \quad$ eq $(61)$ 
Since the matrix compressibility is too small compare to the pore compressibility thus equation (61) simplifies to:

$C_{b}=\varnothing C_{P} \quad$ eq(62)

Therefore:

$C_{P}=\frac{1}{\emptyset} C_{b} \quad$ eq (63)

From the definition of Zimmerman (2000) and Fjaer et al (1992) bulk volume compressibility can be obtained from Young modulus and Poisson ratio of rock as follow:

$C_{b}=\propto_{b} \frac{1}{E_{t}} \frac{\left(1+v_{t}\right)\left(1-2 v_{t}\right)}{\left(1-v_{t}\right)} \quad$ eq $(64)$

Then by substituting equation (64) in equation (63) one can write:

$C_{P}=\frac{1}{\emptyset} \propto_{b} \frac{1}{E_{t}} \frac{\left(1+v_{t}\right)\left(1-2 v_{t}\right)}{\left(1-v_{t}\right)} \quad$ eq $(65)$

To find a relation describing porosity change as a function of pressure follow mathematical procedure has been taken by substituted equation (59) and (56) in the equation (65):

$\frac{1}{V_{P}} \frac{\partial V_{P}}{\partial P}=\frac{1}{\frac{V_{P}}{V_{b}}} \propto_{b} \frac{1}{E_{t}} \frac{\left(1+v_{t}\right)\left(1-2 v_{t}\right)}{\left(1-v_{t}\right)} \quad$ eq(66)

$\frac{\partial V_{P}}{\partial P}=\frac{V_{P}}{\frac{V_{P}}{V_{b}}} \propto_{b} \frac{1}{E_{t}} \frac{\left(1+v_{t}\right)\left(1-2 v_{t}\right)}{\left(1-v_{t}\right)} \quad$ eq(67)

$\frac{\partial V_{P}}{\partial P}=\propto_{b} \frac{V_{b}}{E_{t}} \frac{\left(1+v_{t}\right)\left(1-2 v_{t}\right)}{\left(1-v_{t}\right)} \quad$ eq(68)

$\frac{1}{V_{b}} \frac{\partial V_{P}}{\partial P}=\propto_{b} \frac{1}{E_{t}} \frac{\left(1+v_{t}\right)\left(1-2 v_{t}\right)}{\left(1-v_{t}\right)} \quad$ eq $(69)$

Since

$-\frac{1}{V_{b}} \frac{\partial V_{b}}{\partial P}=\emptyset \frac{1}{V_{P}} \frac{\partial V_{P}}{\partial P}$

$\frac{\partial V_{b}}{\partial P}=-\emptyset \frac{V_{b}}{V_{P}} \frac{\partial V_{P}}{\partial P}$

Thus 
$\frac{\partial V_{b}}{\partial P}=-\frac{\partial V_{P}}{\partial P} \quad$ eq $(70)$

$\frac{\partial \emptyset}{\partial P}=\frac{\frac{\partial V_{P}}{\partial P} * V_{b}-\frac{\partial V_{b}}{\partial P} * V_{p}}{V_{b}^{2}}$

One can substitute equation (70) in the equation (71) as follow:

$\frac{\partial \emptyset}{\partial P}=\frac{\frac{\partial V_{P}}{\partial P} * V_{b}+\frac{\partial V_{P}}{\partial P} * V_{p}}{V_{b}^{2}} \quad$ eq $(72)$

$\frac{\partial \emptyset}{\partial P}=\frac{\frac{\partial V_{P}}{\partial P} *\left(V_{b}+V_{p}\right)}{V_{b}^{2}}$

$\frac{\partial \emptyset}{\partial P}=\frac{1}{V_{b}} \frac{\partial V_{P}}{\partial P} \frac{\left(V_{b}+V_{p}\right)}{V_{b}}$

$\frac{\partial \emptyset}{\partial P}=\propto_{b} \frac{1}{E_{t}} \frac{\left(1+v_{t}\right)\left(1-2 v_{t}\right)}{\left(1-v_{t}\right)} * \frac{\left(V_{b}+V_{p}\right)}{V_{b}} \quad$ eq $(73)$

Then the final pore compressibility equation describing the change in porosity with pressure as a function of rock properties can be written as:

$\frac{\partial \emptyset}{\partial P}=\propto_{b} \frac{\left(1+\emptyset_{\circ}\right)}{E_{t}} \frac{\left(1+v_{t}\right)\left(1-2 v_{t}\right)}{\left(1-v_{t}\right)} \quad$ eq(74)

Integrating both side of equation (74)

$$
\begin{aligned}
& \int_{\phi_{\circ}}^{\varnothing} \partial \emptyset=\propto_{b} \frac{\left(1+\emptyset_{\circ}\right)}{E_{t}} \frac{\left(1+v_{t}\right)\left(1-2 v_{t}\right)}{\left(1-v_{t}\right)} \int_{p_{\circ}}^{p} \partial P \\
& \left(\varnothing-\emptyset_{\circ}\right)=\propto_{b} \frac{\left(1+\emptyset_{\circ}\right)}{E_{t}} \frac{\left(1+v_{t}\right)\left(1-2 v_{t}\right)}{\left(1-v_{t}\right)}\left(P-P_{\circ}\right)
\end{aligned}
$$

Thus, the equation of dynamic porosity change is given by equation below

$\varnothing=\emptyset_{\circ}+\propto_{b} \frac{\left(1+\emptyset_{\circ}\right)}{E_{t}} \frac{\left(1+v_{t}\right)\left(1-2 v_{t}\right)}{\left(1-v_{t}\right)}\left(P-P_{\circ}\right) \quad$ eq $(75)$

Since

$$
P={ }_{z C R T}
$$

Thus the final equation will be

$$
\frac{\partial \emptyset}{\partial C}=z R T \propto_{b} \frac{\left(1+\emptyset_{\circ}\right)}{E_{t}} \frac{\left(1+v_{t}\right)\left(1-2 v_{t}\right)}{\left(1-v_{t}\right)} \quad \text { eq(76) }
$$




$$
\varnothing=\emptyset_{\circ}+{ }_{z} C R T \propto_{b} \frac{\left(1+\emptyset_{\circ}\right)}{E_{t}} \frac{\left(1+v_{t}\right)\left(1-2 v_{t}\right)}{\left(1-v_{t}\right)} \quad \text { eq(77) }
$$

Equations (76) and (77) can represent explicit relation between inorganic porosity and inorganic matrix rock properties:

$$
\begin{array}{cc}
\frac{\partial \emptyset_{I}}{\partial C}=z R T \propto_{b} \frac{\left(1+\emptyset_{I 0}\right)}{E_{t}} \frac{\left(1+v_{t}\right)\left(1-2 v_{t}\right)}{\left(1-v_{t}\right)} & \text { eq(78) } \\
\emptyset_{I}=\emptyset_{I 0}+z C R T \propto_{b} \frac{\left(1+\emptyset_{I 0}\right)}{E_{t}} \frac{\left(1+v_{t}\right)\left(1-2 v_{t}\right)}{\left(1-v_{t}\right)} & \text { eq }(79)
\end{array}
$$

Equation (78) will be substituted in equation (52).

\subsection{4: Development of Storage and Transport Model for Multi-Scale Matrix- Fracture "Case IV"}

In this case shale matrix is seen as a Multi-scale matrix consists of two components organic and Inorganic surrounded by fracture system. The system is assumed to be a quad porosity dual permeability system. The governing equations for gas storage and transport in kerogen and inorganic part of matrix are derived earlier in "Case III". In this case we have two different mass exchange term with different length and time characteristics one is the mass exchange term between organic and Inorganics " $W_{k m}$ " in the matrix and one between inorganics and fractures " $W_{m f}$ ".

$\frac{\emptyset_{f} \partial C_{f}}{\partial t}=\frac{\partial}{\partial x}\left(\emptyset_{f} K_{L} \frac{\partial C_{f}}{\partial x}\right)+\frac{\partial}{\partial x}\left(C_{f} \frac{k_{f}}{\mu} \frac{\partial p_{f}}{\partial x}\right)-W_{m f} \quad$ eq(80)

Macro-dispersion and convection terms in right hand side of mass balance equation in fracture can be expanded as:

$$
\begin{aligned}
& \frac{\partial}{\partial x}\left(\emptyset_{f} K_{L} \frac{\partial C_{f}}{\partial x}\right)=\emptyset_{f} K_{L} \frac{\partial}{\partial x} * \frac{\partial C_{f}}{\partial x}=\emptyset_{f} K_{L} \frac{\partial^{2} C_{f}}{\partial x^{2}} \\
& \frac{\partial}{\partial x}\left(C_{f} \frac{k_{f}}{\mu} \frac{\partial p_{f}}{\partial x}\right)=\frac{k_{f}}{\mu}\left[C_{f} * \frac{\partial}{\partial x}\left(\frac{\partial p_{f}}{\partial x}\right)+\frac{\partial p_{f}}{\partial x} * \frac{\partial C_{f}}{\partial x}\right] \\
& \frac{\emptyset_{f} \partial C_{f}}{\partial t}=\emptyset_{f} K_{L} \frac{\partial^{2} C_{f}}{\partial x^{2}}+\frac{k_{f}}{\mu}\left[C_{f} * \frac{\partial}{\partial x}\left(\frac{\partial p_{f}}{\partial x}\right)+\frac{\partial p_{f}}{\partial x} * \frac{\partial C_{f}}{\partial x}\right]-W_{m f}
\end{aligned}
$$

Assuming real gas compressibility equation of state:

$P={ }_{z} C R T$

We have: 


$$
\begin{aligned}
& \frac{\emptyset_{f} \partial C_{f}}{\partial t}=\emptyset_{f} K_{L} \frac{\partial^{2} C_{f}}{\partial x^{2}}+\frac{k_{f}}{\mu}\left[C_{f} * \frac{\partial}{\partial x}\left(z R T \frac{\partial C_{f}}{\partial x}\right)+z R T \frac{\partial C_{f}}{\partial x} * \frac{\partial C_{f}}{\partial x}\right]-W_{m f} \\
& \frac{\emptyset_{f} \partial C_{f}}{\partial t}=\emptyset_{f} K_{L} \frac{\partial^{2} C_{f}}{\partial x^{2}}+\frac{k_{f}}{\mu}\left[C_{f} * \frac{\partial}{\partial x}\left(z R T \frac{\partial C_{f}}{\partial x}\right)+z R T *\left(\frac{\partial C_{f}}{\partial x}\right)^{2}\right]-W_{m f} \\
& \frac{\emptyset_{f} \partial C_{f}}{\partial t}=\emptyset_{f} K_{L} \frac{\partial}{\partial x} * \frac{\partial C_{f}}{\partial x}+\frac{k_{f}}{\mu}\left[C_{f} * \frac{\partial}{\partial x}\left(z R T \frac{\partial C_{f}}{\partial x}\right)+z R T *\left(\frac{\partial C_{f}}{\partial x}\right)^{2}\right]-W_{m f}
\end{aligned}
$$

$W_{m f}$ is the coupling term which is a function of shape factor, transport in Inorganics and the difference between free gas concentrations in inorganic matrix and fracture at the interface as shown in the equation below.

$W_{m f}=\tau_{f} \Psi\left(C_{f}-C\right) \quad \mathrm{eq}(81)$

Transport in inorganic pores are characterized by convection "Darcy flow"

$\Psi=Z R T \frac{k}{\mu} \emptyset_{I} * C$

Thus

$W_{m f}=\tau_{f}\left(Z R T \frac{k}{\mu} \emptyset_{I} * C\right)\left(C_{f}-C\right) \quad$ eq $(82)$

So the final equation for gas transport in fracture can be written as:

$$
\frac{\emptyset_{f} \partial C_{f}}{\partial t}=\emptyset_{f} K_{L} \frac{\partial}{\partial x} * \frac{\partial C_{f}}{\partial x}+\frac{k_{f}}{\mu}\left[C_{f} * \frac{\partial}{\partial x}\left(z R T \frac{\partial C_{f}}{\partial x}\right)+z R T *\left(\frac{\partial C_{f}}{\partial x}\right)^{2}\right]-\tau_{f}\left(Z R T \frac{k}{\mu} \emptyset_{I} * C\right)\left(C_{f}-C\right)
$$

Where $\emptyset_{f}$ is the fracture porosity which assumed to be constant. $C$ and $C_{f}$ are free gas concentrations in inorganic and fracture respectively. $K_{L}$ is the fracture dispersion coefficient. $k_{f}$ is the fracture permeability. $\mu$ is the gas viscosity. $\tau_{f}$ is the fracture shape factor. 


\section{6: Sensitivity Analysis}

In order to fully understand the impact of each parameter on gas transport and storage in multicontinuum shale gas reservoir sensitivity analysis based on one variable at a time is performed on all four different cases that have been discussed earlier to see the importance of including more physics to the problem versus simpler models with some averaged characteristics. List of parameters and their range of variability is presented in Table (4).

\begin{tabular}{|l|c|c|c|}
\hline \multicolumn{1}{|c|}{ Parameter } & Maximum value & Minimum value & Unit \\
\hline Poisson ratio for kerogem & 0.39 & 0.2 & dimensionless \\
\hline Initial porosity & 0.05 & 0.02 & Fraction \\
\hline Matrix bulk permeability & 100 & 1 & $\mathrm{nd}$ \\
\hline Surface diffusion coefficient & $5^{\wedge}-7$ & $5^{\wedge}-10$ & $\mathrm{~cm} 2 / \mathrm{s}$ \\
\hline Matrix pore diffusion coefficient & $5^{\wedge}-5$ & $5^{\wedge}-8$ & $\mathrm{~cm} 2 / \mathrm{s}$ \\
\hline Kerogen pore diffusion coefficient & $5^{\wedge}-6$ & $5^{\wedge}-8$ & $\mathrm{~cm} 2 / \mathrm{s}$ \\
\hline Fracture porosity & 0.01 & 0.005 & $\mathrm{fraction}$ \\
\hline Fracture permeability & 1000 & 10 & $\mu \mathrm{d}$ \\
\hline Inorganic poisson ratio & 0.4 & 0.166 & dimensionless \\
\hline Inorganic young modulus & 10 & 1.4 & $\mathrm{Gpa}$ \\
\hline Matrix shape factor & 0.8 & 0.5 & $\mathrm{vol} / \mathrm{vol} \%$ \\
\hline $\begin{array}{l}\text { kerogen pore volume per total matrix } \\
\text { pore volume }\end{array}$ & 0.67 & 0.43 & \\
\hline
\end{tabular}

Table 4the sensitivity analysis table 


\section{CHAPTER: 4: RUSELTS AND CONCLUSION}

\section{1: Results and Discussion}

Gas transport and sorption in organic rich shale is investigated using multi-scale multi-continuum approach under poroelastic effect of shale matrix. Pore and rock compressibility effects have been investigated using ultimate gas recovery predictions. For the purpose four different cases are investigated in a progressive manner. First case has been defined in which the shale matrix is seen as dual porosity system with initial porosity to store free gas and Langmuir-Henry dual-model isotherm to describe equilibrium sorption dynamics. As discussed earlier modified Palmer and Mansoori's model (1998) is used to investigate poroelastic effect on ultimate gas recovery from shale matrix. In the second case we add a fracture to the dual porosity system which is described in the first case. Also modified palmer and Mansoori equation (1998) is used to study the poroelastic effect on the gas recovery .Free gas is stored with initial porosity of the matrix and dual Langmuir-Henry isotherm is used to describe the equilibrium sorption dynamics. In third case shale matrix has divided in to two parts organic or Kerogen material and inorganic materials. Organic pore compressibility is described using Palmer and Mansoori modified equation while inorganic pore compressibility is described following Fjaer et al. (1992), Raaen(1993) and Zimmerman(2000) under uniaxial strain conditions. In fourth case we add a fracture to the system we described previously in the third case. Same pore compressibility equations for organic material and inorganic matrix are used to study the effect of the pore elasticity on the ultimate recovery from the shale matrix when retardation in pressure decline added due to mass exchange between matrix inorganic and fracture. In this study typical range of Poisson ratio and Young Modulus for organic and inorganic materials are used. The basic parameters, initial and boundary conditions for all four cases are shown in Table 1, Table 2 and Table 3.

\section{Case 1: Matrix only}

In this case equations (37) derived earlier is used with boundary condition defined in Table 2 with base parameters presented in Table 3 is used. Fractional recovery curve is used to quantify the impact of different parameters. For the purpose governing equations are solved numerically using time implicit finite difference approach based on Newton method using MATLAB. Figure 17shows the simulation result of fractional gas recovery from shale half matrix length described earlier. 


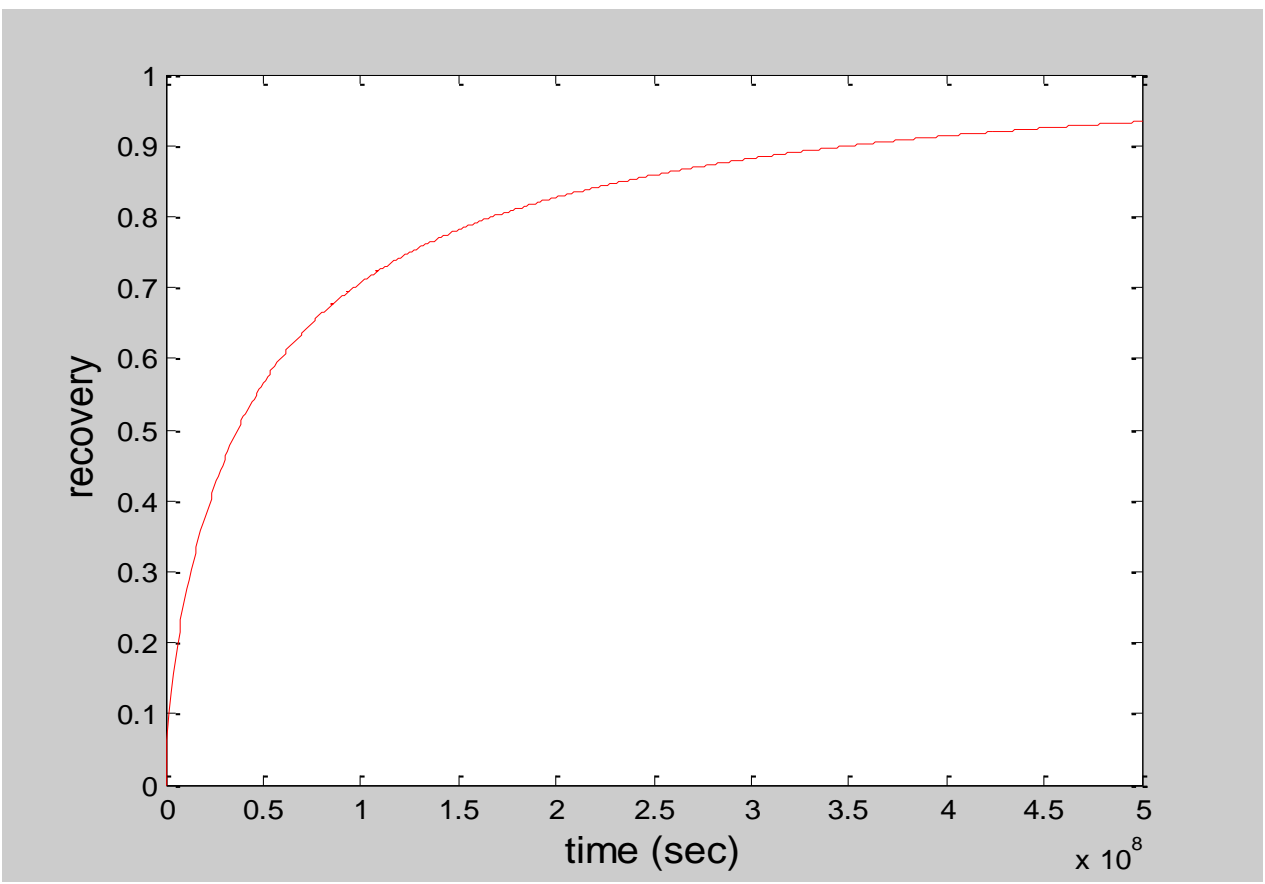

Figure 17 the ultimate gas recovery from the shale matrix for the base case $a_{1} \neq 0, a_{3} \neq 0$

In order to investigate the effect of pore compressibility of the shale matrix on the ultimate recovery of the gas, Poisson ratio is varied between minimum and maximum value (as shown in Table 4).Figure 18clearly shows that Poisson ratio can impact the ultimate gas recovery. Three different time scale for this effect can be observed from this plot at early time effect is negligible then starts kicking in at mid time and alleviates at late time. This due to nonlinear relation of compressibility with rock properties and pressure when pore pressure is high effect as minimal and when we are almost at depletion with low pore pressure again effect decreases. Also we can see that increasing Poisson ratio leads to decrease in ultimate recovery that makes sense since increasing Poisson ratio can be assigned to less axial strain therefore less compaction drive for primary production. This relation can be shown as follow:

$$
\frac{1}{\beta}=K=\frac{E}{3(1-2 v)} \quad \mathrm{eq}(84)
$$




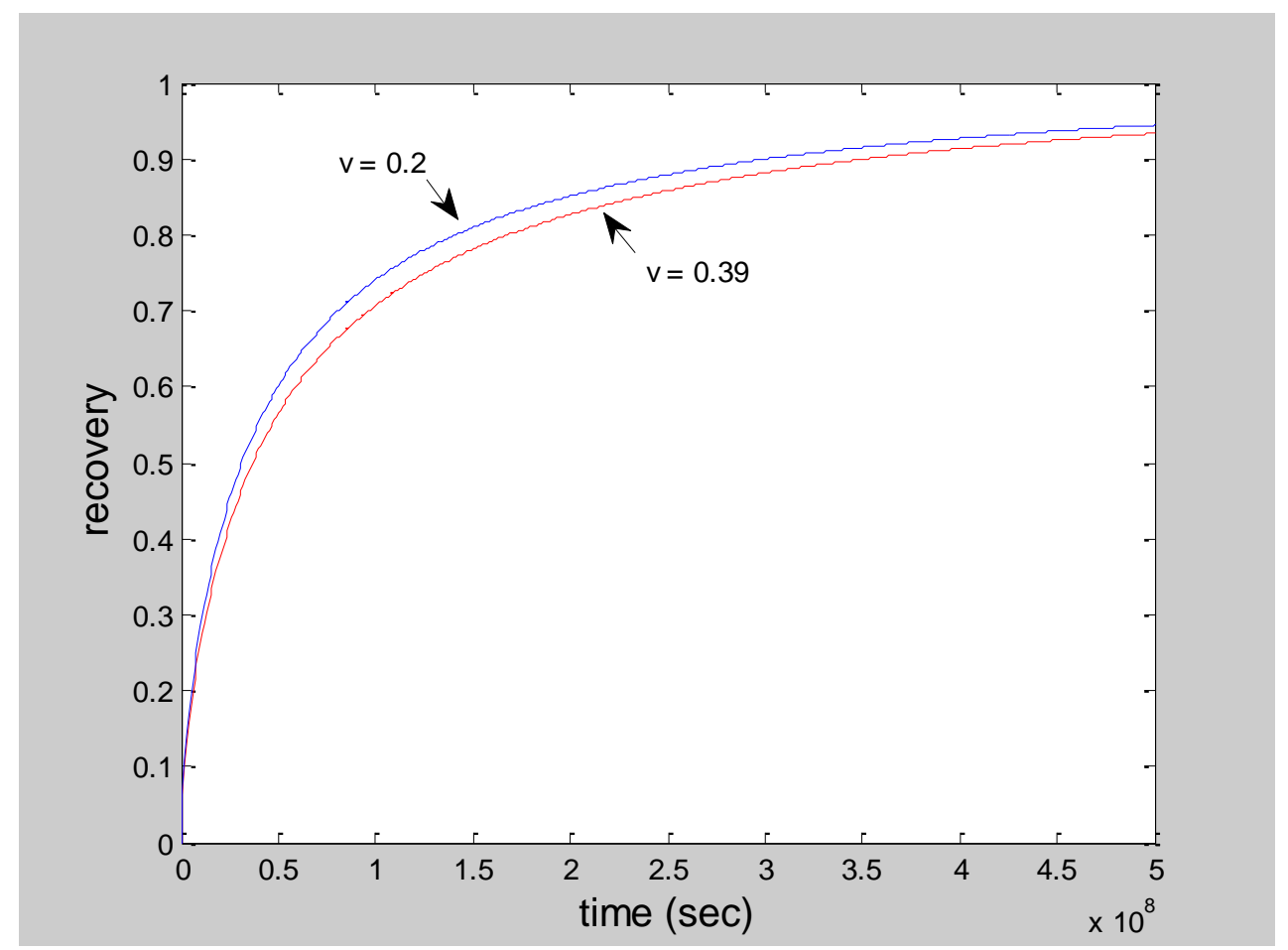

Figure 18the effect of varying Poisson ratio on the ultimate recovery $a 1 \neq 0, a 3 \neq 0$

Reduction in Poisson ratio also leads to increase in porosity and through cubic equation increase in permeability therefore increase in ultimate recovery. Figure 19 shows change in porosity and permeability as a function of Poisson ratio at different pore pressure.
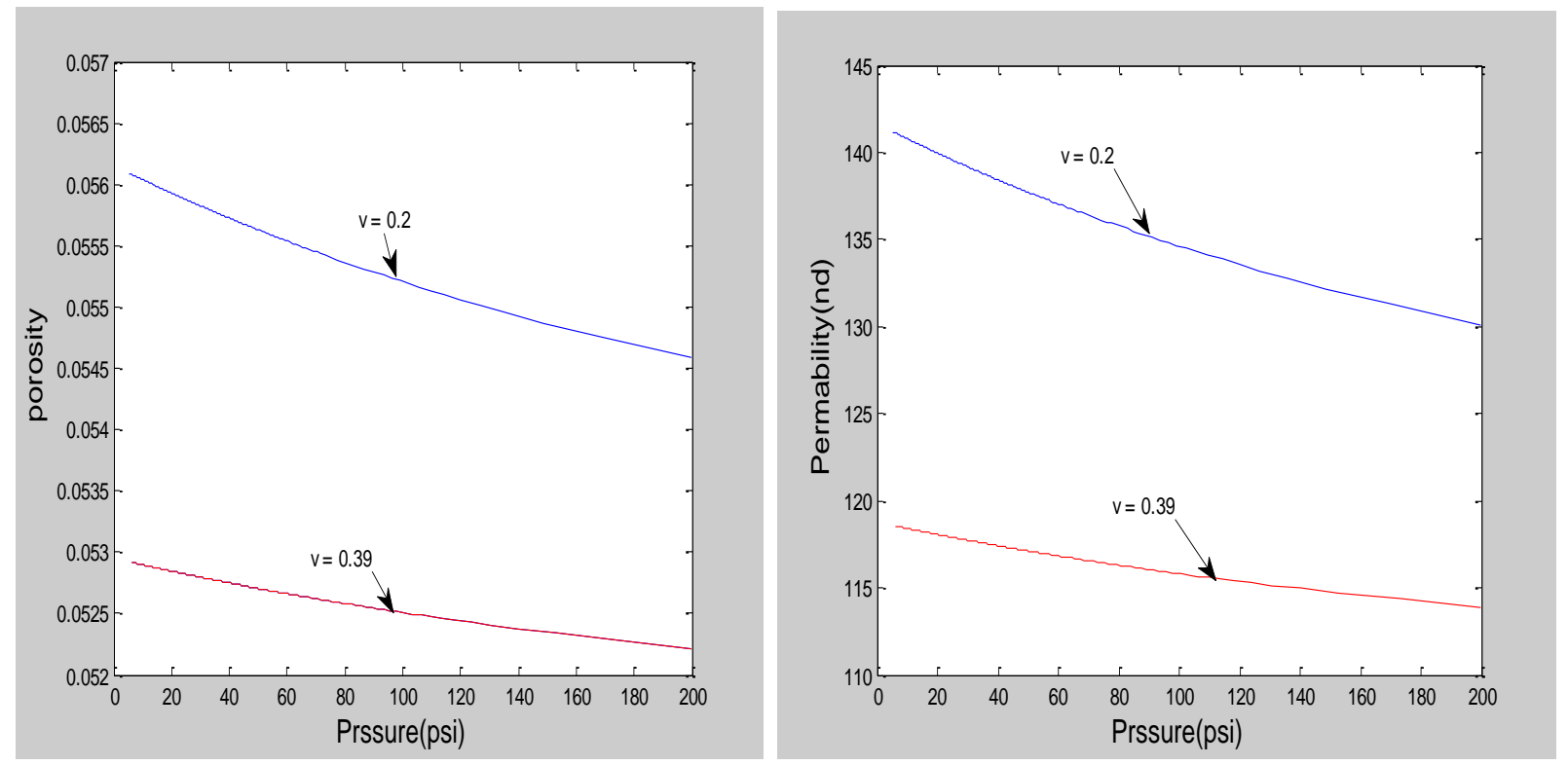

Figure 19(right) shows the effect of varying Poisson ratio on the matrix porosity; ( left) shows the effect of varying Poisson ratio on the matrix permeability 
Pore compressibility according to the Palmer and Mansoori (1998) modified model consist of three components pore compression, shrinkage and swelling due to dissolution and adsorption/desorption as we explained earlier. Thus, in order to investigate which one of these components has the most contribution in pore compressibility we study the impact of each one of them separately.

Assuming all rock mechanical properties are fixed the effect of different components of pore compressibility can be studied following Palmer and Mansoori equation (50). First, the effect of the macro-pore compression $a_{1}$ on the ultimate recovery from the shale matrix is investigated assuming the rest of parameters are constant. The investigation is done by having or dropping the term from equation (50). Figure 20, clearly shows that assuming constant rock properties pore compressibility has no effect through Palmer and Mansoori equation(50) on ultimate gas recovery for numerical domain of "Case I" as presented in Table 3.

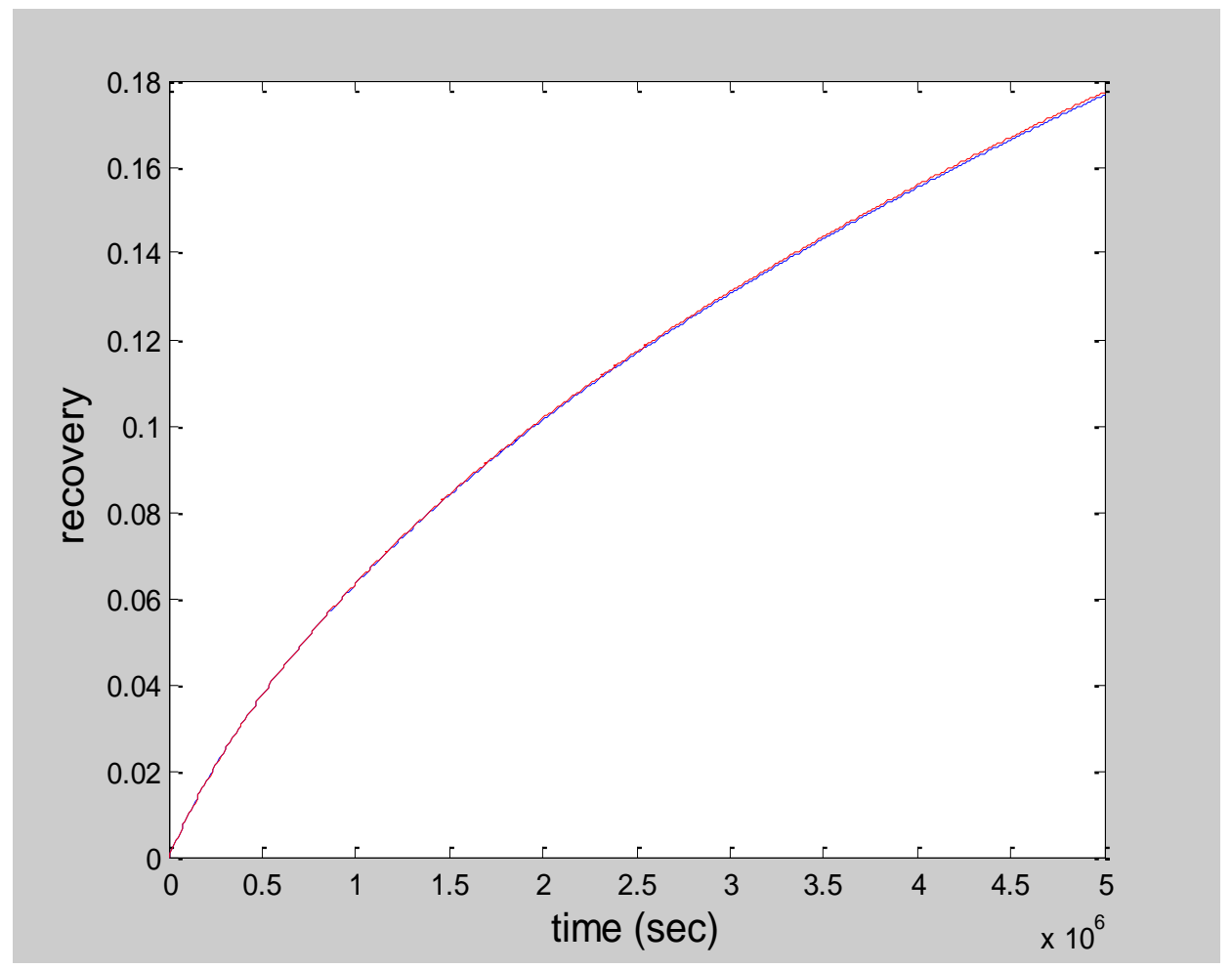

Figure 20the effect of pore compression on the ultimate recovery of the gas from the shale matrix ; red) shows the base case recover curve $a 1 \neq 0, a 3 \neq 0$ and the (blue) shows the recovery curve when we neglect the effect of pore compression on the pore compressibility $\mathrm{a}_{1}=0, \mathrm{a}_{3} \neq 0$.

Next, the effect of the adsorption $\mathrm{a}_{3}$ on the pore compressibility is studied. Figure 21 shows that when we include the effect of the adsorption $a_{3}$ in the formula the recovery increases while when we ignore the effect of the adsorption the recovery drops. Gas desorption can introduce extra pore compaction drive that helps to increase the ultimate recovery. Gas desorption also leads to increase in 
porosity by increasing the pore volume and therefore permeability of the system that also is in favor of ultimate recovery as shown in Figure 22.

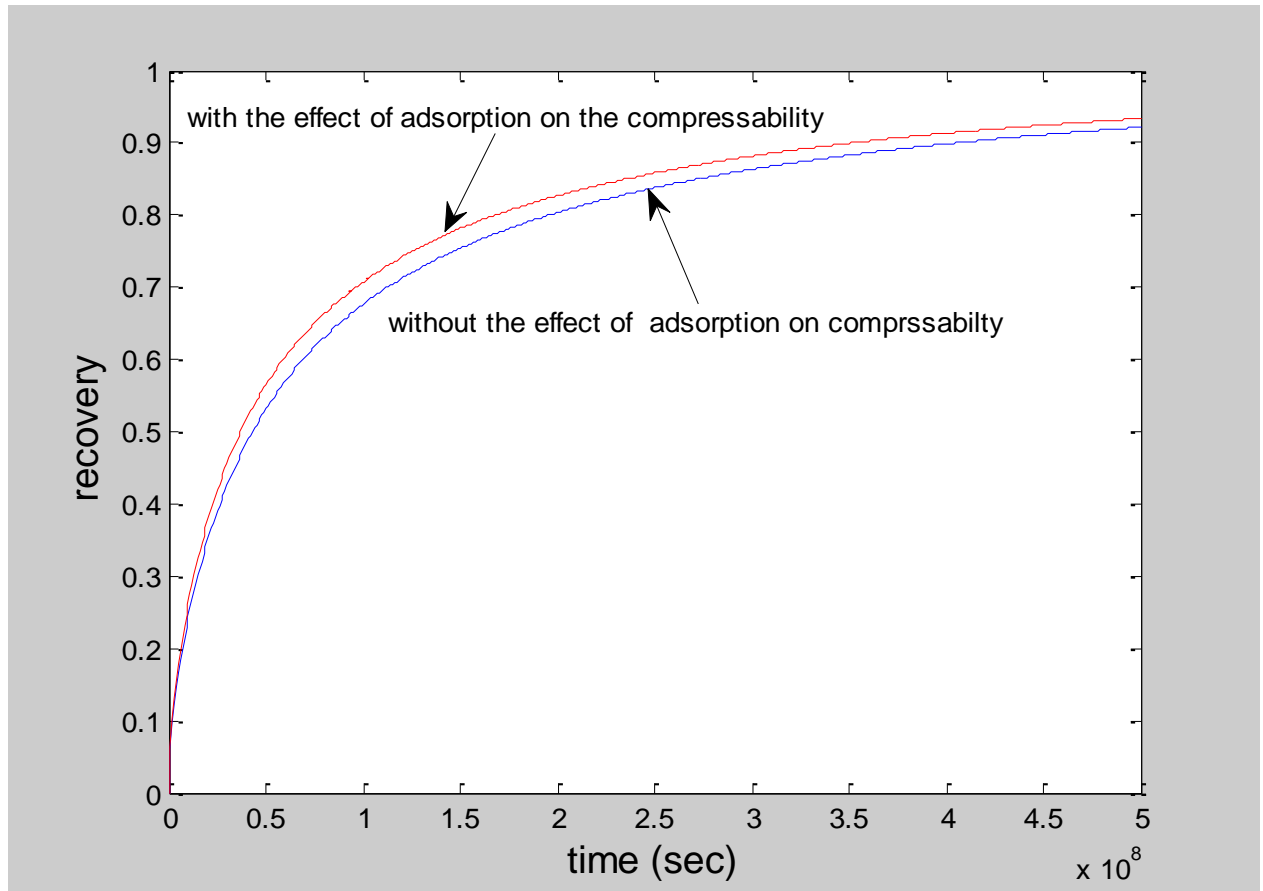

Figure 21 effect of pore compression on the ultimate recovery of the gas from the shale matrix ;(red) shows the base case recover curve $a 1 \neq 0, a 3 \neq 0$ and the (blue) shows the recovery curve when we neglect the effect of adsorption on the pore compressibility $a 1 \neq 0, a_{3}=0$.
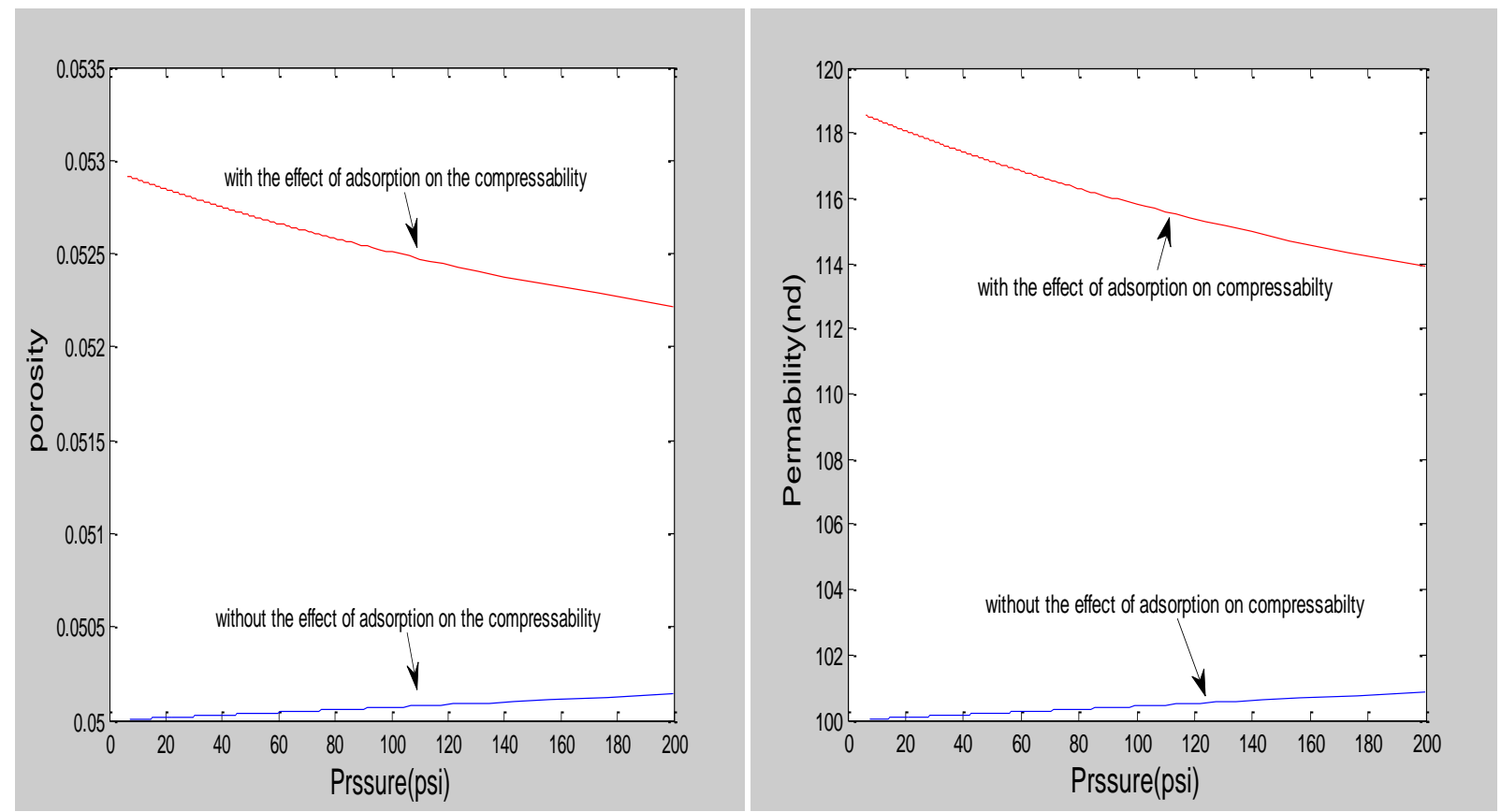

Figure 22shows the porosity with and without the effect of adsorption on the pore compressibility and the ;( left) shows the permeability with and without the effect of adsorption on the pore compressibility 
Matrix shrinkage and swelling effect $\mathrm{a}_{3}$ on pore compressibility is ignored in this studies since total organic content of shale gas reservoir are very low less than $10 \%$ in compare to coalbed methane reservoirs.

\section{Case 2: Matrix and Fracture}

As we mention earlier in second case we added fracture system to the dual porosity model described in first case. Base case simulation results for set of parameters describe in Table 3leads to ultimate recovery that is less than case one for the same period of production as shown in Figure 23 ultimate recovery of $90 \%$ against $94 \%$ recovery. This is due to the fact that adding fracture system introduces additional resistance to flow through mass exchange term. On the other hand, fracture volume is insignificant that cannot significant additional storage volume for gas to be added to recovery. Thus, increasing fracture volume as shown in Figure 24 increases the gas recovery. However, if we change the shape factor only and keep all the other parameters we notice there is no effect on the recovery.

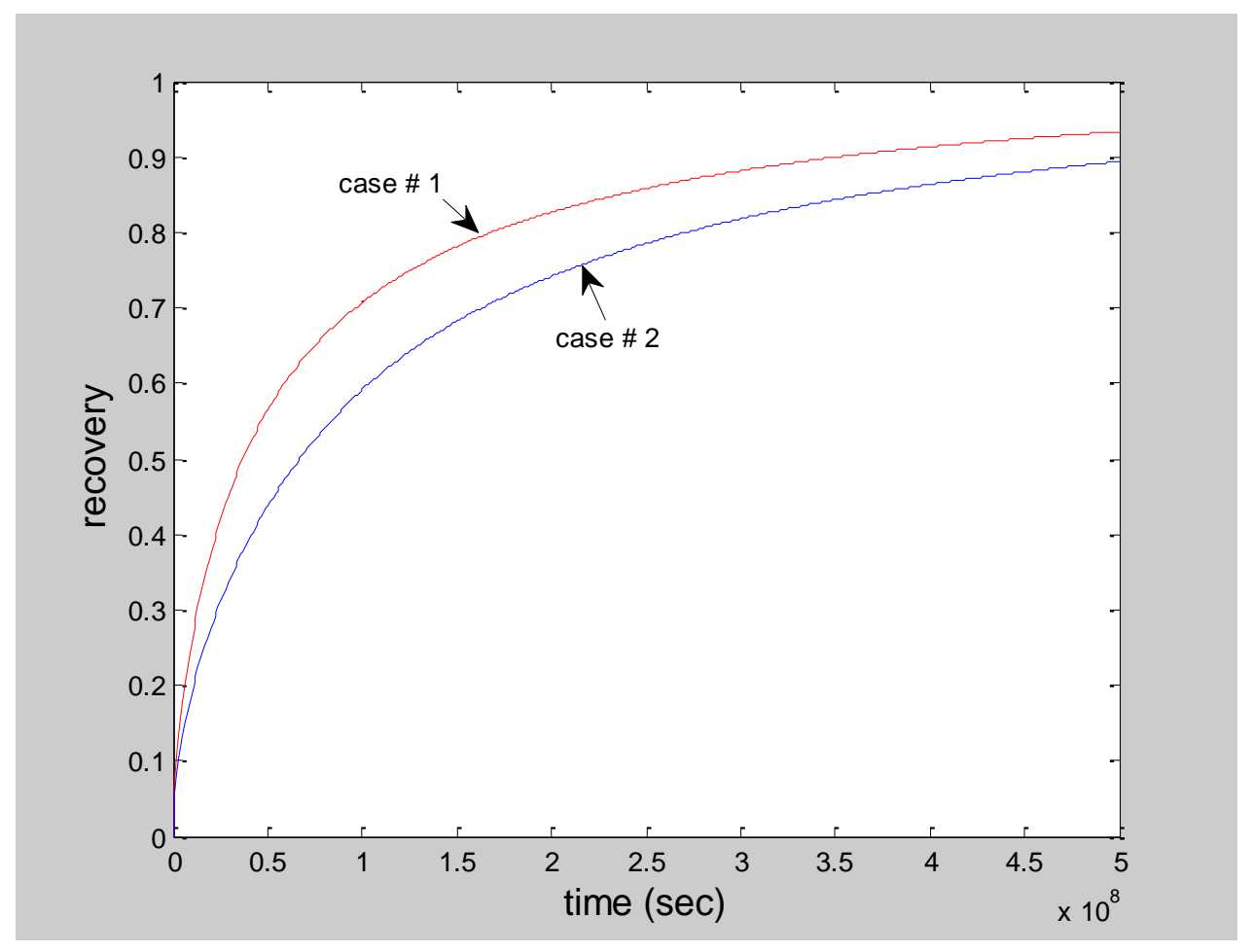

Figure 23 comparison between the ultimate gas recovery from the shale matrix for the base case 1 and 2 al $\neq 0, a 3 \neq 0$ 


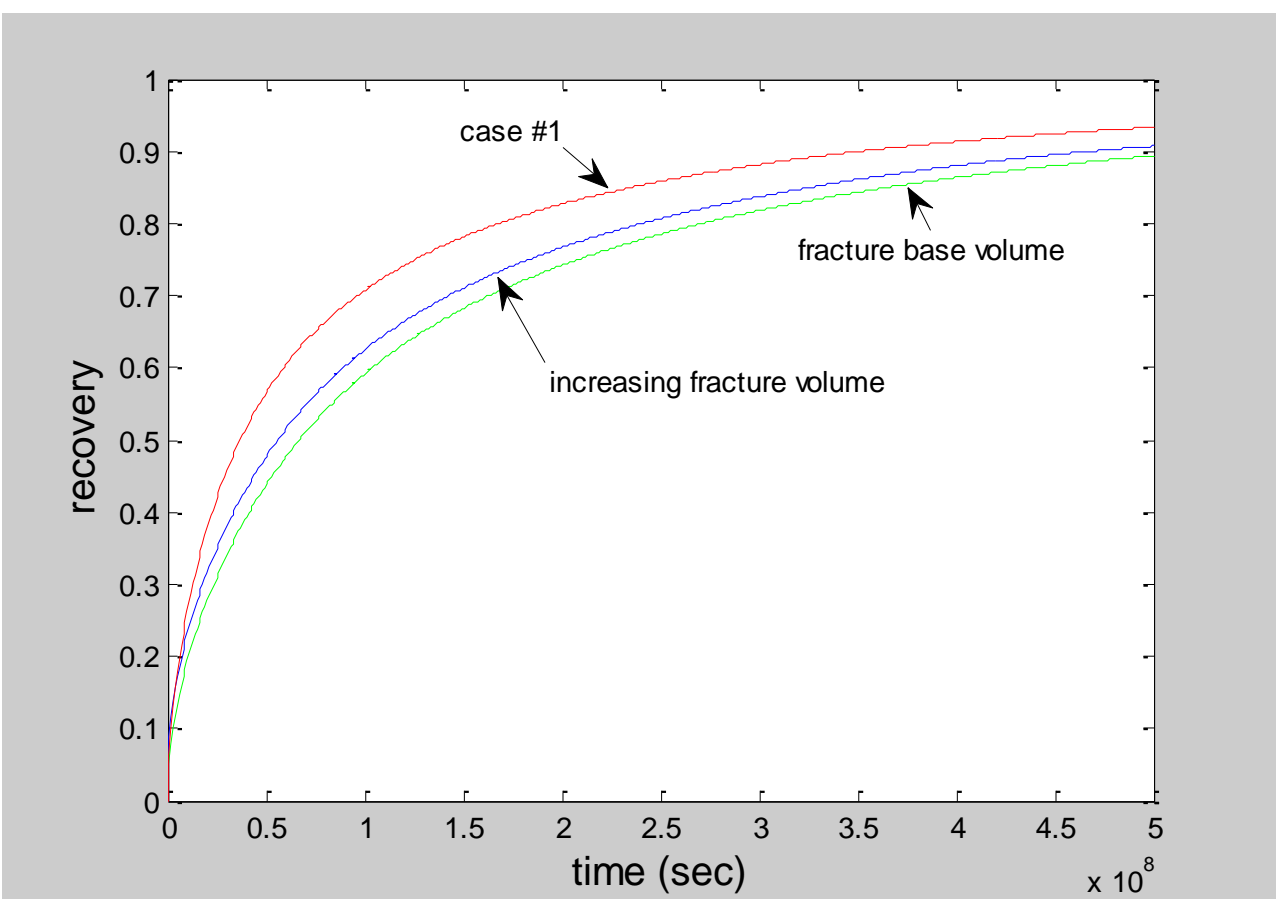

Figure 24 the effect of increasing fracture volume for case \# 2 on the fractional gas recovery

Similar approach as discussed in case model 1 is used here too. Effect of rock poroelastic properties of through changing Poisson ratio between minimum and maximum value is studied first. simulation results are presented in Figure 25. Figure 25shows similar results as Figure 18 however the effect is somehow pronounced due to presence of fractures volumes that introduce more free space to the system even though the fracture compressibility is assumed to be constant. Similar discussion as Figure 18is valid here. Similar discussions as Figure 19are also valid in Figure 26where decrease in Poisson ratio leads to increase in porosity and therefore permeability of the system. 


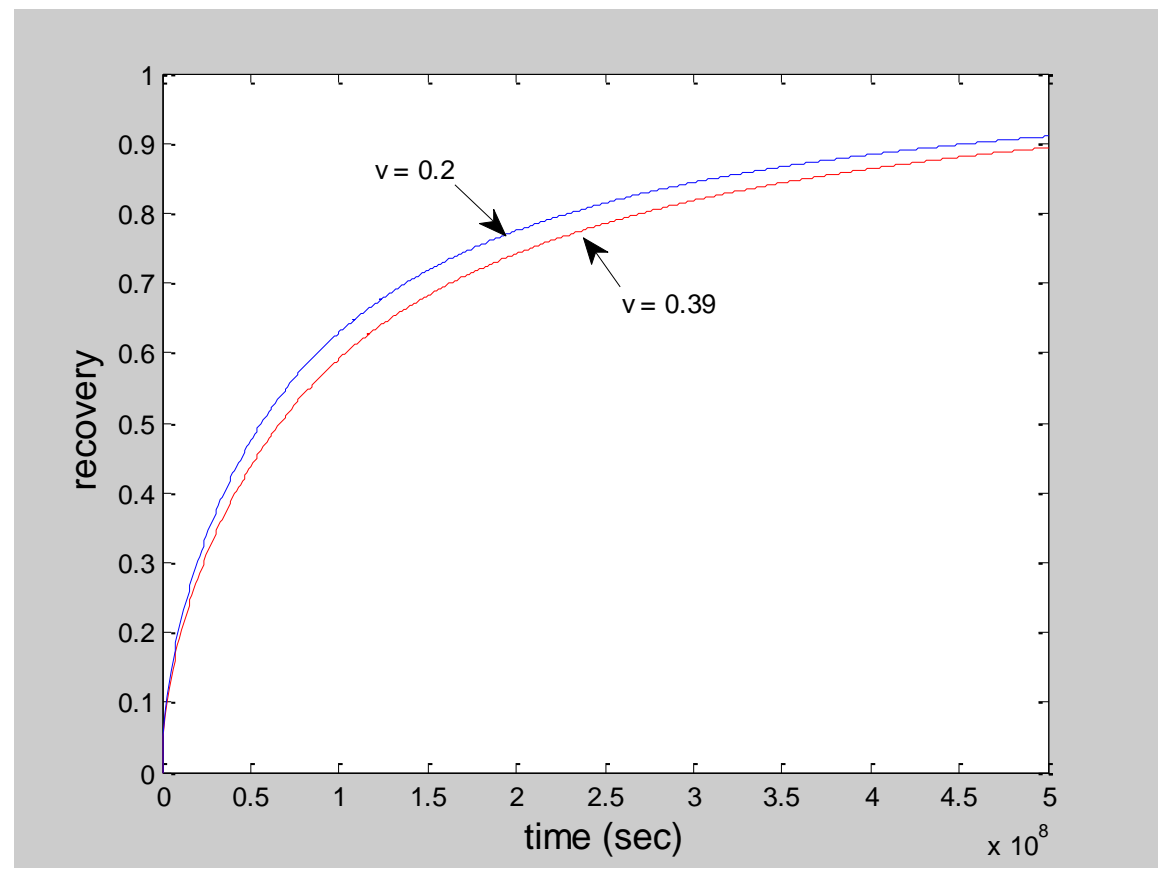

Figure 25Case \#2: the effect of varying Poisson ratio on the gas ultimate recovery a $1 \neq 0, a 3 \neq 0$
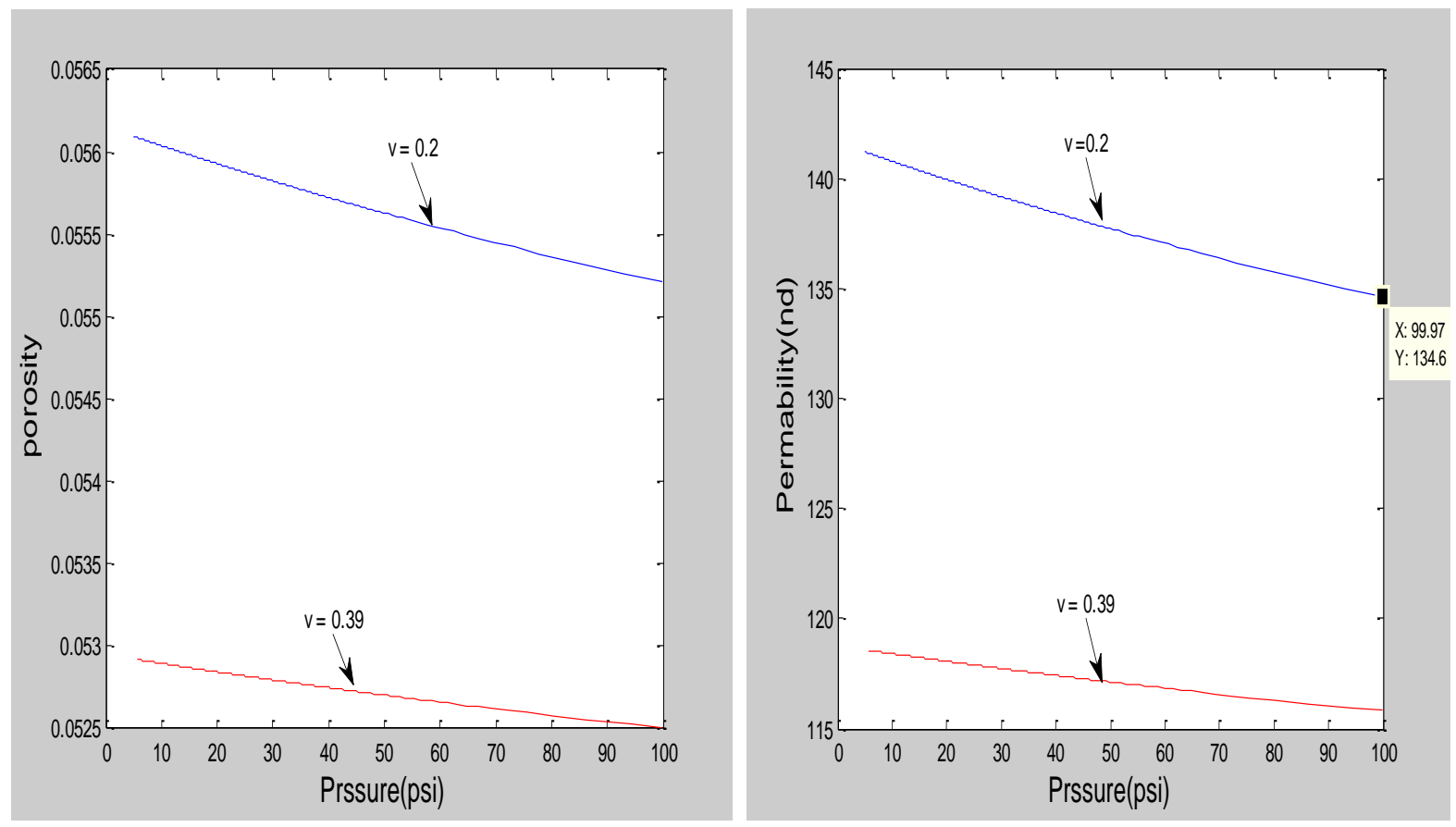

Figure 26shows the effect of varying Poisson ratio on the matrix porosity ; left) shows the effect of varying Poisson ratio on the matrix permeability

Similar discussion for pore compressibility and adsorption effect through Palmer and Mansoori equation is also valid here as shown in Figure 27. 


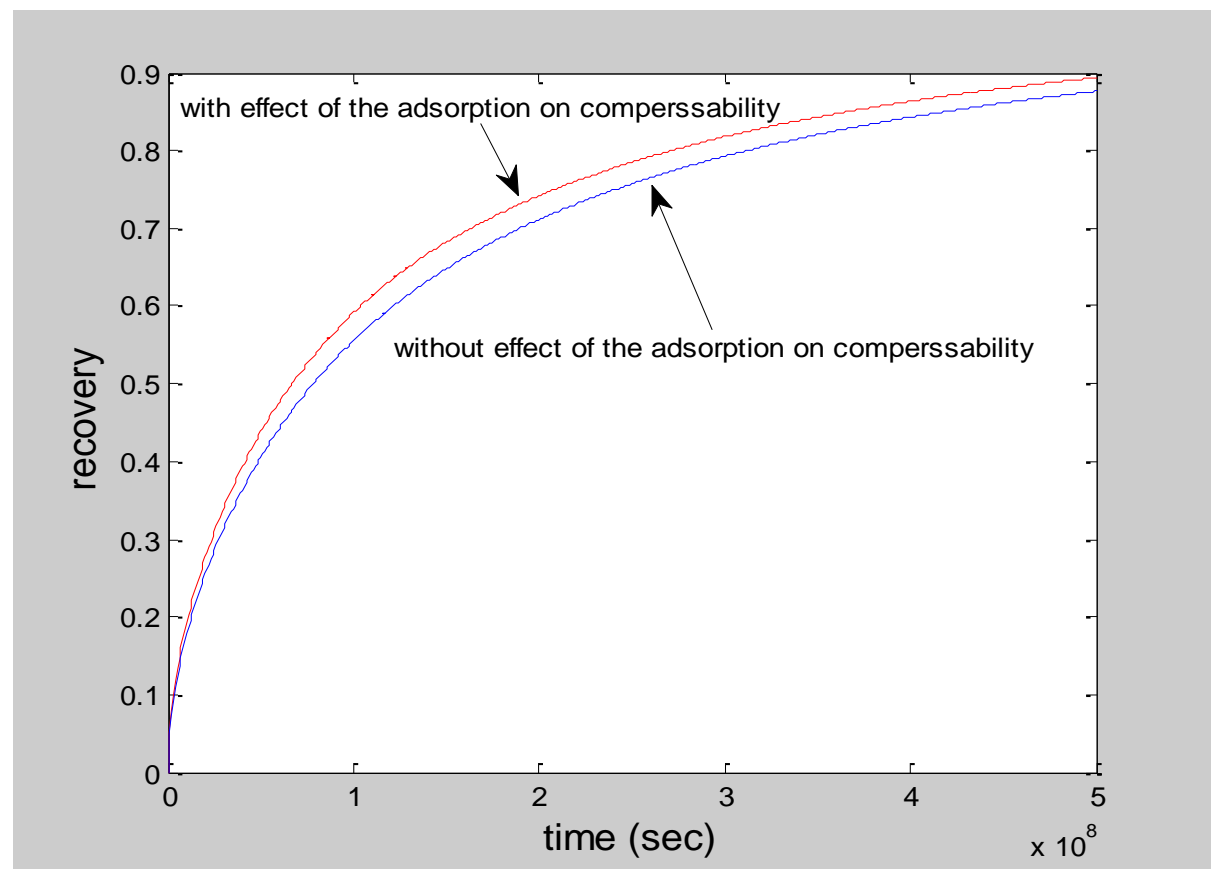

Figure 27 case \#2: the effect of pore compression on the ultimate recovery of the gas from the shale matrix ; (red) shows the base case recover curve $a 1 \neq 0, a 3 \neq 0$ and the (blue) shows the recovery curve when we neglect the effect of adsorption on the pore compressibility

\section{Case 3: Triple porosity Matrix system}

In this case, shale matrix has been divided into two parts organic and inorganic. This case is different than previous two cases in which here two different sets of equations are governing pore compressibility of organic and inorganic materials. Running case III for base case parameters introduced in Table 3 we clearly see that recovery has been dropped significantly from $94 \%$ to $75 \%$ for the same period of production as shown in Figure 29 and Figure 28. This is due to extra resistance applied here due to presence of organic materials. Since here organic materials are the main source of gas and transport in organics are governed by diffusion that is a very slow process in compare to convection we have introduced earlier in case I and II. Thus whole process is controlled by slowest transport mechanism that is diffusion. Effect of Poisson ratio on ultimate recovery and porosity and permeability follows the same trend as discussed earlier for Case I and II considering Palmer and Mansoori effect on organic matters. Also, the pore compressibility and adsorption effect through Palmer and Mansoori equation have the same behavior for Case I and II; therefore; the similar discussion for is also valid here. However, here study is extended to pore compressibility effect of inorganic materials described by equation (75) following Fjaer et al. (1992), Raaen(1993) and Zimmerman(2000). 


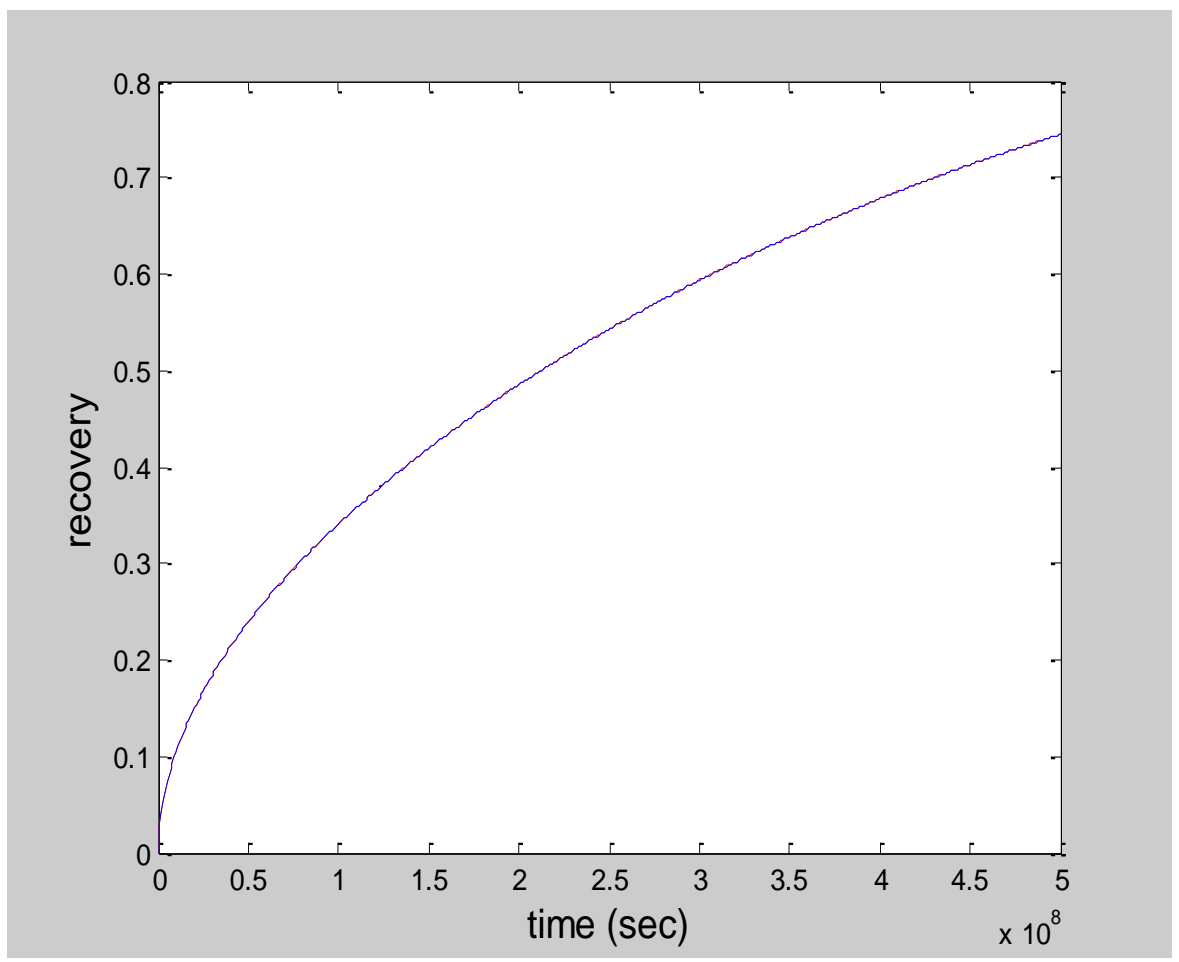

Figure 28 the ultimate gas recovery from the shale matrix for the base case $a 1 \neq 0, a 3 \neq 0$

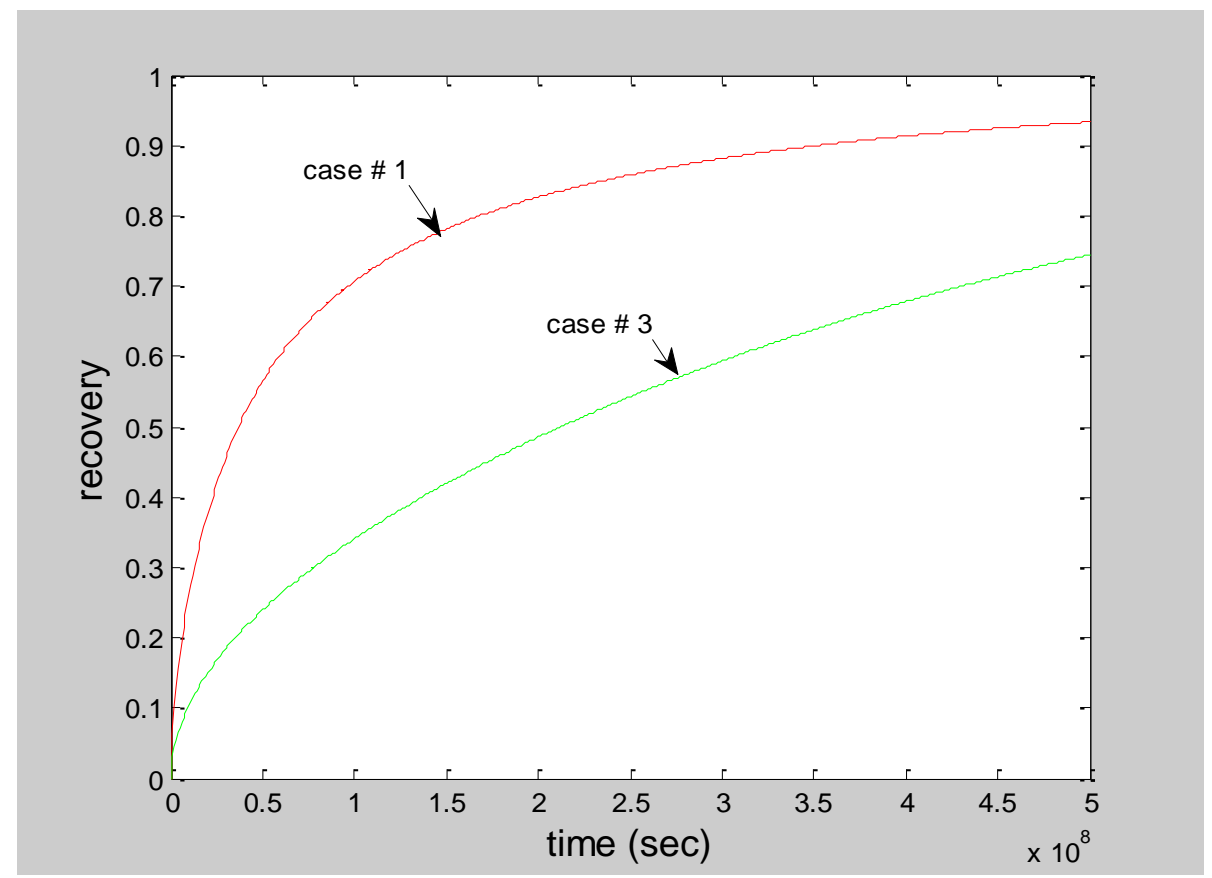

Figure 29 comparison between the ultimate gas recovery from the shale matrix for the base case 1 and 3 al $\neq 0, a 3 \neq 0$

For the purpose sensitivity analysis on Poisson ratio of inorganic matrix is performed using maximum and minimum values presented in Table 4. Figure 30shows the effect of Poisson ratio in 
inorganic materials while all other rock properties kept constant is negligible. This observation for set of base case parameters defined in Table 3 follows the logic since inorganic materials are less deformable in compare to organic materials therefore their impacts on contraction drive energy is minimal leading to no significant impact on recovery. Change in Poisson ratio of inorganic material has limited impact on inorganic porosity and therefore permeability as shown Figure 31.

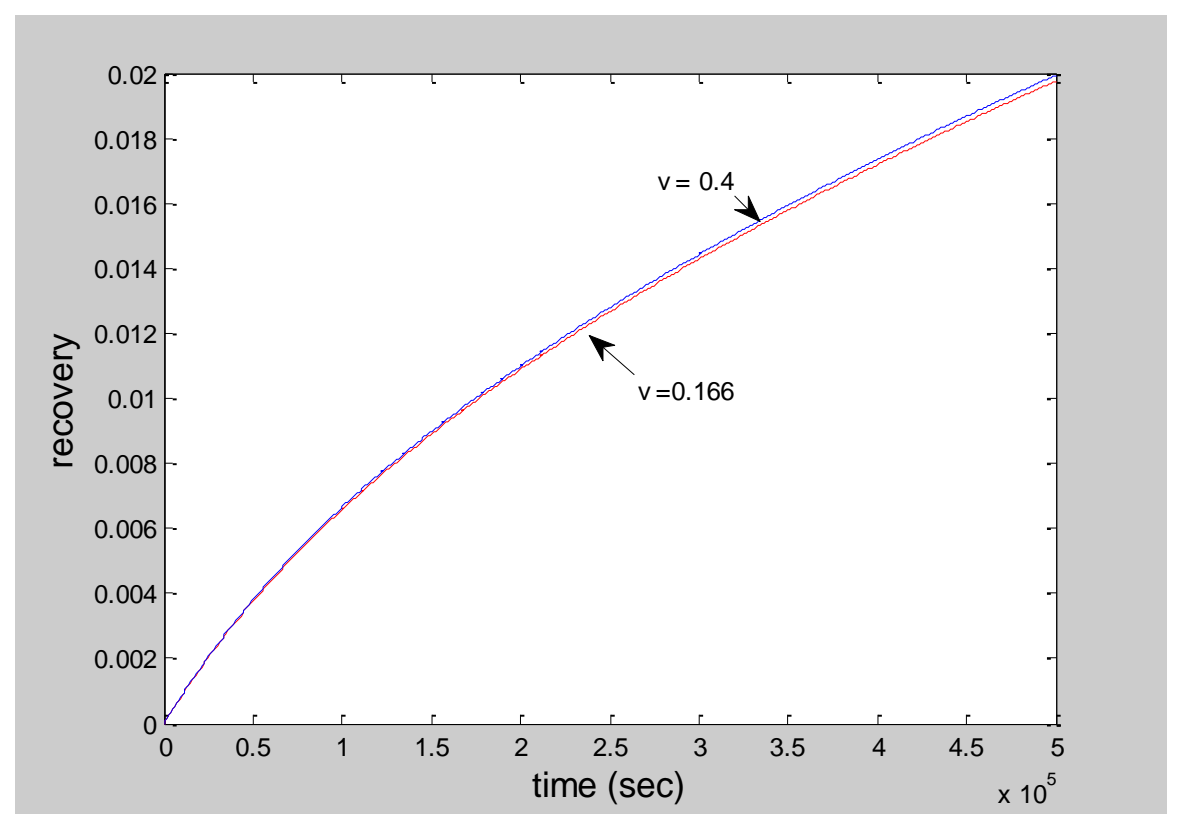

Figure 30Case \#3 the effect of varying inorganic Poisson ratio on the gas ultimate recovery a $1 \neq 0, a 3 \neq 0$

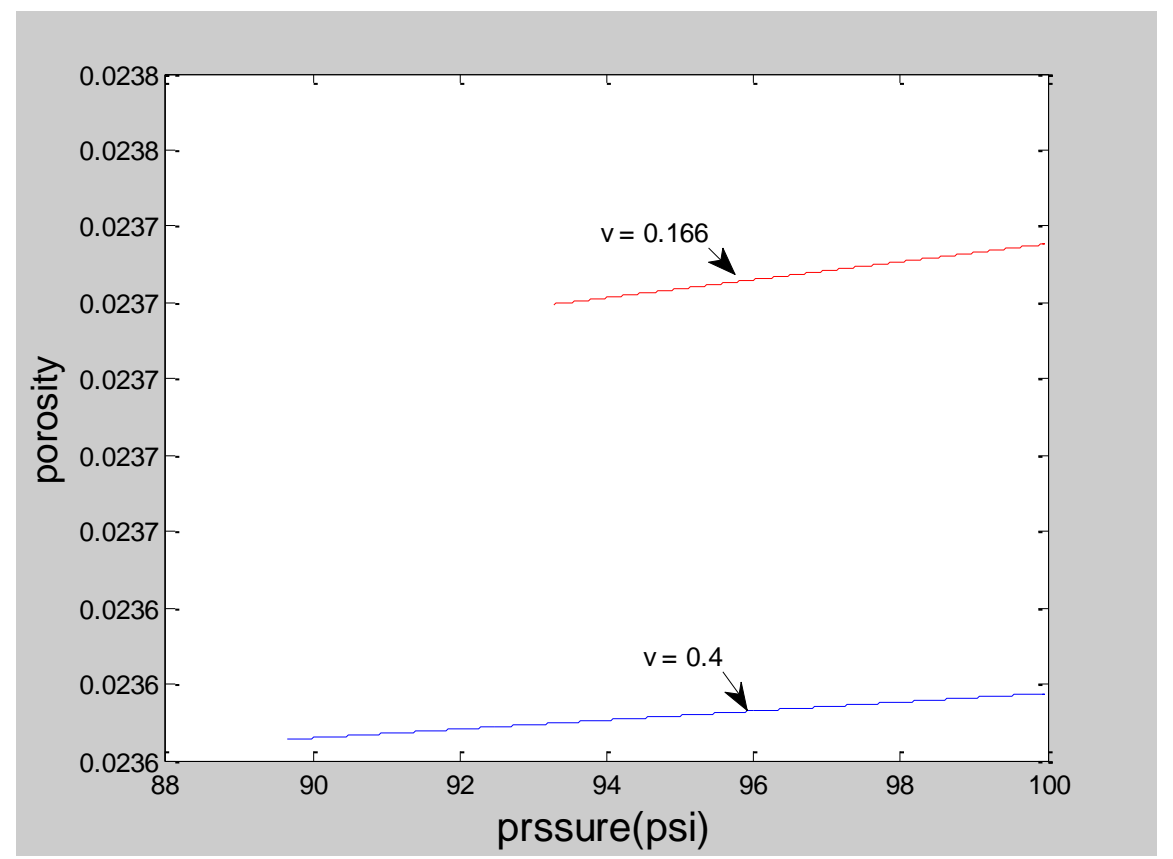

Figure 31the effect of varying inorganic Poisson ratio on the inorganic matrix porosity 
In case of inorganic materials we also have looked over the impact of Young Modulus on ultimate recovery but that apparently has minimum effect on ultimate recovery as shown in Figure 32.

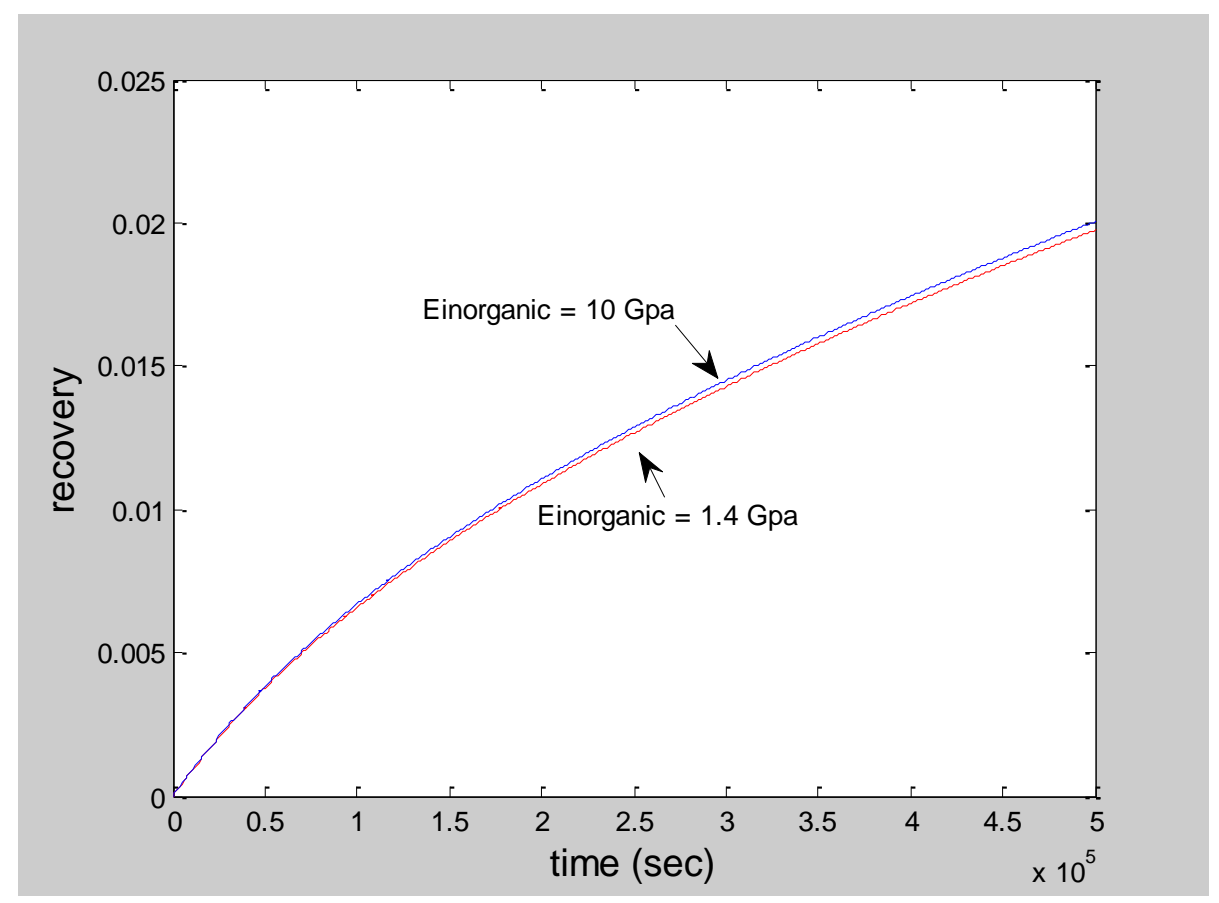

Figure 32the impact of varying inorganic young modulus on the gas ultimate recovery

Figure 33 basically just confirms our previous observation in Figure 30that the overlall compressibility effect on production is mainly controlled by organic compressibility. This is an important observation since most of the uni- or tri-axial experiments are performed on shale core samples are not providing mechanical properties of organics but, they are mainly reflecting the inorganic mechanical properties therefore the effect of pore compressibility on gas transport and storage mechanism is underestimated. For more precise prediction of poroelastic effect on shale gas transport and storage more detailed experimental techniques such as nano-indentation test is required to obtain reliable mechanical properties of shale organic materials. 


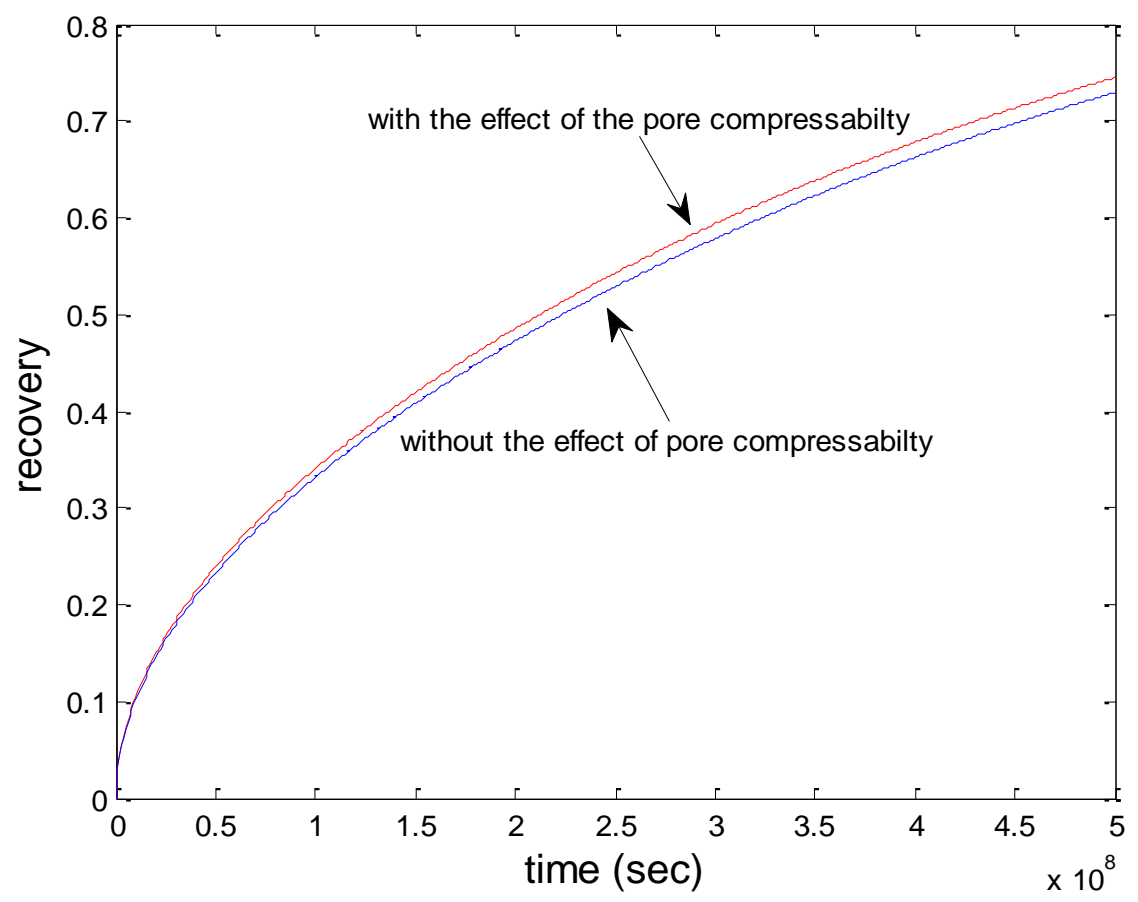

Figure 33 comparison between the ultimate gas recovery with and without the pore compressibility effect ; ( red) show the recovery with the pore compressibility $a 1 \neq 0, a 3 \neq 0$ and (blue) shows the recovery without pore compressibility effect a $1=0, a 3=0$

\section{Case 4: quad porosity dual permeability shale model}

In this case, fracture system is added to triple-porosity system in Case III. Fractional gas recovery from half-length shale matrix is shown in Figure 34. In contrast to case II where adding the fracture system slows down the production due to extra resistance to flow through mass exchange term here comparing Figure 28 and Figure 34 no significant change has been observed. This is due to the fact that in this model unlike model I the slowest transport mechanism that controls the whole flow is diffusive transport in organic materials therefore resistance in mass exchange between matrix and fracture cannot impact ultimate recovery. 


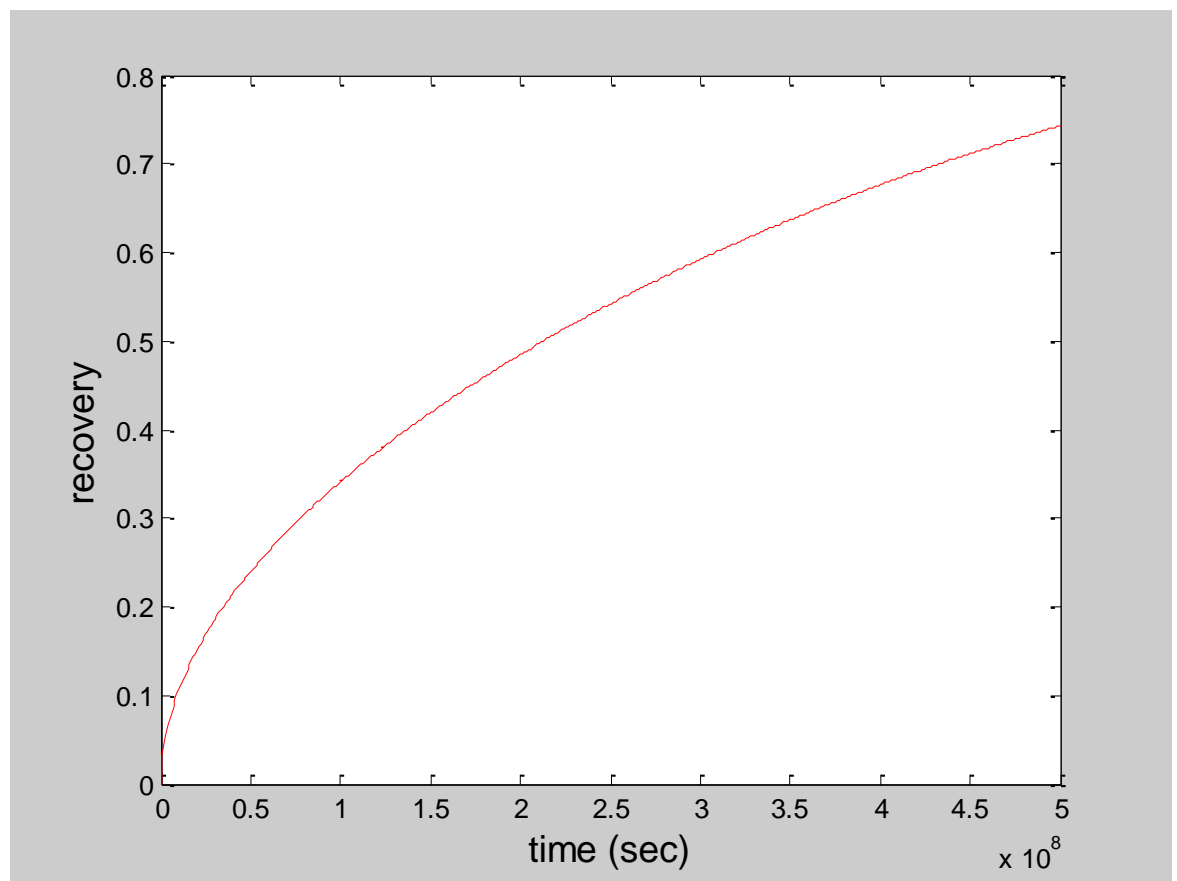

Figure 34the ultimate gas recovery from the shale matrix for the base case $a 1 \neq 0, a 3 \neq 0$

Similar discussion for inverse relation of Poisson ratio and ultimate recovery due to increasing compaction drive force is also valid here as shown in Figure 35and presence of fracture system has no positive or negative effect in this regard. Effect of organic rock properties on organic porosity in compare to effect of inorganic rock properties is more pronounced comparing Figure 31and Figure 36.

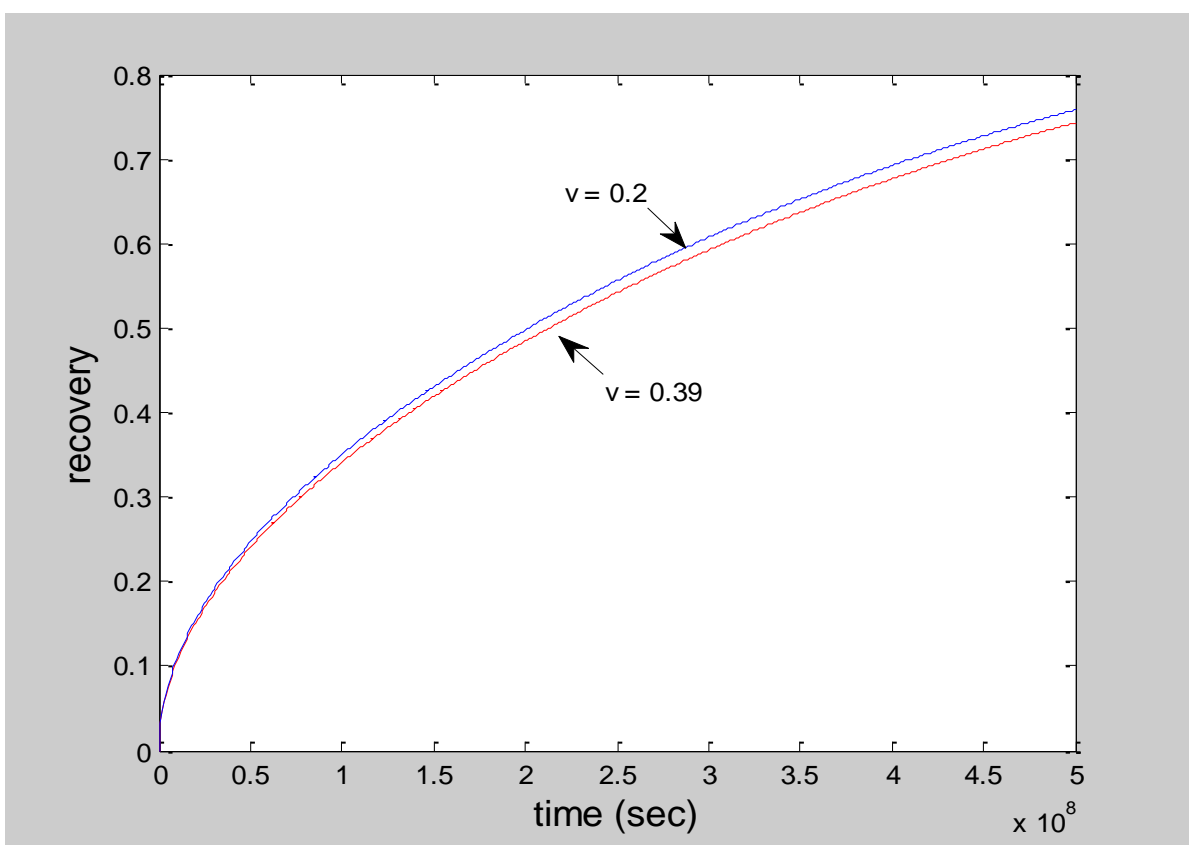

Figure 35Case \#4: the effect of varying Poisson ratio on the gas ultimate recovery a $1 \neq 0, a 3 \neq 0$ 


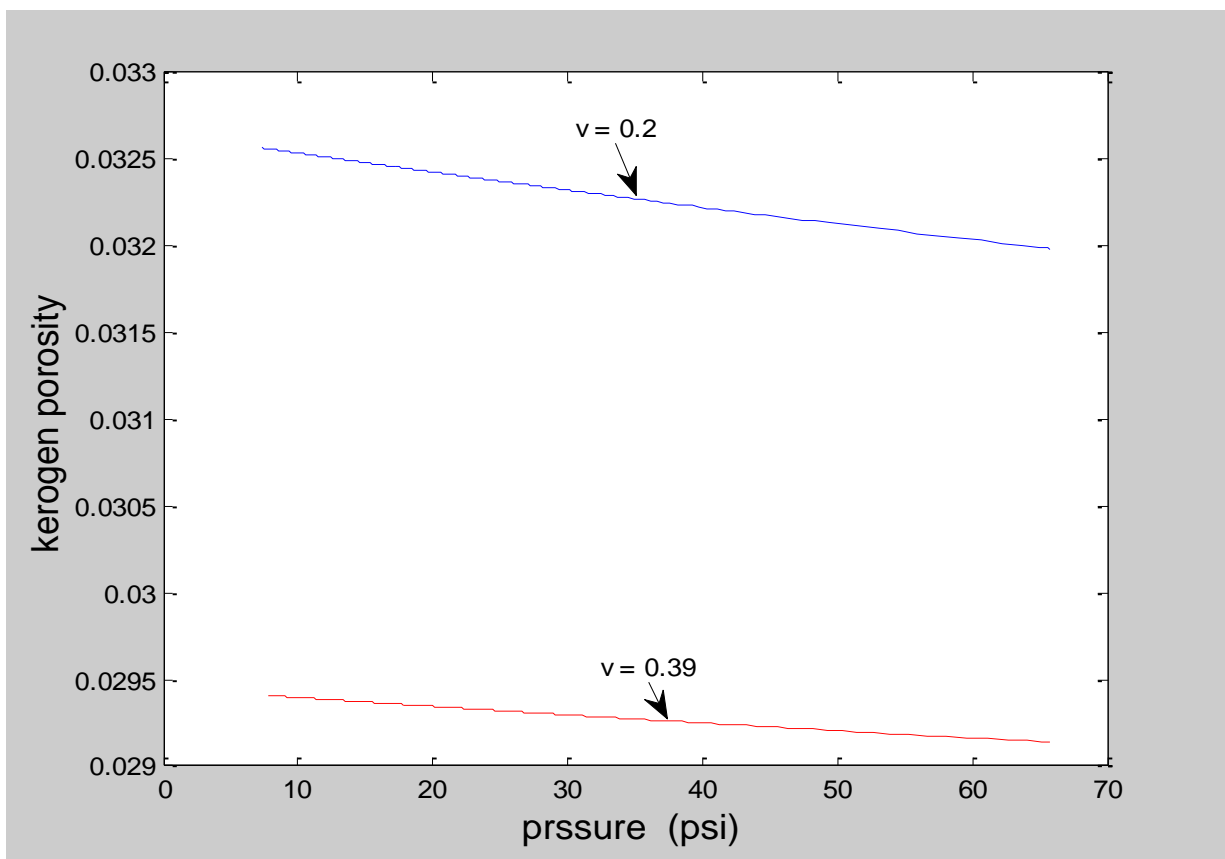

Figure 36shows the effect of varying Poisson ratio on the matrix porosity (red) when Poisson ratio is 0.30 and (blue) when Poisson ration is 0.2

Sorption dynamics in organic materials influence the ultimate gas recovery as shown in Figure 37. Similar discussions are valid as stated earlier in Case III.

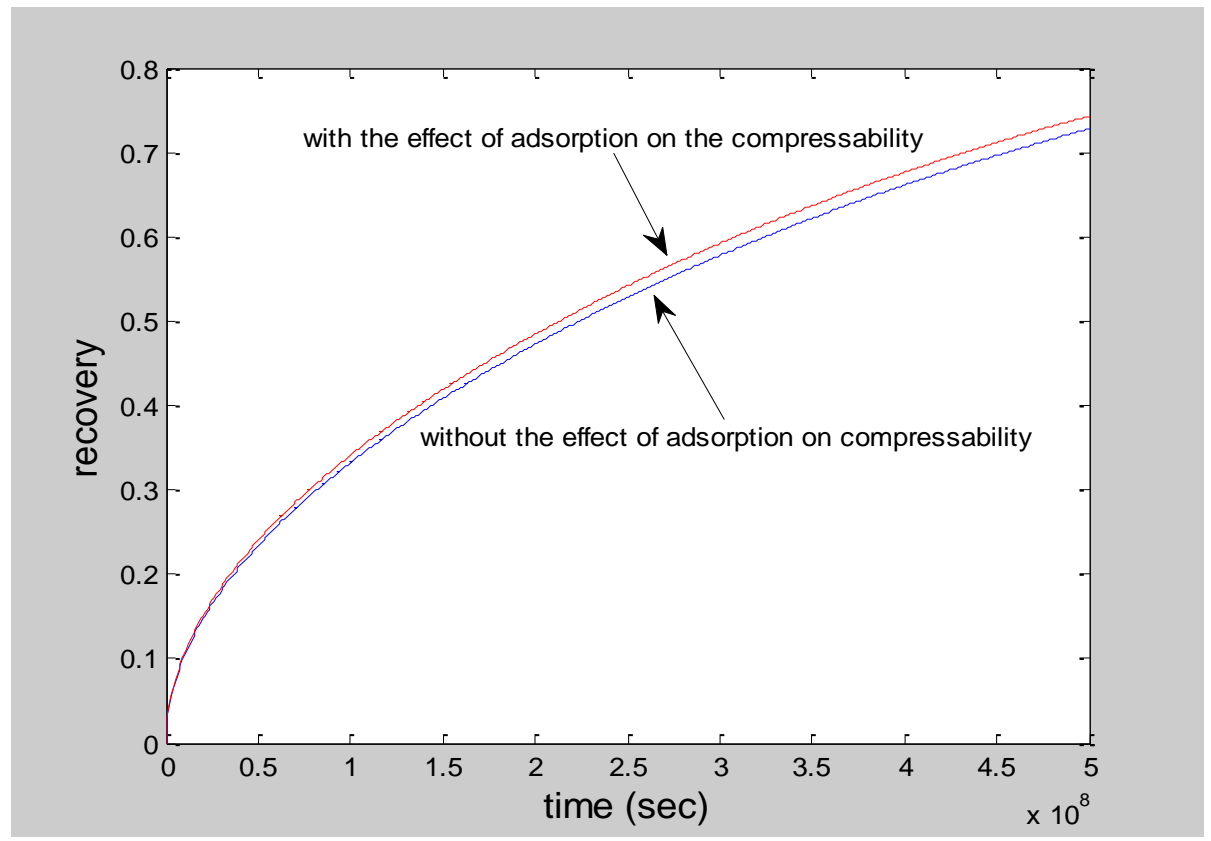

Figure 37the effect of pore compression on the ultimate recovery of the gas from the shale matrix; (red) shows the base case recover curve $a 1 \neq 0, a 3 \neq 0$ and the (blue) shows the recovery curve when we neglect the effect of adsorption on the pore compressibility 


\section{2: Conclusion}

The purpose of this study is to investigate the effects shale mechanical properties on gas transport and storage within the shale matrix, briefly the following conclusions are obtained:

1- Multi-continuum approach has been introduced in this research to study overall shale matrix poroelastic effects due to presence of organic, inorganic and fracture system on gas transport and storage. In addition, the approach has the advantage of taking into consideration the dual isotherm phenomena represented by Langmuir-Henry dual isotherm which is used to describe the equilibrium sorption dynamic.

2- The poroelastic properties of shale organic materials have shown significant impact on ultimate gas recovery and thus flow and transport in organic rich shale. The impact of the mechanical properties of the kerogen found to be more pronounced comparing with that of inorganic materials.

3- Contribution of gas adsorption/desorption on overall poroelastic behavior is more significant than the pore compressibility leading to extra compaction driving mechanism to increase the ultimate production.

4- For more precise prediction of poroelastic effect on shale gas transport and storage more detailed experimental techniques such as nano-indentation test is required to obtain reliable mechanical properties of shale organic material 


\section{References}

Akkutlu, I. Y., \& Fathi, E. (2011, January 1). Gas Transport in Shales with Local Kerogen Heterogeneities. Society of Petroleum Engineers. doi:10.2118/146422-MS

Akkutlu, I. Y., \& Fathi, E. (2012, December 1). Multiscale Gas Transport in Shales With Local Kerogen Heterogeneities. Society of Petroleum Engineers. doi:10.2118/146422-PA

Allen, N., Aplin, A. \& Thomas, M. (2009). Introduction to shale gas storage. 2014, from http://www.slideshare.net/kyqoy2/allen-2009-introshalegasstorage

Ambrose, R. J., Hartman, R. C., \& Akkutlu, I. Y. (2011, January 1). Multi-component sorbed phase considerations for Shale Gas-in-place Calculations. Society of Petroleum Engineers. doi:10.2118/141416-MS

Ambrose, R. J., Hartman, R. C., Diaz Campos, M., Akkutlu, I. Y., \& Sondergeld, C. (2010, January 1). New Pore-scale Considerations for Shale Gas in Place Calculations. Society of Petroleum Engineers. doi:10.2118/131772-MS

Belyadi, A. (2011). Modeling studies to evaluate performance of the horizontal wells completed in shale. Dissertation (Ph.D.), West Virginia University). , 5. (www.libraries.wvu.edu)

Bustin, R. M., Bustin, A. M. M., Cui, A., Ross, D., \& Pathi, V. M. (2008, January 1). Impact of Shale Properties on Pore Structure and Storage Characteristics. Society of Petroleum Engineers. doi:10.2118/119892-MS

Cheng, A., \& Huang, W. (2004). Selective adsorption of hydrocarbon gases on clays and organic matter.OrganicGeochemistry, 35(4), 413-423.

Civan, F., Rai, C. S., \& Sondergeld, C. H. (2010, January 1). Intrinsic Shale Permeability Determined by Pressure-Pulse Measurements Using a Multiple-Mechanism Apparent-Gas-Permeability Non-Darcy Model. Society of Petroleum Engineers. doi:10.2118/135087-MS

Clarkson, C. R. (2003, September 1). Application of a New Multicomponent Gas Adsorption Model to Coal Gas Adsorption Systems. Society of Petroleum Engineers. doi:10.2118/78146-PA 
Clarkson, C. R., \& Bustin, R. M. (2000). Binary gas adsorption/desorption isotherms: Effect of moisture and coal composition upon carbon dioxide selectivity over methane. International Journal of Coal Geology, 42(4), 241-271. doi:http://dx.doi.org/10.1016/S0166-5162(99)00032-4

Clarkson, C. R., \& Haghshenas, B. (2013, April 10). Modeling of Supercritical Fluid Adsorption on Organic-Rich Shales and Coal. Society of Petroleum Engineers. doi:10.2118/164532-MS

Clarkson, C. R., Bustin, R. M., \& Levy, J. H. (1997). Application of the mono/multilayer and adsorption potential theories to coal methane adsorption isotherm at elevated temperature and pressure .Carbon, 35(12), 1689-1705.

Clarkson, C.R., Bustin, R.M. (1999). The effect of pore structure and gas pressure upon the transport properties of coal: A laboratory and modeling study. Fuel, 78, 1333-1344.

Connell-Madore,S.Kastsub,T.J.(2006). Pore size disrtibution characteristiscs of Beaufort-Mackenzie Basine shale samples,Northen Territories, Geological Survey of Canada. Reseach, 2006-B1,18

Cui, X., \& Bustin, R. M. (Septmeber 2005). Volumetric strain associated with methane desorption and its impact on coalbed gas production from deep coal seams. The American Association of Petroleum Geologists, 89(9), 1181-1202. doi: 10.1306/05110504114

Cui, X., Bustin, R. M., \& Dipple, G. (2004). Differential transport of CO2 and CH4 in coalbed aquifers: Implications for coalbed gas distribution and composition . AAPG Bulletin, 88, 1149-1161.

Curtis, J. B. (2002). Fractured shale-gas systems. The American Association of Petroleum Geologists, 86(11), 1921-1938.

Daniels, F., \& Alberty, R. A. (1957). Physical chemistry. New York: John Wiley \& Sons, Inc.

Das, M., Jonk, R., \& Schelble, R. (2012, January 1). Effect Of Multicomponent Adsorption/Desorption Behavior On Gas-In-Place (GIP) and Estimated Ultimate Recovery (EUR) In Shale Gas Systems. Society of Petroleum Engineers. doi:10.2118/159558-MS

Diamond, S. (1970). Pore size distributions in clays. Clay and Clays Minerals, 18, 7-23

Dietrich, P., Helmig, R., Sauter, M., Hotzl, H., Kongeter, J., \& Teutsch, G. (2005). Flow and transport in fractured porous meida. Netherlands: Springer. 
doi:10.1016/j.marpetgeo.2008.06.004

Fathi, E., \& Akkutlu, I. Y. (2008, January 1). Counter Diffusion and Competitive Adsorption Effects During $\mathrm{CO} 2$ Injection and Coalbed Methane Production. Society of Petroleum Engineers. doi:10.2118/115482-MS

Fathi, E., \& Akkutlu, I. Y. (2014). Multi-component gas transport and adsorption effects during CO2 injection and enhanced shale gas recovery. International Journal of Coal Geology, 123(0), 52-61. doi:http://dx.doi.org/10.1016/j.coal.2013.07.021

Gray, I. (1987, February 1). Reservoir Engineering in Coal Seams: Part 1-The Physical Process of Gas Storage and Movement in Coal Seams. Society of Petroleum Engineers. doi:10.2118/12514-PA

Green, T. K., \& Selby, T. D. (1994). Pyridine sorption isotherms of argonne premium coals:Dual-mode sorption and coal microporosity . Energy \& Fuels, 8(1), 213-218.

Gregg, S. J., \& Sing, K. S. W. (1967). Adsorption, surface area and porosity. London and New York: Academic Press

Guo, S. (2013). Experimental study on isothermal adsorption of methane gas on three shale samples from upper paleozoic strata of the ordos basin. Journal of Petroleum Science and Engineering, 110(0), 132-138. doi:http://dx.doi.org/10.1016/j.petrol.2013.08.048

Hao, F., Zou, H., \& Lu, Y. (2013). Mechanisms of shale gas storage: Implications for shalegas exploration in china . American Association of Petroleum Geologist, 97(8), 1325-1346.

Hartman, R. C., Ambrose, R. J., Akkutlu, I. Y., \& Clarkson, C. R. (2011, January 1). Shale Gas-in-Place Calculations Part II - Multicomponent Gas Adsorption Effects. Society of Petroleum Engineers. doi:10.2118/144097-MS

Huang, J., \& Ghassemi, A. (2011, January 1). Poroelastic Analysis of Gas Production From Shale. American Rock Mechanics Association.

Javadpour, F. (2009, August 1). Nanopores and Apparent Permeability of Gas Flow in Mudrocks (Shales and Siltstone). Petroleum Society of Canada. doi:10.2118/09-08-16-DA 
javadpour, F., \& Ghanbarnezhad Moghanloo, R. (2013, April 19). Contribution of Methane Molecular Diffusion in Kerogen to Gas-in-Place and Production. Society of Petroleum Engineers. doi:10.2118/165376-MS

Javadpour, F., Fisher, D., \& Unsworth, M. (2007, October 1). Nanoscale Gas Flow in Shale Gas Sediments. Petroleum Society of Canada. doi:10.2118/07-10-06

Jun, Y., Hai, S., Dong-yan,F, Cheng-chen, W, \& Zhi-xiu, S. (2013). Numerical simulation of gas transport mechanisms in tight shale gas reservoirs. Petroleum Science, 10(4), 528-537. doi: $10.1007 / \mathrm{s} 12182-013-0304-3$

Kang, S. M., Fathi, E., Ambrose, R. J., Akkutlu, I. Y., \& Sigal, R. F. (2010, January 1). CO2 Storage Capacity of Organic-Rich Shales. Society of Petroleum Engineers. doi:10.2118/134583-MS

Kuila, U., \& Prasad, M. (2011, January 1). Understanding Pore-Structure And Permeability In Shales. Society of Petroleum Engineers. doi:10.2118/146869-MS

Lee, H., Kim, H., Shi, Y., Keffer, D., \& Lee, C. (2013). Competitive adsorption of CO2/CH4 mixture on dry and wet coal from subcritical to supercritical conditions. Chemical Engineering Journal, 230(0), 93-101. doi:http://dx.doi.org/10.1016/j.cej.2013.06.036

Liu, Y., \& Wilcox, J. (2013). Molecular simulation studies of CO2 adsorption by carbon ModelCompounds for carbon capture and sequestration applications. Environmental Science \& Technology, 47, 95-101. dx.doi.org/10.1021/es3012029

Loucks, R. G., Reed, R. M., Ruppel, S. C., \& Hammes, U. (2012). Morphology,genesis and distribution of nanometer-scale pores in siliceous mudstone of the mississippain branett shale. American Association of Petroleum Geologist, 96(6), 1071-1098.

Marc Bustin, R. (2012). Shale gas and shale oil petrology and petrophysics. International Journal of Coal Geology, 103(0), 1-2. doi:http://dx.doi.org/10.1016/j.coal.2012.09.003

Milliken, K. L., Esch, W. 1., Reed, R. M., \& Zhang, T. (2012). Grain assemblages and storge diagentic overprinting in siliceous mudrocks,barnett shale (mississppian), fort worth basin, texas. American Association of Petroleum Geologist, 96(8), 1553-1578. 
Myers, A. L. (1968). Adsorption of gas mixtures a thermodynamic approch. Applied Thermodynamic Symposium, 60(5), 45-49.

Palmer, I., \& Mansoori, J. (1998, December 1). How Permeability Depends on Stress and Pore Pressure in Coalbeds: A New Model. Society of Petroleum Engineers. doi:10.2118/52607-PA

Ross, D. J. K., \& Bustin, R. M. (2007). Shale gas potential of the lower jurassic gordondale member, northeastern british columbia, canada . Bulletin of Canadian Petroleum Geology, 55(51-57) doi:10.2113/gscpgbull.55.1.51

Ross, D. J. K., \& Bustin, R. M. (2009). The importance of shale composition and pore structure upon gas storage potential of shale gas reservoirs . Marine and Petroleum Geology, 26(26), 916-927.

Rutherfored, D. W., Chiou, D. W., \& Ebrel, D. D. (1997). Effects of exchanged cation on the microporosity of montmorillonite:Clays and clat minerals. Clays and Clay Minerals, 45(4), 534543.

Santos Rueda, J. M., \& Akkutlu, I. Y. (2012, January 1). Laboratory Measurement of Sorption Isotherm under Confining Stress with Pore Volume Effects. Society of Petroleum Engineers. doi:10.2118/162595-MS

Schettler, P. D., \& Parmely, C. R. (1991, January 1). Contributions to Total Storage Capacity in Devonian Shales. Society of Petroleum Engineers. doi:10.2118/23422-MS

Seidle, J. P., Jeansonne, M. W., \& Erickson, D. J. (1992, January 1). Application of Matchstick Geometry To Stress Dependent Permeability in Coals. Society of Petroleum Engineers. doi:10.2118/24361MS

Shi, J.-Q., \& Durucan, S. (2005, August 1). A Model for Changes in Coalbed Permeability During Primary and Enhanced Methane Recovery. Society of Petroleum Engineers. doi:10.2118/87230PA

Shimizu, K., Takanohashi, T., Iino, \& Masashi. (1998). Sorption behaviors of various organic vapors to argonne premium coal samples. Energy \& Fuels, 12(5), 8961-896.

Siedle, J. (Ed.). (2011). Fundamentals of coal bed methane reservoir engineering. Tulsa,OK ,USA: Penn Well. 
Sircar, S. (1992). Estimation of isosteric heats of adsorption of single gas and multicomponent gas mixtures. Industrial and Engineering Chemistry Research, 31, 1813-1819. doi:10.1021/ie00007a030.

Sondergeld, C. H., Rai, C. S., \& Curtis, M. E. (2013, April 10). Relationship Between Organic Shale Microstructure and Hydrocarbon Generation. Society of Petroleum Engineers. doi:10.2118/164540MS

Sondergeld, C. H., Rai, C. S., \& Curtis, M. E. (2013, April 10). Relationship Between Organic Shale Microstructure and Hydrocarbon Generation. Society of Petroleum Engineers. doi:10.2118/164540-MS

Stadie, Nicholas P. (2013) Synthesis and thermodynamic studies of physisorptive energy storage materials.Dissertation(Ph.D.),California Institute of Technology

Suloff, E. C. (2002) Sorption behavior of an aliphatic series if aldehydes in the presence of the ploy (ethylene terephthalate) blends containing aldehyde scavenging agents. Dissertation (Ph.D.), Virginia Polytechnic Institute and State University. http://scholar.lib.vt.edu/theses/available/etd-12042002-124439/

Tiab, D., \& Donaldson, E. C. (1996). Petrophysics :Theory and practice of measuring reservoir rock and fluid transport properties. Houston, Texas,USA: Gulf Pub. Co.

Yang, R.T., (1987). Gas Separation by Adsorption Processes. Butterworth, Boston, MA.

Yee, D., Seidle, J., \& Hanson, W. B. (1993). Gas sorption on coal and measurment of has content. Hydrocarbons from coal (pp. 203-218) AAPG Special Volumes.

Yi, J., Akkutlu, I. Y., \& Deutsch, C. V. (2008, October 1). Gas Transport in Bidisperse Coal Particles: Investigation for an Effective Diffusion Coefficient in Coalbeds. Petroleum Society of Canada. doi:10.2118/08-10-20

Yi, J., Akkutlu, I. Y., Karacan, C. Ö., \& Clarkson, C. R. (2009). Gas sorption and transport in coals: A poroelastic medium approach. International Journal of Coal Geology,77(1-2), 137-144. doi:http://dx.doi.org/10.1016/j.coal.2008.09.016

Yi, X., Ong, S. H., \& Russell, J. E. (2005, January 1). Characterizing Pore Compressibility, Reservoir Compaction and Stress Path under Uniaxial Strain Condition for Nonlinear Elastic Rock. American Rock Mechanics Association. 
Zhang, L., Li, X., Wang, T., Li, Y., Shi, J., Liu, N., Yu, W. (2013, November 5). Diffusion and Flow Mechanisms of Shale Gas through Matrix Pores and Gas Production Forecasting. Society of Petroleum Engineers. doi:10.2118/167226-MS

Zhang, T., Ellis, G. S., Ruppel, S. C., Milliken, K., \& Yang, R. (2012). Effect of organic-matter type and thermal maturity on methane adsorption in shale-gas systems. Organic Geochemistry, 47(0), 120131. 